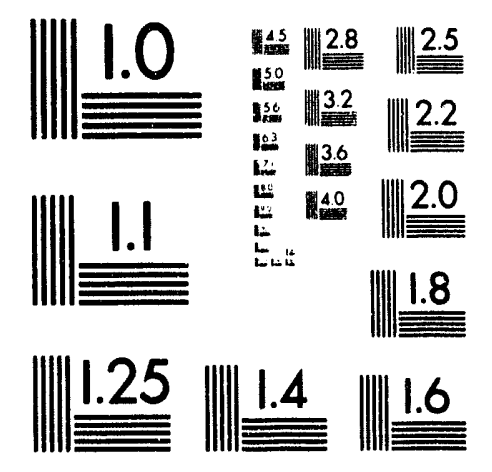



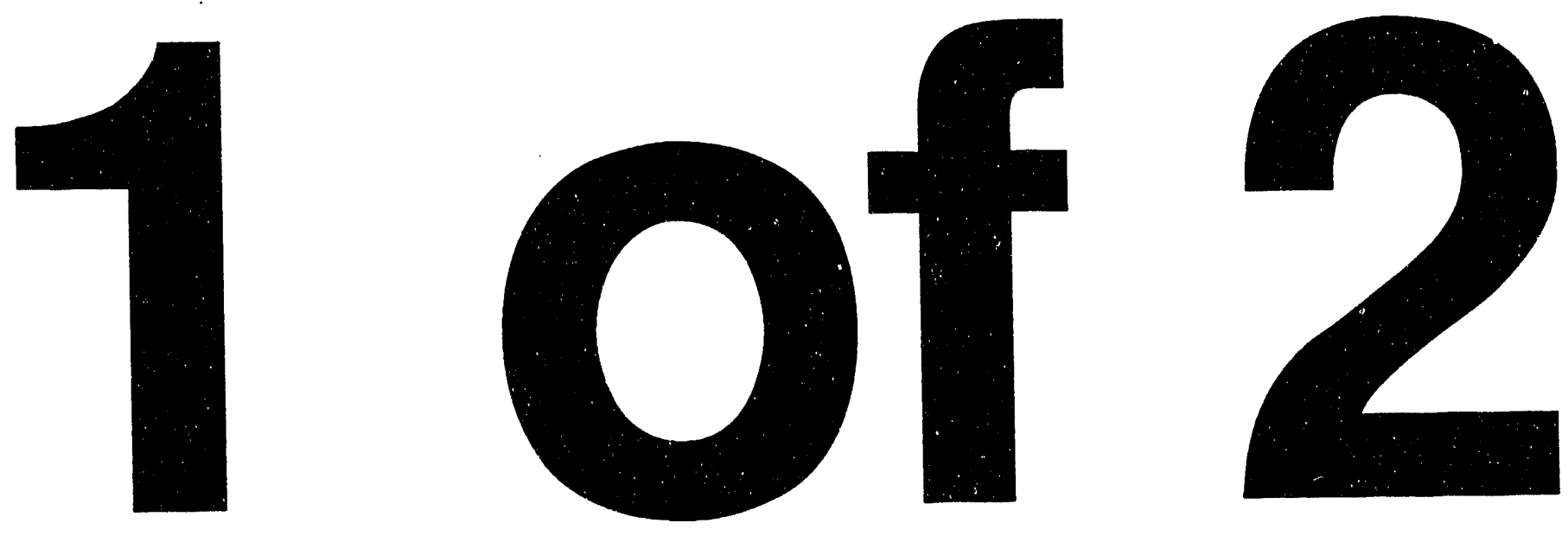


\section{Environmental Management Assessment of the Continuous Electron Beam Accelerator Facility (CEBAF)}

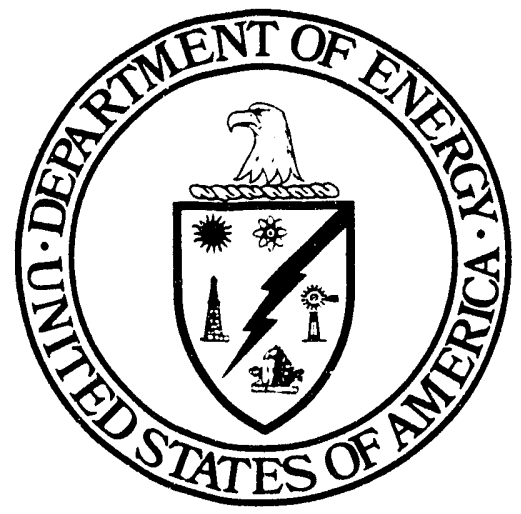

U.S. Department of Energy Office of Environmental Audit Washington, DC 20585

March 1993

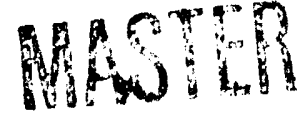

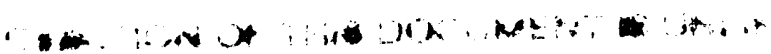


This page intentionally left blank. 


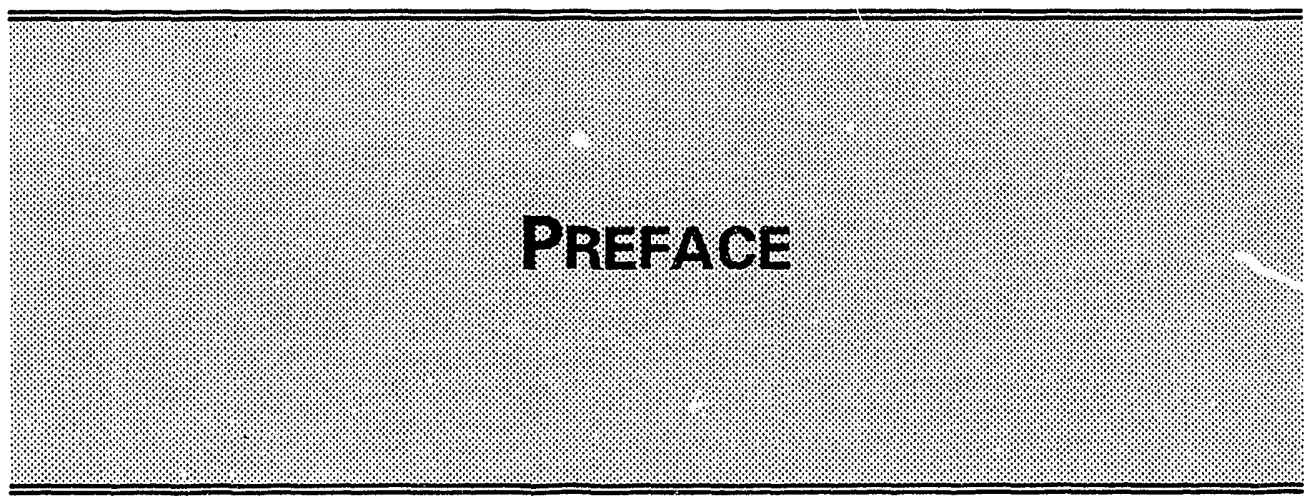


This page intentionally left blank. 


\section{PREFACE \\ U.S. DEPARTMENT OF ENERGY ENVIRONMENTAL MANAGEMENT ASSESSMENT \\ OF THE CONTINUOUS ELECTRON BEAM ACCELERATOR FACILITY (CEBAF)}

In a continuing effort to strengthen environmental protection within the U.S. Departinent of Energy (DOE), the Office of Environment, Safety and Health (EH) has established, as part of the internal oversight responsibilities within DOE, a program within the Office of Environmental Audit (EH-24), to conduct environmental assessments of DOE programs and operating facilities. The ultimate goal of this program is enhancement of environmental protection and minimization of risk to public health and the environment through systematic and periodic evaluations of the Department's environmental programs within line organizations.

This document contains the results of the Environmental Management Assessment of the Continuous Electron Beam Accelerator Facility (CEBAF). This Environmental Management Assessment was conducted by EH-24 from March 8 through March 19, 1993. The assessment's objective is to advise the Secretary of Energy, through the Assistant Secretary for Environment, Safety and Health, as to the adequacy of management systems established at CEBAF to ensure the protection of the environment and compliance with Federal, state, and DOE environmental requirements.

\section{March 1993}

Washington, D.C. 
This page intentionally left blank. 


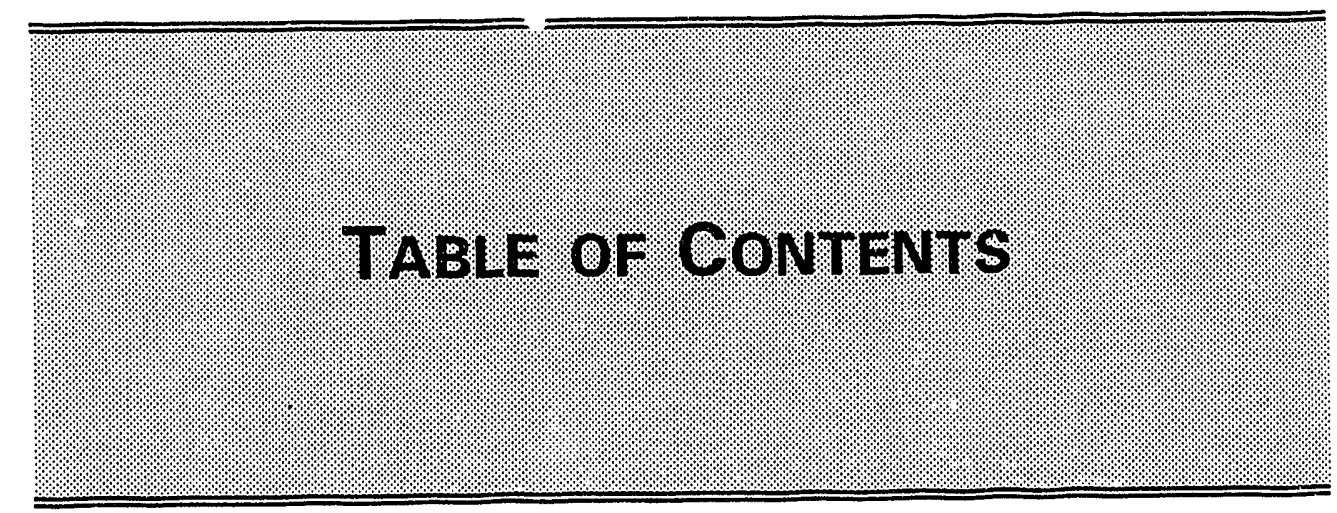


This page intentionally left blank. 


\section{TABLE OF CONTENTS}

\section{PREFACE}

EXECUTIVE SUMMARY

1.0 INTRODUCTION $\ldots \ldots \ldots \ldots \ldots \ldots \ldots \ldots \ldots \ldots \ldots \ldots \ldots$

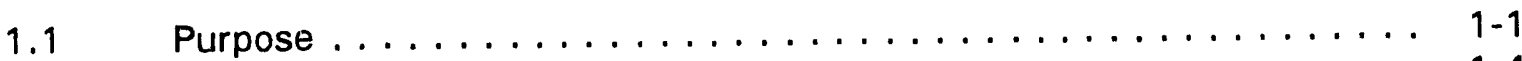

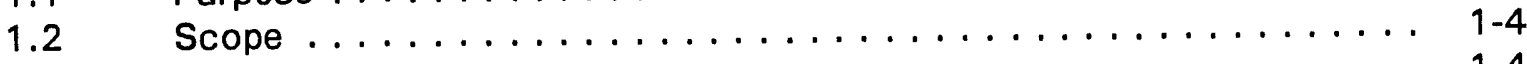

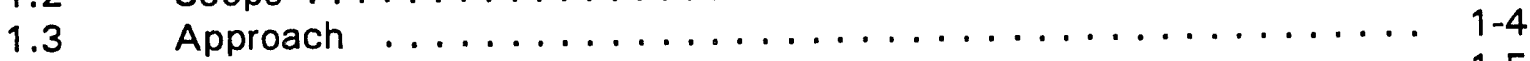

1.4 Background and Project Description . . . . . . . . . . . . . 1-5

1.5 Environmental Management Programs and Organization .......... 1-6

2.0 SUMMARY OF ENVIRONMENTAL MANAGEMENT ASSESSMENT RESULTS . . . 2-1

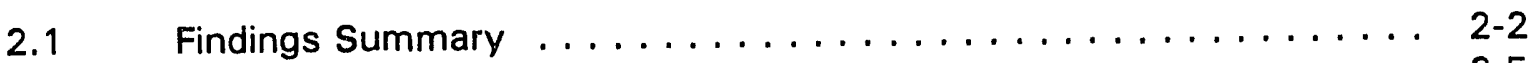

2.2 Causal Factors Summary ................... 2-5

3.0 ENVIRONMENTAL OVERVIEWS AND ASSESSMENT FINDINGS . . . . . . . . 3-1

$3.1 \quad$ Organizational Structure (OS) $\ldots \ldots \ldots \ldots \ldots \ldots \ldots \ldots \ldots \ldots$

3.1 .1 Overview ......................

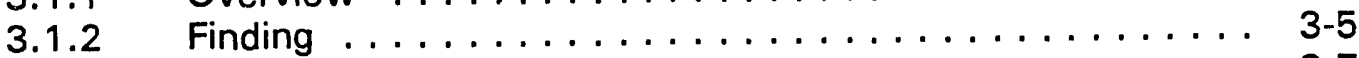

3.2 Environmental Commitment (EC) $\ldots \ldots \ldots \ldots \ldots \ldots \ldots \ldots$

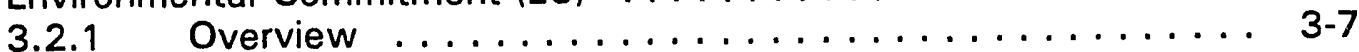

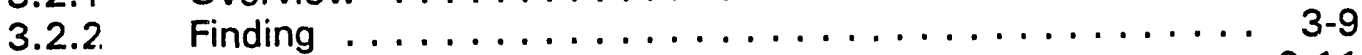

Environmental Protection Programs (EP) $\ldots \ldots \ldots \ldots \ldots \ldots \ldots \ldots$ 3-11

3.3.1 Overview ......................... $3-11$

3.3.2 Finding .......................... $3-14$

3.4 Formality of Environmental Programs (FP) $\ldots \ldots \ldots \ldots \ldots \ldots \ldots$

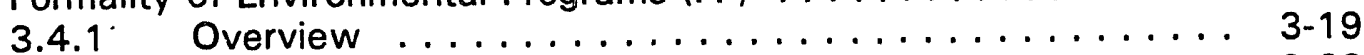

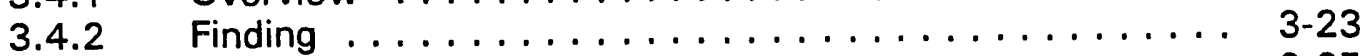

3.5 Internal and External Communication (IC) $\ldots \ldots \ldots \ldots \ldots \ldots \ldots$. $\ldots \ldots$

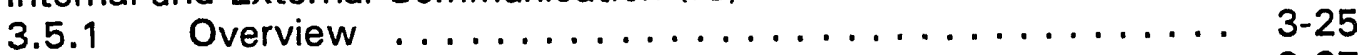

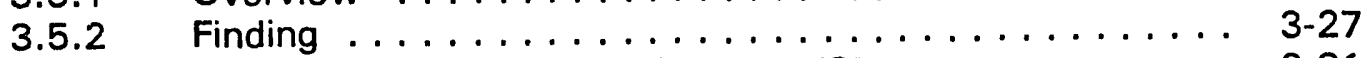

3.6 Staff Resources, Training, and Development (SR) . . . . . . . . 3-31

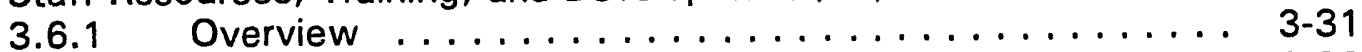

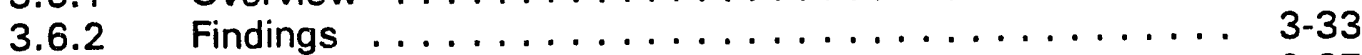

3.7 Program Evaluation, Reporting, and Corrective Action (PE) . . . . . 3-37

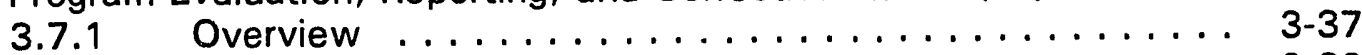

3.7.2 Finding ...................... 3-39

3.8 Environmental Planning and Risk Management (RM) . . . . . . . . 3-41

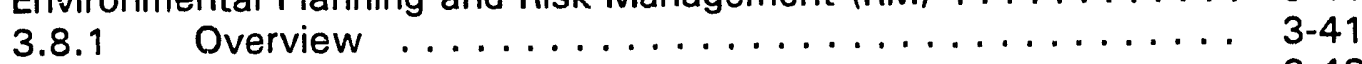

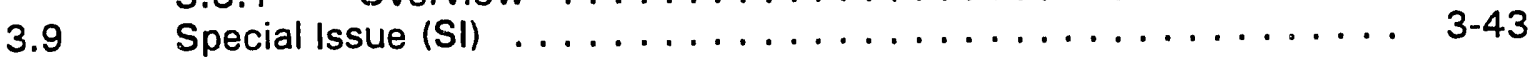




\section{TABLE OF CONTENTS (continued)}

\section{LIST OF FIGURES}

Figure $1-1 \quad$ CEBAF Location Map $\ldots \ldots \ldots \ldots \ldots \ldots \ldots$

Figure $1-2$ DOE/CEBAF Project Organization $\ldots \ldots \ldots \ldots \ldots \ldots$

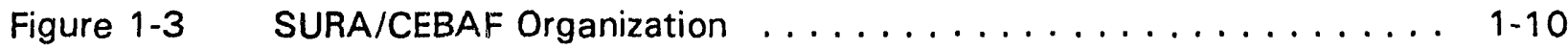

\section{LIST OF TABLES}

Table 1-1 List of Environmental Management Requirements and Guidelines . . . 1-2

Table 2-1 Environmental Management Assessment Team Findings . . . . . . 2-3

Table 2-2 . Summary of Causal and Contributing Factors

Identified by Assessment Finding .............. 2-6

\section{LIST OF APPENDICES}

Appendix A Biographical Sketches of the Assessment Team $\ldots \ldots \ldots \ldots \ldots$. . . .

Appendix B Assessment Plan $\ldots \ldots \ldots \ldots \ldots \ldots \ldots \ldots \ldots \ldots \ldots \ldots$ B-1

Appendix $\mathrm{C} \quad$ Schedule of Onsite Activities $\ldots \ldots \ldots \ldots \ldots \ldots \ldots \ldots$

Appendix D List of Site Documents Reviewed by the Assessment Team . . . . D-1

Appendix E List of Contacts/Interviews Conducted by the Assessment Team . . . E-1

Appendix $F \quad$ Definitions of Causal and Contributing Factors . . . . . . . . . F F-1

Appendix $\mathbf{G}$ Glossary of Acronyms and Abbreviations . . . . . . . . . . G-1 
EXECUTIVE SUMMARY 
This page intentionally left blank. 


\section{EXECUTIVE SUMMARY}

This report documents the results of the Environmental Management Assessment performed at the Continuous Electron Beam Accelerator Facility (CEBAF) in Newport News, Virginia. During this assessment, activities and records vvere reviewed and interviews were conducted with personnel from the CEBAF Site Office; the CEBAF management and operating contractor (M\&O), Southeastern Universities Research Association, Inc. (SURA); the Oak Ridge Field Office (OR); and the responsible DOE Headquarters Program Office, the Office of Energy Research (ER). The onsite portion of the assessment was conducted from March 8 through March 19, 1993, by the U.S. Department of Energy's (DOE's) Office of Environmental Audit (EH-24) located within the Office of Environment, Safety and Health (EH).

DOE 5482.1B, "Environment, Safety and Health Appraisal Program," and Secretary of Energy Notice (SEN)-6E-92, "Departmental Oiganizational and Management Arrangements," establish the mission of EH-24 to provide comprehensive, independent oversight of Department-wide environmental programs on behalf of the Secretary of Energy. The ultimate goal of EH-24 is enhancement of environmental protection and minimization of risk to public health and the environment. EH-24 accomplishes its mission utilizing systematic and periodic evaluations of the Department's environmental programs within line organizations, and through use of supplemental activities which serve to strengthen self-assessment and oversight functions within program, field, and contractor organizations.

The Environmental Management Assessment of CEBAF was designed to evaluate the effectiveness of the CEBAF Site Office and SURA in establishing effective management systems to carry out their environmental responsibilities.

The scope of environmental concerns at CEBAF is relatively limited in comparison to many of the research facilities within the DOE complex. Based on a limited sampling during this assessment, SURA appears to be meeting the permitting and regulatory requirements associated with its operations.

Currently, CEBAF is in its final phase of construction, with all major structures in place and the focus of activities turning towards equipment installation and pre-operational testing. Although significant activity is occurring in areas subject to environmental compliance requirements and environmental radiological protection, the majority of the attention of DOE and SURA management in the environment, safety, and health (ES\&H) arena has been on safety and health issues. The inherent safety hazards of a major construction project clearly necessitate this strong management attention. However, environmental concerns have not been afforded a level of management attention consistent with the "commitment" embodied in the SURA Director's October 28, 1992 policy statement and the high expectations of the Department. For example, SURA has not developed any issue-specific policies or other guidance to support implementation of its strong overall ES\&H policy statement. In addition, although elements are in place, SURA has not fully developed and implemented formal and comprehensive environmental protection programs and plans to institutionalize the systems which are used to attain environmental performance goals, requirements, and standards. SURA has not established visible and measurable laboratory-wide environmental performance goals for the Accelerator, Physics, and Administration Divisions, nor does it consistently apply specific envirorimental performance objectives in performance stand 3 : ds for key line managers. Finally, SURA has not fully developed and implemented its self-assessment programs. 
Many of the deficiencies noted by the assessment team had been identified, to some extent, by SURA and are in the process of being addressed. The organization is continuing to develop and mature in response to the recent organizational change which decentralized environmental responsibilities into SURA's line organizations. Adequate resources have been allocated within SURA's line organizations to fulfill their current assigned responsibilities, although some positions were not filled at the time of the assessment. Resource issues may need to be reassessed upon the resolution of the applicability of DOE Orders (see Section 3.9, Special Issue). SURA is in the process of establishing and/or improving many of the necessary management systems, including systems for training, facility inspections, and environmental self-assessments.

The CEBAF Site Office has been diligent in developing and institutionalizing the necessary systems for conducting its environmental oversight responsibilities. A solid self-assessment program has been developed and formalized procedures to direct and control the various aspects of their oversight responsibilities have been established. In light of the limited ES\&H staffing level, the CEBAF Site Office has instituted an aggressive training program for their Environment, Health, and Safety (EH\&S) Manager. The fulfillment of the CEBAF Site Office's environmental responsibilities is complicated by a contractual disagreement with SURA regarding the applicability of DOE ES\&H Orders and the limited formal and routine management reporting on the status of environmental programs and performance.

The assessment team identified the following strengths of CEBAF's environmental programs and staff:

- $\quad$ Environmental Policy - On October 28, 1992, the Director of SURA issued an ES\&H policy statement which clearly articulated the position of management that ES\&H was an integral part of the operations at CEBAF. The environmental component of the policy is one of the strongest within the DOE complex. This policy has been widely distributed and awareness of it is high throughout SURA.

- $\quad$ Line Responsibility and Commitment - Management and staff from both the CEBAF Site Office and SURA exhibit a genuine sense of ownership and commitment to environmental performance at CEBAF. This commitment is critical to adhering to the high standards of the DE partment and SURA's aggressive environmental policy.

- Radiation Protection Management - The professional radiation protection staff within SURA are knowledgeable in accelerator health physics and have demonstrated a high level of competency in t'.'eir ability to comprehend and manage radiological environmental protection and associated regulatory issues within CEBAF. 


\section{SeCtion 1.0}

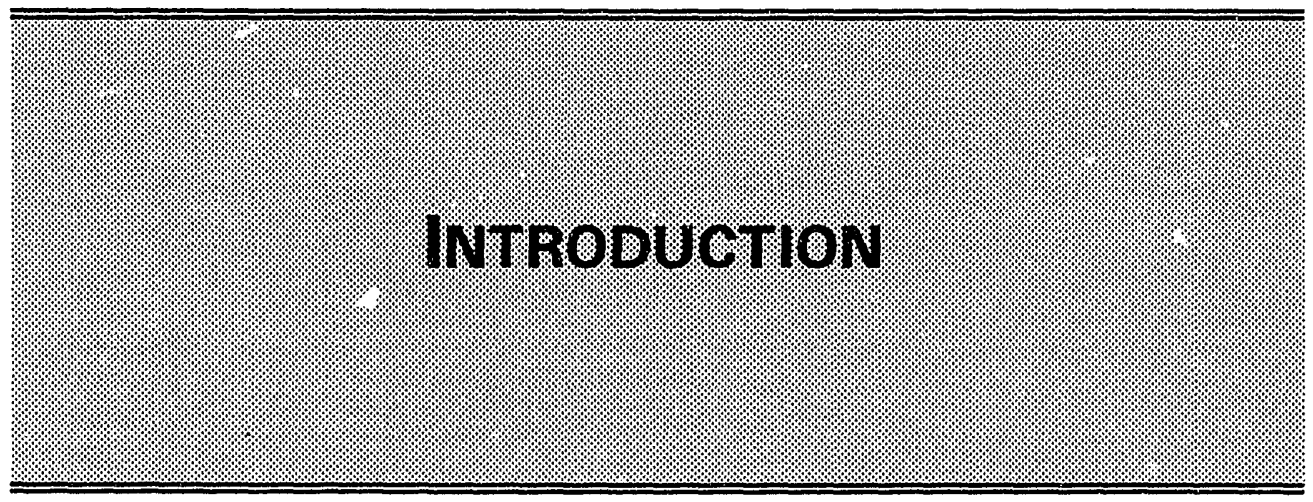


This page intentionally left blank. 
This report documents the results of the Environmental Management Assessment of the Continuous Electron Beam Accelerator Facility (CEBAF) located in Newport News, Virginia. The assessment was conducted from March 8 through March 19, 1993 by the Office of Environmental Audit (EH-24).

DOE 5482.1B, "Environment, Safety and Healt'، Appraisal Program," and Secretary of Energy Notice (SEN)-6E-92, "Departmental Organizational and Management Arrangements, "establish the mission of EH-24 to provide comprehensive, independent oversight of Department-wide environmental programs on behalf of the Secretary of Energy. The ultimate goal of EH-24 is enhancement of environmental protection and minimization of risk to public health and the environment. EH-24 accomplishes its mission using systematic and periodic evaluations of the Department's environmental programs within line organizations, and through use of supplemental activities which serve to strengthen self-assessment and oversight functions within program, field, and contractor organizations.

These evaluations function as a vehicle to apprise the Secretary and Program Senior Officials (PSOs) of the current status and vulnerabilities of Departmental environmental activities and environmental management systems. Several types of evaluations are conducted, including:

- comprehensive baseline environmental audits (frequently conducted as a component of Environment, Safety and Health (ES\&H) Tiger Team Assessments);

- $\quad$ periodic routine reaudits;

- $\quad$ environmental management assessments; and

- $\quad$ focused, special issue reviews.

The purpose, scope, and approach of this environmental management assessment is described below.

\section{$1.1 \quad$ PURPOSE}

The purpose of the Environmental Management Assessment of CEBAF is to provide the Secretary of Energy, through the Assistant Secretary for Environment, Safety and Health, with concise information pertaining to the following areas:

- adequacy of environmental management programs and organizations;

- $\quad$ adherence to best management (and accepted industry) practices pertaining to environmental management programs;

- $\quad$ compliance with DOE Orders, SENs, and DOE environmental policies (as identified in Table 1-1) which address environmental management programs; 
TABLE 1-1

\section{LIST OF ENVIRONMENTAIL MANAGEMENT , REQUIREMENTS AND GUIDELINES}

\begin{tabular}{|c|c|c|}
\hline $\begin{array}{l}\text { Regutationst } \\
\text { Requirements: }\end{array}$ & Sectionshtitle. & authority \\
\hline $\begin{array}{l}\text { Executive Order } \\
11514 \text { and } 11991\end{array}$ & $\begin{array}{l}\text { Protection and Enhancement of Environmental } \\
\text { Quality }\end{array}$ & $\begin{array}{l}\text { Office of } \\
\text { President }\end{array}$ \\
\hline $\begin{array}{l}\text { Executive Order } \\
12088\end{array}$ & $\begin{array}{l}\text { Federal Compliance with Pollution Control } \\
\text { Standards }\end{array}$ & $\begin{array}{l}\text { Office of } \\
\text { President }\end{array}$ \\
\hline SEN-6E-92 & $\begin{array}{l}\text { Departmental Organizational and Management } \\
\text { Arrangements }\end{array}$ & DOE \\
\hline SEN-20-90 & $\begin{array}{l}\text { Interaction with Internal and External Oversight } \\
\text { Organizations }\end{array}$ & DOE \\
\hline SEN-29-91 & $\begin{array}{l}\text { Performance Indicators and Trending Program for } \\
\text { Department of Energy Operations }\end{array}$ & DOE \\
\hline DOE $1000.3 B$ & Internal Control Systems Manual & DOE \\
\hline DOE 1280.1 & Memorandums of Understanding & DOE \\
\hline DOE 2300.1A & Audit Resolution and Followup & DOE* \\
\hline DOE $2321.1 \mathrm{~A}$ & Auditing of Programs and Operations & DOE \\
\hline DOE $3410.1 B$ & Training & DOE \\
\hline DOE 4700.1 & Project Management Systems & DOE \\
\hline DOE 5000.3A & $\begin{array}{l}\text { Occurrence Reporting and Processing of } \\
\text { Operations Information }\end{array}$ & DOE \\
\hline DOE 5400.1 & General Environmental Protection Programs & DOE \\
\hline DOE 5400.2A & Environmental Compliance Issue Coordination & DOE \\
\hline DOE 5400.3 & Hazardous and Radioactive Mixed Waste Program & DOE \\
\hline DOE 5400.5 & $\begin{array}{l}\text { Radiation Protection of the Public and the } \\
\text { Environment }\end{array}$ & DOE \\
\hline DOE 5400.9 & Sealed Radioactive Source Accountability & DOE \\
\hline DOE 5480.1B & Environment, Safety and Health Appraisal Program & DOE \\
\hline DOE 5480.2A & Radioactive Waste Management & DOE \\
\hline DOE 5480.19 & $\begin{array}{l}\text { Conduct of Operations Requirements for DOE } \\
\text { Facilities }\end{array}$ & DOE \\
\hline
\end{tabular}


TABLE 1-1

LIST OF ENVIRONMENTAL MANAGEMENT REQUIREMENTS AND GUIDELINES (continued)

\begin{tabular}{|c|c|c|}
\hline $\begin{array}{l}\text { Regulationst } \\
\text { Requirementst } \\
\text { Guidelines }\end{array}$ & Sectionsititle & Authority \\
\hline DOE 5480.4 & $\begin{array}{l}\text { Environmental Protection, Safety and Health } \\
\text { Protection Standards }\end{array}$ & DOE \\
\hline DOE 5482.1B & Environment, Safety and Health Appraisal Program & DOE \\
\hline DOE 5484.1 & $\begin{array}{l}\text { Environmental Protection, Safety and Health } \\
\text { Protection Information Reporting Requirements }\end{array}$ & DOE \\
\hline DOE 5500.2A & $\begin{array}{l}\text { Emergency Notification Reporting and Response } \\
\text { Levels }\end{array}$ & DOE \\
\hline DOE $5700.6 \mathrm{C}$ & Quality Assurance & DOE \\
\hline DOE $6430.1 \mathrm{~A}$ & General Design Criteria & DOE \\
\hline $\begin{array}{l}\text { DOE Memorandum, } \\
\text { July } 31,1990\end{array}$ & $\begin{array}{l}\text { Guidance on Environment, Safety, and Health } \\
\text { (ES\&H) Self-Assessment }\end{array}$ & $\mathrm{DOE}$ \\
\hline June 92 Guidance & Self-Assessment Guidance Document & DOE \\
\hline $\begin{array}{l}15 \text { U.S.C. } 2601 \\
\text { et seq. }\end{array}$ & Toxic Substances and Control Act & EPA \\
\hline $\begin{array}{l}42 \text { U.S.C. } 6901 \\
\text { et seq. }\end{array}$ & Resource Conservation and Recovery Act & EPA \\
\hline $\begin{array}{l}42 \text { U.S.C. } 7401 \\
\text { et seq. }\end{array}$ & Clean Air Act & EPA \\
\hline 33 U.S.C. 1344 & Clean Water Act & EPA \\
\hline 40 CFR 112 & Oil Pollution Control & EPA \\
\hline 40 CFR 261 & Identification and Listing of Hazardous Waste & EPA \\
\hline 40 CFR 268 & Land Disposal Restriction Program & EPA \\
\hline 40 CFR 302 & $\begin{array}{l}\text { Designation, Reportable Quantities, and } \\
\text { Notification }\end{array}$ & EPA \\
\hline 40 CFR 761 & $\begin{array}{l}\text { Polychlorinated Biphenyls (PCBs) Manufacturing, } \\
\text { Processing, Distribution, and Use Prohibitions }\end{array}$ & EPA \\
\hline
\end{tabular}


DOE vulnerabilities and liabilities associated with environmental management practices;

- causal factors contributing to the occurrence of findings; and

- noteworthy environmental management practices.

The information gathered during this assessment and embodied in this report will assist DOE in determining patterns and trends in environmental deficiencies, as well as causal factors contributing to the observed deficiencies. Line management is expected to fully utilize this information to develop corrective actions, to make appropriate modifications to internal self-assessment programs to prevent recurrence, and to supplement their formalized lessons learned programs to ensure broad applications to other operations, programs, and facilities.

\subsection{SCOPE}

The scope of the Environmental Management Assessment was comprehensive, addressing all areas of environmental management, with the exception of environmental programs pertaining to the National Environmental Policy Act (NEPA). Environmental management considerations were evaluated within and between the CEBAF Site Office; the CEBAF management and operating (M\&O) contractor, Southeastern Universities Research Association, Inc. (SURA); and the Oak Ridge Field Office (OR). Additional consideration was given to reporting and oversight relationships with the Office of Energy Research (ER), the responsible DOE Headquarters Program Office. Since the focus of this assessment is specifically related to environmental management rather than individual physical structures and facilities, site inspections of ongoing operations and operating facilities were not conducted.

\subsection{APPROACH}

The Environmental Management Assessment followed accepted assessment techniques and was guided by implementation of procedures and programs cited in the DOE Environmental Audit Program Guidance (January 1992) and the draft Protocols for Conducting Environmental Management Assessments (January 1993). The assessment was conducted by a team of professionals managed by a DOE Headquarters Assessment Team Leader and Deputy Team Leader from EH-24, and a Group Coordinator and six management systems specialists from Arthur D. Little, Inc. (ADL). The names, areas of responsibility, affiliations, and biographical sketches of the team members are provided in Appendix $A$. The assessment included three phases: planning, onsite activities, and reporting.

During the planning phase, a memorandum was sent to the CEBAF Site Office announcing the assessment and requesting information about CEBAF and environmental programs in general. A pre-assessment site visit was conducted on January 11 and January 12, 1993, by the DOE Team Leader, Deputy Team Leader, and the Group Coordinator from ADL. The site's response to the information request memorandum combined with the pre-assessment site visit formed the basis for the Assessment Plan (see Appendix B), including a preliminary onsite agenda. Once onsite, the assessment team modified the 
preliminary agenda as more information was obtained and additional areas of interest were identified. Appendix $C$ provides the final schedule of onsite activities.

Onsite assessment activities were conducted from March 8 through March 19, 1993 and included interviews in Newport News, Virginia, with the staff and management of the CEBAF Site Office and SURA and document reviews (including previous audit and self-assessment reports). The assessment team conducted daily debriefs that were open to the CEBAF Site Office and SURA. Lists of site documents reviewed and interviews conducted are provided in Appendices $D$ and $E$, respectively. Using these sources of information, the assessment team developed findings as discussed in Sections 2.0 and 3.0 of this report.

Findings identified by the assessment team are conditions that, in the judgment of the assessment team, may not satisfy DOE Orders, SENs, Agreements with regulatory agencies, environmental permit conditions, internal DOE or contractor environmental policies and procedures, regulatory agency or DOE guidance, and accepted industry practice or technical standards.

The findings detailed in Section 3.0 are organized into the following eight categories: organizational structure; environmental commitment; environmental protection programs; formality of environmental programs; internal and external communication; staff resources, training, and development; program evaluation, reporting, and corrective action; and environmental planning and.risk management. Each finding is organized into three sections: the performance objective, the finding statement, and a discussion of the facts and observations supporting the finding. The performance objectives specify the particular standards against which the finding is being evaluated. The findings are not arranged in order of relative significance.

It is the intent of this Environmental Management Assessment to go beyond the findings and to identify the apparent causal factors of observed environmental deficiencies. If one or more of these apparent causal factors are identified as contributing to a specific finding, it will be included in the supporting discussion. The apparent causal factors are then used to assist in the determination of corrective actions required to rectify identified findings. A listing and definition of causal factors used by the assessment team can be found in Appendix F.

\section{4 \\ BACKGROUND AND PROJECT DESCRII'TION}

CEBAF was authorized by Congress in 1986. Construction began in 1987 and is scheduled to be completed in 1994. Accelerator operations for the first experiments are scheduled for 1994. The site's mission is to serve as an experimental tool to support research in nuclear physics; to provide technology transfer; and to contribute to technology development in accelerator physics, electron beams, detector equipment, data acquisition, and superconducting radiofrequency (SRF) technology'.

CEBAF will house a high intensity, continuous wave electron accelerator for nuclear physics research. Utilizing SRF technology, CEBAF will be capable of delivering continuous beams of energy simultaneously to three experimental halls. There researchers position spectrometers and other detection devices to observe the interactions of subatomic particles. During operation, the beam will pass through the experiment's target, 
typically a thin sheet of material whose nuclei are under study. Scientists will then measure the angles and energies of particles scattered by the target to aid in the conduct of nuclear physics research.

The site is located in Newport News, Virginia (see Figure 1-1, CEBAF Location Map) and contains three components: a 162 acre Federally-owned area; a 44 acre parcel owned by the operating contractor, SURA; and 68 acres owned by the College of William and Mary and leased through SURA to DOE.

The facility consists of the following major facilities/operations:

- a linear electron accelerator which uses superconducting technology to drive electrons to higher and higher energies;

- a refrigeration plant which provides liquid helium for ultra-low-temperature, superconducting operation;

- a manufacturing/assembly and quality assurance operation for the production of accelerator components and experimental equipment; and

- three experimental halls for simultaneous research by teams of user physicists.

From an environmental impact perspective, CEBAF is a relatively low risk facility. Nonetheless, construction and operation of the facility may result in the following potential environmental impacts:

- $\quad$ Air Quality - fugitive dust, vehicle and equipment exhaust, asbestos, heating plant exhaust, solvent and acid fumes, and radionuclides;

- Water Quality - groundwater depletion, induced radioactivity in the soils and groundwater, and wastewater discharges (containing heavy metals and low $\mathrm{pH}$ levels); and

- Waste - storage of solid and hazardous waste, mixed wastes, and low-level radioactive wastes.

\subsection{ENVIRONMENTAL PROGRAMS AND ORGANIZATION}

ER, within DOE Headquarters, is the Program Office with responsibility for establishing environmental policy and program goals and objectives for CEBAF (see Figure 1-2, DOE/CEBAF Project Organization). OHi is respons:ble to ER for field oversight of CEBAF and implementing programs in accordance with the goals, objectives, and budgets established by ER. The OR Manager has assigned overall responsibility for carrying out these responsibilities to the Assistant Manager for Energy Research and Development (AMERD). AMERD has subsequently assigned responsibilities and authorities for managing activities at CEBAF to the CEBAF Site Office Manager, who is supported by a total staff of seven personnel. 


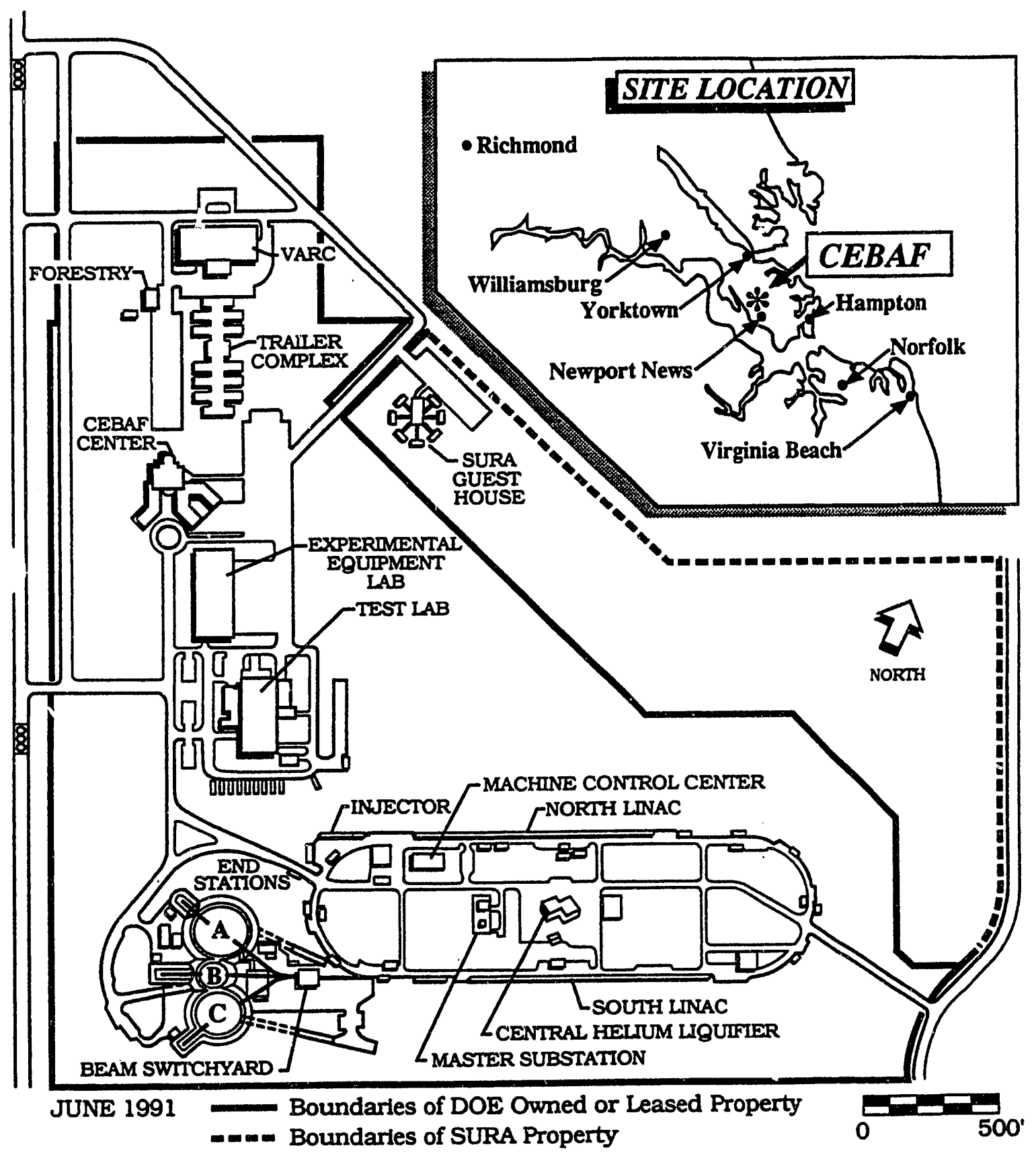

FIGURE 1-1. CEBAF LOCATION MAP 


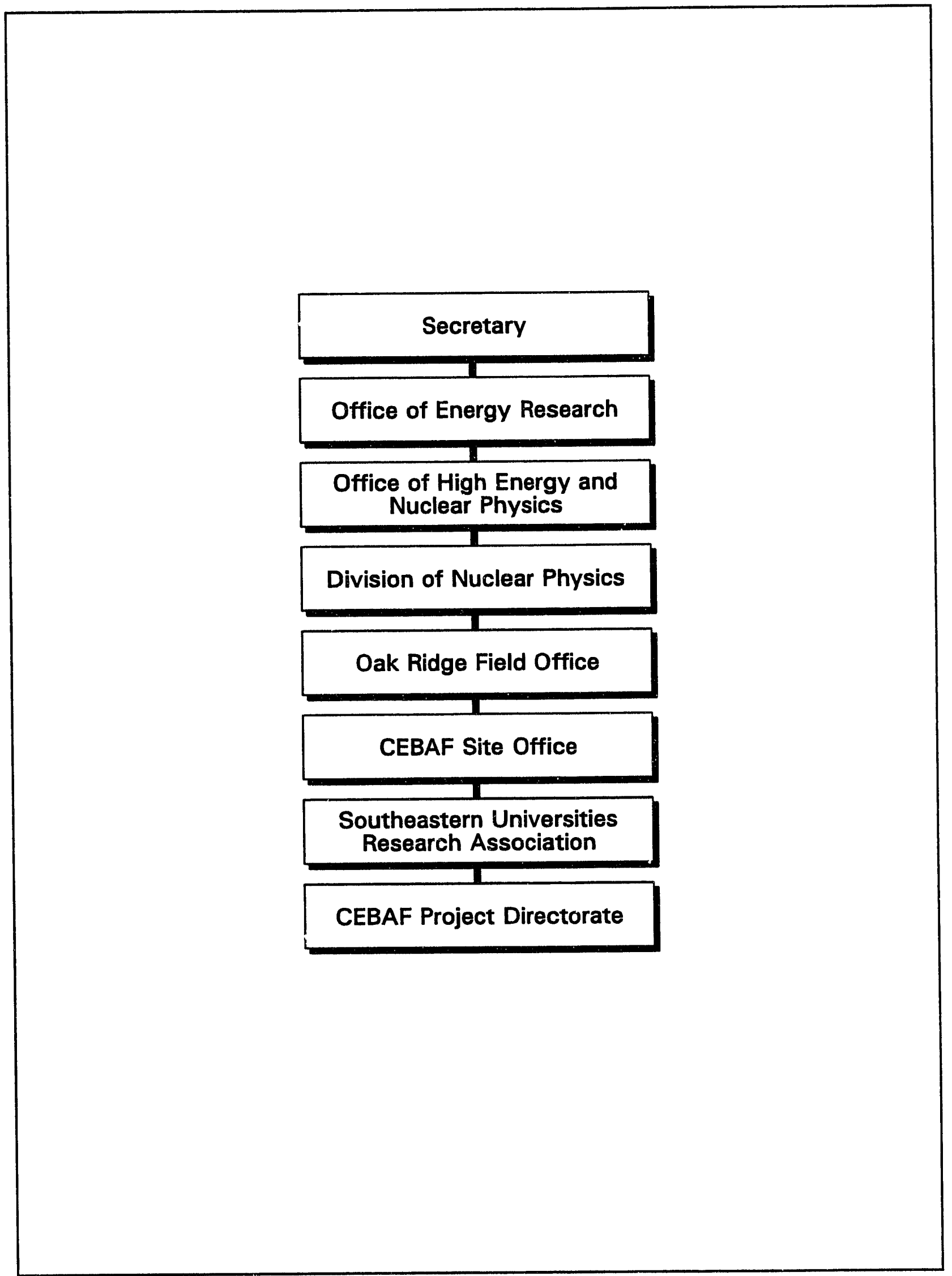


SURA is the M\&O contractor for CEBAF and has direct responsibility for conducting environmental protection activities, subject to DOE direction and approval. SURA'S CEBAF organization consists of three "line" divisions (Accelerator, Physics, and Administration), each of which has responsibility for specific aspects of the laboratory's operations, and two offices (Project Management and Technical Performance), both of which have laboratory-wide responsibility for certain key functions (see Figure 1-3, SURA/CEBAF Organization). SURA currently has a total staff (excluding subcontractors) of approximately 450 .

SURA recently reorganized its ES\&H activities within the overall organization. The thrust of these changes were to:

- $\quad$ reinforce line management responsibility for environmental management by providing the line divisions with greater control over ES\&H resources;

- $\quad$ create an environmental oversight function that is independent of day-to-day line management and ES\&H staff responsible for developing and implementing environmental programs; and

- $\quad$ establish committees, subcommittees, and other groups to deal with ES\&H issues that cut across some or all of SURA's divisions (e.g., the coordination of ES\&H training activities).

The line divisions have primary responsibility for ensuring that the activities they are responsible for are carried out in an environmentally sound manner. Each division has created an Environment, Health, and Safety (EH\&S) Group that reports directly to the division's Associate Director/Division Manager. Each of these groups is, or will be, staffed by at least one full-time ES\&H professional who provides guidance and support to division staff and assists the Associate Director in assuring that operations are conducted in an environmentally sound manner. Division ES\&H staff also have other responsibilities, including providing up to 50 percent of their time developing laboratory-wide ES\&H policies and procedures (under a matrix reporting arrangement to the EH\&S Policy and Manuals Group within the Office of Technical Performance), and assisting other line divisions in areas where they have special expertise that is not duplicated in the other division (e.g., hazardous waste management).

Several other groups within the divisions also have laboratory-wide environmental responsibilities. Within the Accelerator Division, the Radiological Control Department has laboratory-wide responsibility for radiological issues, including environmental radiological concerns. Within the Administration Division, the Plant Engineering Department has responsibilities for a variety of day-to-day environmental management activities, including the management of the laboratory's back-flow prevention system.

The Office of Technical Performance provides laboratory-wide leadership, oversight, support, and coordination for line environmental activities. This office is divided into three groups. The Self-Assessment and Quality Assurance Group manages SURA's central self-assessment, quality assurance, and continuous improvement functions. The EH\&S Policy and Manuals Group creates and maintains SURA's ES\&H policies and assists line management in translating these documents into suitable procedures and training programs. The EH\&S Reporting Group manages SURA's central ES\&H records systems 


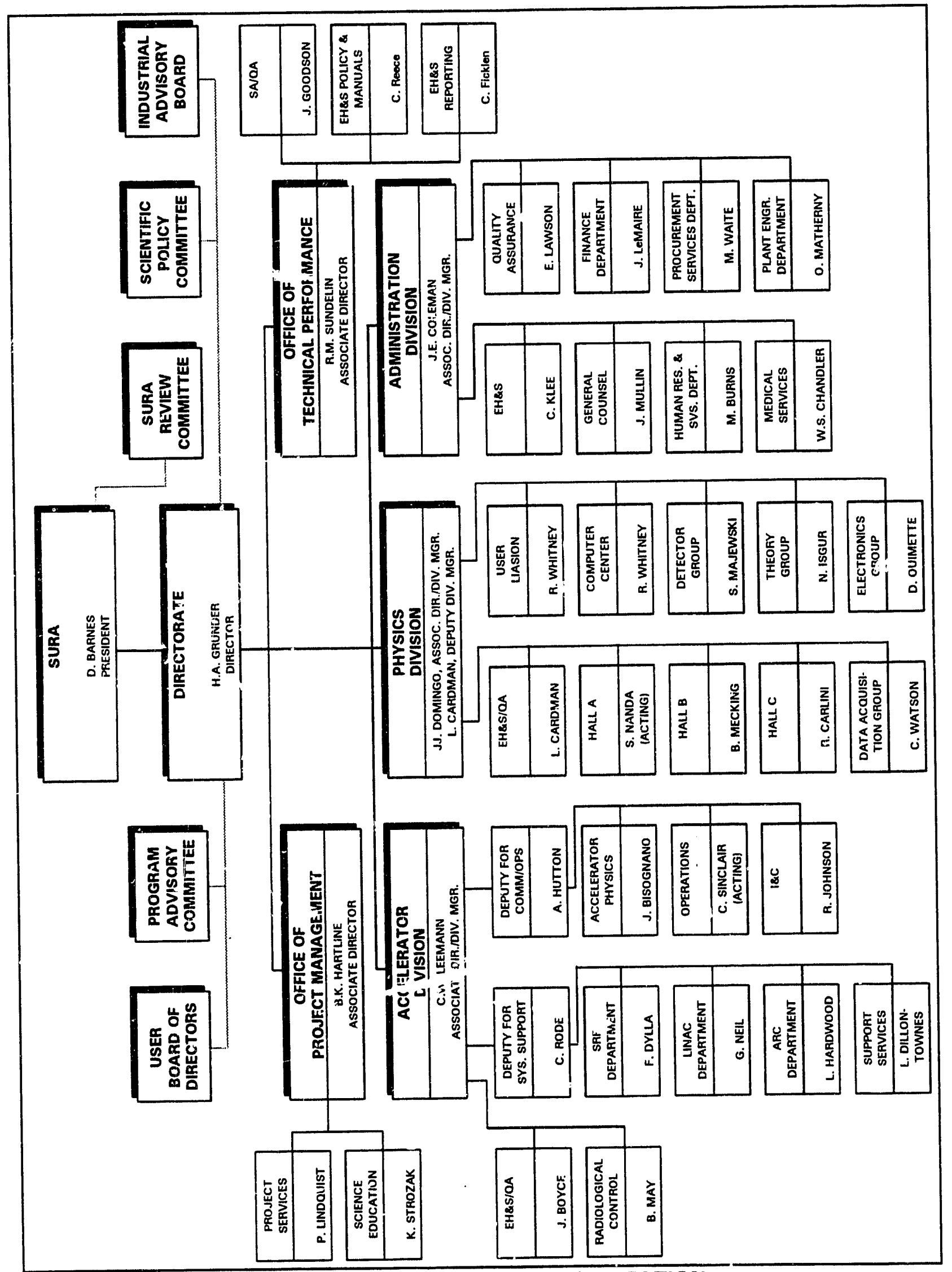

FIGURE 1-3. SURA/CEBAF ORGANIZATION 
(including regulatory reporting requirements), coordinates with outside groups on ES\&H issues (including the CEBAF Site Office and regulatory agencies), and provides input to line organizations and the EH\&S Policy and Manuals Group on new environmental regulatory requirements.

The Office of Project Management directs and oversees all aspects of SURA's construction activities at CEBAF using a matrix management structure that involves the Associate Directors and key department managers from other parts of the SURA organization. The Associate Director of the Office of Project Management is responsible for ensuring satisfactory ES\&H performance of all construction-related activities. 
This page intentionally left blank. 


\section{Section 2.0}

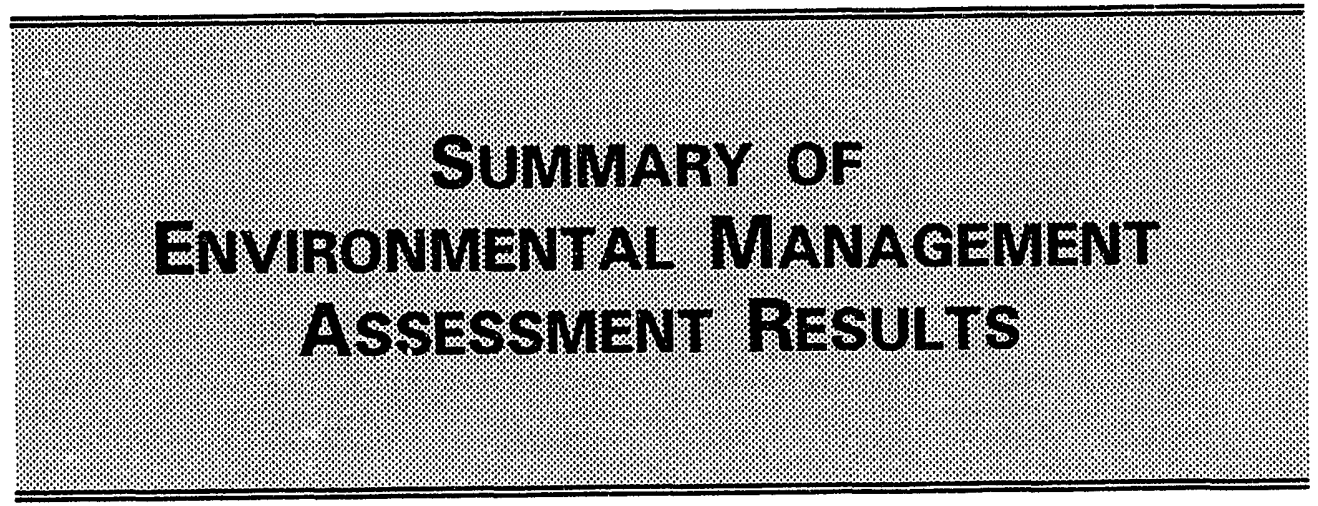


This page intentionally left blank. 
This section of the report summarizes the results and conclusions of the Office of Environmental Audit's (EH-24's) Environmental Management Assessment of CEBAF which was conducted between March 8 and March 19, 1993.

The scope of environmental concerns at CEBAF is relatively limited in comparison to many of the research facilities within the DOE complex. Based on a limited sampling during this assessment, SURA appears to be meeting the permitting and regulatory requirements associated with its operations.

Currently, CEBAF is in its final phase of construction, with all major structures in place and the focus of activities turning towards equipment installation and pre-operational testing. Although significant activity is occurring in areas subject to environmental compliance requirements and environmental radiological protection, the majority of the attention of DOE and SURA management in the environment, safety, and health (ES\&H) arena has been on safety and health issues. The inherent safety hazards of a major construction project clearly necessitate this strong management attention. However, environmental concerns have not been afforded a level of management attention consistent with the "commitment" embodied in the SURA Director's October 28, 1992 policy statement and the high expectations of the Department. For example, SURA has not developed any issue-specific policies or other guidance to support implementation of its strong overall ES\&H policy statement. In addition, although elements are in place, SURA has not fully developed and implemented formal and comprehensive environmental protection programs and plans to institutionalize the systems which are used to attain environmental performance goals, requirements, and standards. SURA has not established visible and measurable laboratory-wide environmental performance goals for the Accelerator, Physics, and Administration Divisions, nor does it consistently apply specific environmental performance objectives in performance standards for key line managers. Finally, SURA has not fully developed and implemented its self-assessment programs.

Many of the deficiencies noted by the assessment team had been identified, to some extent, by SURA and are in the process of being addressed. The organization is continuing to develop and mature in response to the recent organizational change which decentralized environmental responsibilities into SURA's line organizations. Adequate resources have been allocated within SURA's line organizations to fulfill their current assigned responsibilities, although some positions were not filled at the time of the assessment. Resource issues may need to be reassessed upon the resolution of the applicability of DOE Orders (see Section 3.9, Special Issue). SURA is in the process of establishing and/or improving many of the necessary management systems, including systems for training, facility inspections, and environmental self-assessments.

The CEBAF Site Office has been diligent in developing and institutionalizing the necessary systems for conducting its environmental oversight responsibilities. A solid self-assessment program has been developed and formalized procedures to direct and control the various aspects of their oversight responsibilities have been established. In light of the limited ES\&H staffing level, the CEBAF Site Office has instituted an aggressive training program for their EH\&S Manager. The fulfillment of the CEBAF Site Office's environmental responsibilities is complicated by a contractual disagreement with SURA 
regarding the applicability of DOE ES\&H Orders and the limited formal and routine management reporting on the status of environmental programs and performance.

The assessment team identified the following strengths of CEBAF's environmental programs and staff:

- Environmental Policy - On October 28, 1992, the Director of SURA issued an ES\&H policy statement which clearly articulated the position of management that ES\&H was an integral part of the operations at CEBAF. The environmental component of the policy is one of the strongest within the DOE complex. This policy has been widely distributed and awareness of it is high throughout SURA.

- Line Responsibility and Commitment - Management and staff from both the CEBAF Site Office and SURA exhibit a genuine sense of ownership and commitment to environmental performance at CEBAF. This commitment is critical to adhering to the high standards of the Department and SURA's aggressive environmental policy.

- Radiation Protection Management - The professional radiation protection staff within SURA are knowledgeable in accelerator health physics and have demonstrated a high level of competency in their ability to comprehend and manage radiological environmental protection and associated regulatory issues within CEBAF.

During the assessment, eight findings were identified. The titles of the findings by management discipline are shown in Table 2-1. In addition, a Special Issue was developed to document a contractual dispute between the CEBAF Site Office and SURA on the applicability of DOE ES\&H Orders.

\section{$2.1 \quad$ FINDINGS SUMMARY}

The following paragraphs briefly describe the findings in each of the disciplines included in the CEBAF Environmental Management Assessment.

\section{Organizational Structure (OS):}

There was one finding identified in this portion of the assessment. The finding addresses laboratory-wide environmental roles and responsibilities. While a recent reorganization strengthened line management ES\&H responsibility, there is still a need for senior management to provide stronger laboratory-wide leadership, oversight, support, and coordination for line environmental activities. Further, there is no clear laboratory-wide summary of roles and responsibilities for each of the major environmental programs, and there is a lack of clarity regarding roles and responsibilities for selected environmental management activities. 
TABLE 2-1

ENVIRONMENTAL MANAGEMENT ASSESSMENT TEAM FINDINGE

\begin{tabular}{|c|c|c|}
\hline $\begin{array}{l}\text { Finding } \\
\text { Number }\end{array}$ & Title of Finding. & $\begin{array}{l}\text { Page } \\
\text { No. }\end{array}$ \\
\hline \multicolumn{3}{|c|}{ Organizational Structure (OS) } \\
\hline OS-1 & $\begin{array}{l}\text { Definition of Environmental Management Roles and } \\
\text { Responsibilities }\end{array}$ & $3-5$ \\
\hline \multicolumn{3}{|c|}{ Environmental Commitment ( $\mathrm{EC}$ ) } \\
\hline EC-1 & Environmental Performance Management & 3-9 \\
\hline \multicolumn{3}{|c|}{ Environmental Protection Programs [EP] } \\
\hline EP-1 & $\begin{array}{l}\text { Formalization and Development of Environmental Protection } \\
\text { Programs and Plans }\end{array}$ & 3-14 \\
\hline \multicolumn{3}{|c|}{ Formality of Environmental Programs (FP) } \\
\hline FP-1 & Routine Facility Inspection Program & $3-23$ \\
\hline \multicolumn{3}{|c|}{ Internal and External Communication (IC) } \\
\hline IC-1 & Communication of Routine Environmental Status Information & 3-27 \\
\hline \multicolumn{3}{|c|}{ Staff Resources. Training. and Development (SR) } \\
\hline SR-1 & Staffing Expertise & $3-33$ \\
\hline SR-2 & Environmental Training Program & 3-34 \\
\hline \multicolumn{3}{|c|}{ Program Evaluation, Reporting, and Corrective Action (PE) } \\
\hline PE-1 & Self-Assessment Program & $3-39$ \\
\hline \multicolumn{3}{|c|}{ Environmental Planning and Risk Management (RM) } \\
\hline & No Findings Identified & \\
\hline
\end{tabular}




\section{Environmental Commitment (EC):}

There was one finding identified in this portion of the assessment. The finding points out that while the annual ES\&H self-assessment contained in the ES\&H Quality Assurance Plan contains some specific environmental-related goals and objectives, they generally do not have a high level of visibility within SURA, nor do they quantify environmental performance measures. Also, the environmental goals and objectives have not been incorporated into performance appraisal processes as reflected in job descriptions and performance standards for line managers. Finally, these goals and objectives are not reflected in the current SURA policy statement or subsidiary policies or guidance issued by senior SURA management.

\section{Environmental Protection Programs (EP):}

There was one finding identified in this portion of the assessment related to a lack of formal and comprehensive environmental protection programs. In general, the environmental protection programs seem to be operating effectively. However, many elements of the environmental protection programs have not been developed or are not well-defined and/or documented.

\section{Formality of Environmental Programs (FP):}

There was one finding identified in this portion of the assessment related to routine facility inspections. While SURA conducts routine facility inspections in each of the line organizations, the program lacks an adequate level of formality and focus on environmental issues. Routine inspections for the Administration and Physics Divisions are informal to the extent that no standard checklists have been developed. In addition, the Accelerator Division inspections, as reflected in a recently developed draft checklist, do not provide sufficient detail on environmental issues.

\section{Internal and External Communication (IC):}

There was one finding identified in this portion of the assessment. This finding addresses the lack of formal and routine reporting of environmental information (beyond "exception reporting") to senior managers in both SURA and the CEBAF Site Office. This type of reporting could further assure that senior managers have timely access to relevant information on the status of environmental programs and performance. Current communication systems are heavily oriented toward verbal and/or exception-based reporting.

\section{Staff Resources, Training, and Development (SR):}

There were two findings identified in this portion of the assessment. The first finding (SR-1) addresses nonradiological environmental expertise within SURA. In light of the increased emphasis on line responsibility for environmental management and the important role of the Office of Technical Performance in leading and supporting a number of important ES\&H initiatives (e.g., training, policies and procedures, self-assessment, Accelerator Readiness Review), the current depth of nonradiological environmental expertise is not consistent with SURA's goals as defined in its ES\&H policy statement. 
Additional hires (for open and approved positions) and training initiatives should adequately address these current gaps.

The second finding (SR-2) addresses the environmental training program. SURA has not yet implemented a comprehensive training program that assures all personnel receive training appropriate to their job responsibilities and skill/knowledge level. The current training program does not include a formal needs assessment or an effective recordkeeping system. A cross-divisional training subcommittee has recently been chartered to address these and other training issues.

\section{Program Evaluation, Reporting, and Corrective Action (PE):}

There was one finding in this portion of the assessment. The finding points out that the SURA self-assessment program has not yet been implemented to the extent that it provides a meaningful independent assessment of SURA's environmental management activities. The continued development and implementation of this program is receiving significant attention within the Office of Technical Performance and the divisions.

\section{Environmental Planning and Risk Management (RM):}

There were no findings in this portion of the assessment.

\section{2}

\section{CAUSAL FACTORS SUMMARY}

In an effort to understand why a finding occurred, a systematic approach was initiated to perform a "root cause" analysis. This is a two-step process which first identifies the likely underlying reasons the assessment team believes contributed to each specific finding. This is completed by asking a series of "why" questions to determine the apparent cause(s) for the findings. These "causal factors" and related rationale(s) are identified at the end of the discussion section of the appropriate finding. The next step is for line management to identify the "root cause(s)" for the findings. Root causes are the most basic fundamental causes which, if corrected, will prevent recurrence of the issues of concern.

The causal factors considered by the assessment team are defined in Appendix $F$ of this report. The team identified six causal factors it believes contributed to occurrence of the findings (see Table 2-2). The five causal factors occurring more than once are discussed below:

Design - appeared as a causal factor in four of the eight findings. The design of SURA performance management processes does not assure sustained attainment of environmental performance goals and performance measurement. The existing SURA communication systems do not convey routine environmental management information to all individuals with a need to know. The SURA training systems do not incorporate a formal needs assessment by job activity. Finally, routine facility inspections do not assure frequent review of day-to-day environmental management issues.

Policy Implementation - appeared as a causal factor in two of the eight findings. SURA has not completed the develofment and implementation of their self-assessment program which addresses DOE requireinents as directed by the CEBAF Site Office. 


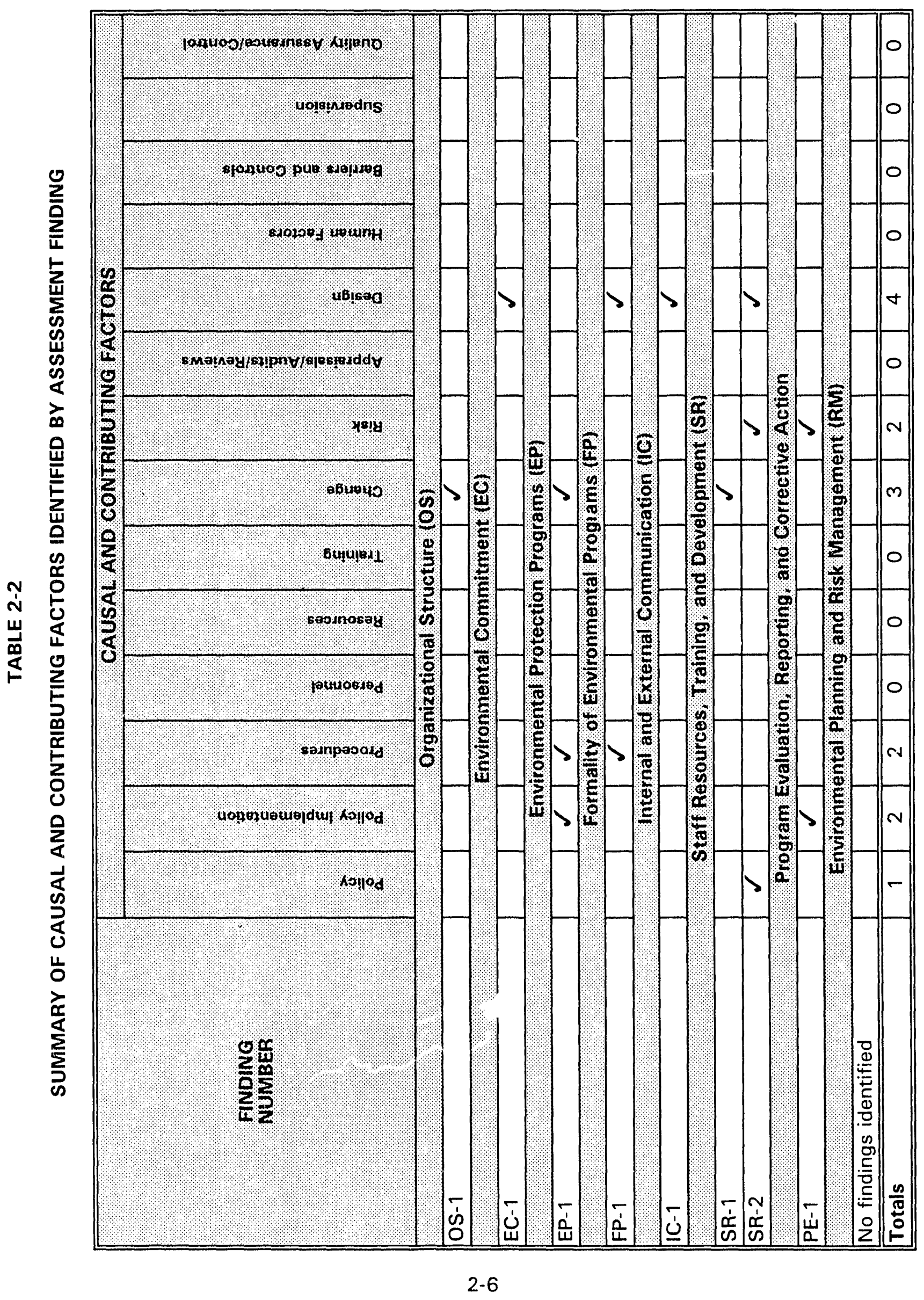


Change - appeared as a causal factor in three of the eight findings. Some environmental management roles are not clear as a result of recent organizational changes. Staffing levels and expertise have also been affected by the decentralization of ES\&H management. Environmental protection programs need to be enhanced, in part to address the changing nature of CEBAF's activities.

Procedures - appeared as a causal factor in two of the eight findings. SURA has not developed procedures to guide the implementation of environmental protection programs, including environmental activity checklists for routine facility inspection programs.

Risk - appeared as a causal factor in two of the eight findings. SURA needs to improve performance measurement and appraisal processes, as well as training programs, in order to help maintain a low potential for environmental vulnerability and liability.

The following section presents in detail the eight findings identified during this assessment. It also provides an overview of each assessment discipline. Finally, it discusses in greater detail the causal factors that appeared to contribute to the findings. 
This page intentionally left blank. 


\section{SeCtion 3.0}

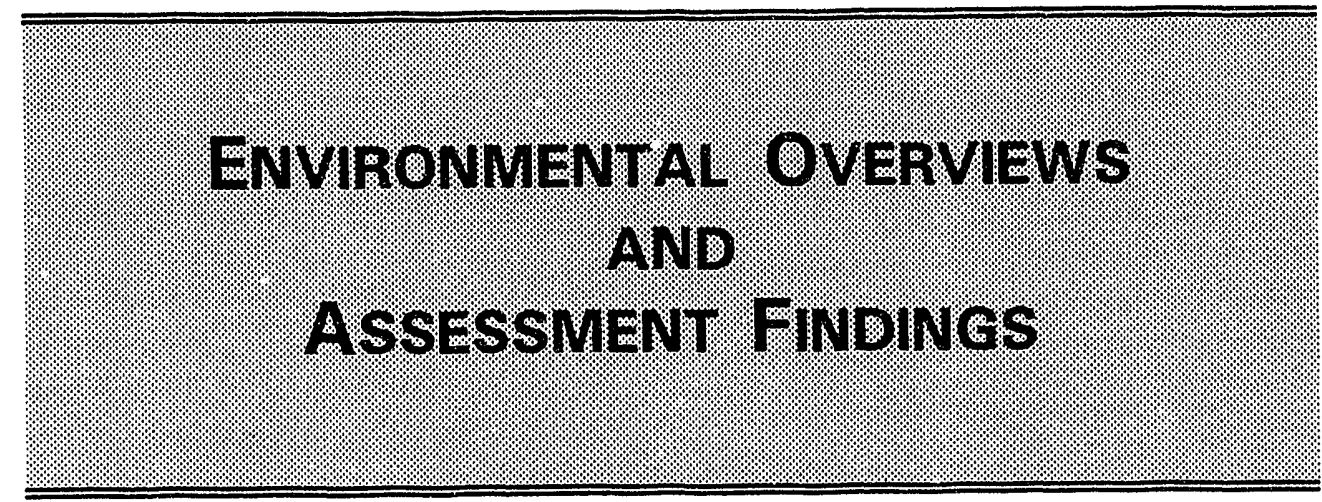


This page intentionally left blank. 
The assessment findings are presented in the following pages and are not necessarily in order of importance. They are grouped by area of investigation, as listed in the draft Protocols for Conducting Environmental Management Assessments (January 1993), and are preceded by an overview. The overview describes the approach taken by the technical specialist in conducting that portion of the assessment: CEBAF programs and activities related to the area of investigation; characterization of the strengths and weaknesses of CEBAF activities; and a brief summary of the findings. Each finding is organized into three sections: the performance objective, the finding statement, and a discussion. The performance objectives specify the particular practices or standards against which the finding is being evaluated. The discussion details the facts and observations supporting the finding. The discussion also provides a summary of the causal factors for the deficiency.

Within each finding, references to other findings, interviews, and documents are presented parenthetically. An example of a referenced finding is: "(see Finding OS-1)," in which "OS" stands for "Organizational Structure," and " $1^{n}$ is the finding number. Other abbreviations used to identify findings are as follows:

$\begin{array}{ll}\text { OS } & \text { Organizational Structure } \\ \text { EC } & \text { Environmental Commitment } \\ \text { EP } & \text { Environmental Protection Programs } \\ \text { FP } & \text { Formality of Environmental Programs } \\ \text { IC } & \text { Internal and External Communication } \\ \text { SR } & \text { Staff Resources, Training, and Development } \\ \text { PE } & \text { Program Evaluation, Reporting, and Corrective Action } \\ \text { RM } & \text { Environmental Planning and Risk Management } \\ \text { SI } & \text { Special Issue }\end{array}$

These abbreviations are used rather than the more conventional annotation for environmental management findings (i.e., EM-1) so that the reader can more easily determine the specific areas of investigation from which the finding was derived.

Several of the technical specialists on the assessment team covered more than one of the areas listed above. As such, interviews and document reviews quite often were completed with multiple areas of responsibility in mind. In order to reduce unnecessary duplication when referencing interviews and documents, they are identified as follows. An example of a referenced interview is (I-A-1) where "I" signifies an interview, " $A$ " represents an individual assessment team member, and " ${ }^{n}$ is the specifically assigned sequential interview number. Documents referenced for this Environmental Management Assessment are numbered starting with "CEB," and followed by a sequential number. The lists of documents reviewed and interviews conducted are presented in Appendices $D$ and E, respectively. Additionally, apparent causal factors are discussed for each finding and are defined in Appendix F. 
This page intentionally left blank.

3-2 


\subsubsection{Overview}

The purpose of the Organizational Structure portion of the Environmental Management Assessment was to evaluate whether CEBAF's environmental management organization is consistent with the overall organizational structure; whether environmental roles and responsibilities are well defined, clearly communicated and understood, and supported by appropriate management systems and documentation; and whether a group independent of line management is responsible for the policy and standards development and oversight functions.

The general approach to this portion of the assessment included a review of background documents provided by SURA and the CEBAF Site Office and onsite interviews with key personnel. Documents reviewed included position descriptions, organizational unit descriptions, organizational charts, and a variety of other documents and memos that describe the current organizational structure and roles at CEBAF. Interviews were conducted with selected line managers; environment, safety, and health (ES\&H) staff; and employees with environmental responsibilities in SURA's Director's Office, Office of Technical Performance, Office of Project Management, Accelerator Division, Physics Division, and Administration Division. DOE personnel from the CEBAF Site Office and managers within the Oak Ridge Field Office (OR) and the Office of Energy Research (ER) were also interviewed to determine their roles in directing and overseeing environmental management activities at CEBAF.

With respect to CEBAF, ER, within DOE Headquarters, is the responsible Program Office with responsibilities for the establishment of poiicy and program goals and objectives. OR is responsible to ER for management oversight of CEBAF, and is responsible for implementation of programs in accordance with the goals, objectives, and budgets established by ER. The OR Manager has assigned overall responsibility to the Assistant Manager for Energy Research and Development (AMERD) for carrying out these responsibilities. The AMERD has subsequently assigned responsibilities and authorities for managing activities at CEBAF to the CEBAF Site Office Manager.

As part of the ES\&H reorganization in January 1993, SURA made significant changes in their environmental management roles and responsibilities. The thrust of these changes were to:

- reinforce line management responsibility for environmental management by providing the line divisions (e.g., Accelerator and Physics) with greater control over ES\&H resources;

- create an environmental oversight function that is independent of day-to-day line management and ES\&H staff responsible for developing and implementing environmental programs; and

- $\quad$ establish committees, subcommittees, and other groups to deal with issues that cut across some or all of SURA's divisions, such as the development of laboratory-wide environmental policies and procedures, and the coordination of ES\&H training activities. 
The new environmental management organiza:ion is a matrix structure that is consistent with the organizational structure that SURA uses to handle other key functions, such as health and safety management and project management for construction activities. Roles and responsibilities are generally well defined and understood for the environmental activities that will be performed by line ES\&H staff (even though these roles sometimes involve specific divisions providing laboratory-wide assistance for certain activities such as radiation control or hazardous waste management). However, these roles and responsibilities are not as clearly defined for the laboratory-wide functions that will be performed by the new committees/ subcommittees or the Office of Technical Performance.

The new organization relies hezvily on matrixed staff from line divisions to develop environmental policies and procedures. The EH\&S Policy and Manuals Minager is a matrixed employee who devotes half of his time to this activity and half to ine responsibilities within the Accelerator Division. Much of the support for developing laboratory-wide environmental policies and procedures is also expected to come from matrixed ES\&H staff within the line divisions and the Office of Technical Performance (CEBO48, 060, 133, and 150; I-A-02, 10, 11, and 15). Although there are many advantages to involving line representatives in developing laboratory-wide policies and procedures, roles and responsibilities need to be more clearly delineated to assure the independence of this function and to clearly outline who has responsibility for assuring that divisiori-specific procedures are consistent with laboratory-wide standards.

SURA has already taken several steps to update the management systems and documents that support the new organizational structure, although more work is needed in this area. It has updated most position descriptions (CEBO60 and CEB133; I-A-03), revised organizational descriptions and charts (CEBO48 and CEB156), held a variety of staff meetings to explain the changes (CEB092; 1-A-01 and I-A-06), and developed a charter for the EH\&S Committee and its subcommittees (CEB1 18). In addition to these laboratory-wide efforts, the Physics Division has prepared a memorandum to all of its Division staff (CEB139) and conducted a Division staff meeting to explain the implications of the recent reorganization on ES\&H responsibilities. The Accelerator Division has drafted and circulated for internal review a reference guide entitled EH\&S Management in the Accelerator Division (February 1993) (CEB150) that describes, among other topics, the new environmental management roles of Division staff. Both of these documents describe the responsibilities of Division managers, ES\&H staff, and other employees; indicate where to obtain ES\&H information; and explain the "stop work" roles and/or process within the Division. In addition, the draft accelerator guide indicates how Division roles and responsibilities are linked to the major laboratory-wide programs.

Overall, CEBAF has an effective organizational structure for environmental management that promotes line responsibility and provides for independent oversight both within SURA and by the CEBAF Site Office. However, roles and responsibilities for laboratory-wide environmental functions need additional clarification.

There was one finding in the area of Organizational Structure relating to definition of laboratory-wide environmental management roles and responsibilities. 


\subsubsection{Finding}

\section{OS-1: Definition of Environmental Management Roles and Responsibilities}

Performance Objective: Best management practices suggest that environmental roles and responsibilities should be well defined, clearly communicated, and understood by all personnel whose activities may impact environmental performance.

Finding: Roles and responsibilities for some environmental management activities at CEBAF are not well defined, clearly communicated, and understood.

Discussion: SURA's reorganization of environment, safety, and health (ES\&H) activities in January 1993, resulted in significant changes in both laboratory-wide and line environmental roles and responsibilities. The new roles and responsibilities for SURA staff are described in position descriptions (CEBO60 and CEB133), organizational unit descriptions (CEBO48), organizational charts (CEB156), and a variety of other documents and memos (CEB118, CEB139, and CEB150). Although SURA has taken several steps to clarify the new roles, including updating position and organizational descriptions and holding meetings with SURA staff, there is still some confusion about the new roles, particularly for laboratory-wide functions, as outlined below.

- There is no clear laboratory-wide summary of roles and responsibilities for each of the major environmental programs (see Finding EP-1), although portions of this material are contained in other documents. These other documents describe roles for a particular organization (CEBO48, CEB139, and CEB150), a particular individual (CEB017, CEB060, and CEB133), or specific activities or procedures, but do not provide a comprehensive picture of how these responsibilities are integrated to carry out the laboratory's major environmental programs. SURA plans to develop an environmental handbook that would contain this information, but does not expect to complete this document until fiscal year 1994 (I-A-12).

- There is some confusion about whether staff in the Office of Technical Performance (OTP) have the authority to stop work. Although several senior SURA managers indicated that OTP staff do have this authority (I-A-01 and I-A-17), some OTP staff were unsure about their authority (I-A-15 and $|-|-11)$.

- $\quad$ Although the primary intent of the recent organizational changes was to strengthen line management responsibility for ES\&H performance, there is still a need for a senior manager to provide laboratory-wide leadership, oversight, support, and coordination for line environmental activities (particularly in light of the many important initiatives, including policies and procedures manual, self-assessment program development, accelerator readiness review, training subcommittee, and others now under development). Based on a review of key documents (CEBO48, CEBO60, and CEB 150), it appears that these responsibilities have been assigned to the Associate Director of OTP, both in his role as head of OTP and chair of the SURA EH\&S Committee. Although some of the SURA staff interviewed by the assessment team also assumed that the Associate Director of OTP 
would play this role (I-A-01 and $1-A-17)$, several other people interviewed indicated that it was unclear who had primary responsibility for laboratory-wide environmental management (I-A-09, !-A-14, and I-A-15).

Because the reorganization happened so recently, there are several other minor areas where laboratory-wide environmental roles and responsibilities are not yet fully developed including training, review of division-specific environmental procedures, and precise division of responsibilities among staff within OTP, as outlined below:

- Line managers have primary responsibility for assuring that their staff are adequately trained (CEBO60). However, with the exception of administrative support from the Human Resource Department, responsibilities for laboratory-wide activities such as providing guidance on training content or assuring senior management that staff have been adequately trained have not been clearly delineated (see Finding SR-2). A new training subcommittee has recently been established and its charter includes "coordinating development of EH\&S training curricula, promoting uniformity, and avoiding duplication of effort..." (CEB1 18).

- It is not clear whether any laboratory-wide staff or committee will have a formal role in reviewing division-specific environmental procedures. Some staff within OTP indicated that there would be no formal review role, and that consistency with laboratory-wide policies and procedures would be assured through informal communication among line and laboratory-wide ES\&H staff responsible for policy and procedure development (I-A-02). Other OTP staff indicated that laboratory-wide ES\&H staff have traditionally reviewed division-specific procedures and that they expected OTP to play this role in the new organization (1-A-12).

- The newly-revised position and organizational descriptions and the Charter for the new EH\&S Committee and subcommittees (CEBO48, CEBO60, and CEB 150) indicate that there are areas of potentially overlapping responsibilities both within OTP and between OTP and the committees that OTP staff sit on and/or chair. Because the new organization has been in place for such a short time, there is little operational experience and no documentation to clarify how these overlapping responsibilities will be handled. Areas that particularly need clarification include: who is the key external spokesman for SURA on environmental issues (in particular, what is the division of responsibility between the Associate Director of OTP and the Manager of Environmental, Health and Safety Reporting); who has primary responsibility for determining the need for new or revised environmental policies and procedures; and what role the Self-Assessment and Quality Assurance Group will play in maintaining ES\&H licenses and permits (CEB048).

The apparent causal factor contributing to this finding is change due to the recent decentralization of the ES\&H function. 


\subsubsection{Overview}

The purpose of the Environmental Commitment portion of the Environmental Management Assessment was to evaluate the level of commitment to environmental protection exhibited by SURA and the CEBAF Site Office. Environmental commitment in this context is defined as follows: the demonstration of senior management's commitment to environmental protection through formal statements, managerial decisions and actions, attitudes, and interests; the establishment of organizational policy which places environment, safety, and health (ES\&H) as a top priority, on an equal level with construction and research activities; and the awareness of and line responsibility for environmental protection at all levels and across all functions within the organizations.

The general approach to this portion of the assessment was to review DOE Orders, Secretary of Energy Notices (SENS), and background documents provided by SURA and the CEBAF Site Office prior to the onsite portion of the assessment. Onsite activities focused on interviewing and reviewing additional documents. Interviews were held with the SURA Director and management and staff within SURA's Accelerator Division, Physics Division, Administration Division, Office of Project Management, and the Office of Technical Performance. Additionally, Interviews were held with the CEBAF Site Office Manager and selected staff.

Staff and management within the CEBAF Site Office exhibit a genuine commitment to effective environmental performance at CEBAF. This commitment has been demonstrated through the development of a solid self-assessment program, the development of formalized procedures to direct and control the various aspects of their oversight responsibilities, and aggressive training of their EH\&S Manager. In the spirit of SEN-20-90, "Interaction with Internal and External Oversight Organizations," the staff and management of the CEBAF Site Office have cooperated fully and openly with this assessment process.

SURA demonstrated their commitment to ES\&H performance at CEBAF in several ways. Specifically, a recent reorganization occurred which reinforced line management responsibility within SURA by decentralizing the ES\&H responsibilities into the SURA line organizations. In interviews with assessment team members, SURA line managers exhibit a genuine sense of ownership for these responsibilities. Additionally, both human and financial resources appear to be adequately allocated to carry out assigned environmental responsibilities.

On October 28, 1992, the Director of SURA issued an ES\&H policy statement which clearly articulated the position of management that ES\&H was an integral part of the operations at CEBAF. This policy has been well distributed and awareness of it is high through all levels of SURA. The environmental component of this policy is one of the strongest within the DOE complex. Specifically, it states:

"CEBAF is committed to the preservation, protection and, where possible, the enhancement of our environment in all areas of operations. This includes the obvious goals of meeting or exceeding all applicable local, state and federal requirements, as well as fostering responsible stewardship by our personnel of all 
natural resources both in the workplace and at home in the community. We promote a proactive policy in environmental matters - one that anticipates and addresses problems before they become a regulatory matter. As part of the community, CEBAF has been and will remain committed to this policy which makes not only ecological, but economical sense."

The Director has been personally involved in advocating this policy by holding an all hands meeting and numerous meetings with "working groups" of SURA staff to discuss the policy.

There was one finding in the area of Environmental Commitment relating to a lack of environmental performance management within SURA. 


\subsubsection{Finding}

EC-1: $\quad$ Environmental Performance Management

Performance Objective: Best management practices suggest that an organization establish specific environmental performance goals in order to establish a measurable system to evaluate the effectiveness of line management's environmental performance. Such goals should be incorporated into performance appraisal processes.

Finding: SURA has not completely established measurable organization-wide environmental performance goals and has not applied existing goals into individual performance appraisal processes.

Discussion: The Environment, Health and Safety Quality Assurance Plan (1993) (CEBO24) establishes the following specific environment, safety, and health (ES\&H) goals with laboratory-wide impacts:

- $\quad$ resubmittal of the Environmental Protection Agency (EPA) National Emission Standards for Hazardous Air Pollutants (NESHAPs) Permit application by Radiation Control, encompassing the End Stations' radionuclide emission estimates;

- thorough review of CEBAF environmental areas by Laboratory EH\&S for incorporation into a comprehensive CEBAF environmental procedures handbook; and

- Materials Management Department developmert of an appropriate system of ES\&H review for procurement of new chemicials and other products with ES\&H impact.

Specific environriental objectives from the FY 1993 CEBAF EH\&S Self-Assessment (CEB074) are also outlined. These objectives include: maintaining compliance with all applicable Federal, state, and local requirements; improved oversight of hazardous waste activities; and monitoring waste generation rates and recycling effectiveness.

While these laboratory-wide goals and objectives establish basic criteria to measure organizational environmental performance and environmental program development, they generally do not have a high level of visibility within SURA, nor do they include quantifiable environmental performance measures (e.g., percent reductions in hazardous waste, percent reduction of toxic chemicals used onsite). Such explicit goals translate the intent of the organization's ES\&H policy into measurable performance indicators in which overall facility performance can be judged. Specific performance indicators have not been developed by SURA, but are in the initial planning stages (I-1-12).

The Directors of the Accelerator and Physics Divisions were not readily aware of the performance goals and objectives embodied in the EH\&S Quality Assurance (QA) Plan (I-G-05 and I-G-06). However, although not formally documented, both Directors voiced strong expectations for the performance of their subordinate managers and staff with regard to specific activities which may have environmental protection consequences. 
Additionally, the environmental performance goals have not specifically been incorporated into performance appraisal processes as reflected in job descriptions and performance standards for line managers (CEBO60 and CEB153), nor are they reflected in the current SURA policy statement or subsidiary policies or guidance issued by senior SURA management. Position descriptions for selected SURA line managers do contain broad statements on environmental performance.

The apparent causal factor contributing to this finding is the incomplete design of SURA's performance assurance management system for establishing environmental performance goals and measuring their implementation through performance appraisal processes. 


\subsection{ENVIRONMENTAL PROTECTION PROGRAMS}

\subsubsection{Overview}

The purpose of the Environmental Protection Programs portion of the Environmental Management Assessment was to evaluate the extent to which CEBAF has developed and implemented specific environmental protection programs and plans as embodied in DOE Orders and best management practices. Because of he nature of this assessment, environmental programs were reviewed from a programmatic perspective to determine if program components exist and to determine the effectiveness of those programs. The focus of the review was on pollution control and abatement programs rather than National Environmental Policy Act (NEPA) or natural resource management programs. Specific programs that were reviewed during the assessment include the following:

- hazardous waste management;

- $\quad$ radioactive and mixed waste management;

- drinking water management;

- environmental radiation protection programs;

- $\quad$ surface water and groundwater protection;

- $\quad$ wastewater disposal;

- air pollution control;

- $\quad$ preventive maintenance activities;

- $\quad$ spill prevention control and countermeasures;

- $\quad$ toxic and chemical material management; and

- $\quad$ quality assurance.

Specific program elements considered in this review included identification of applicable regulatory requirements, assignment of program responsibilities, identification and monitoring of emission sources, training requirements, notification and reporting to regulatory agencies, and program evaluation and oversight. A sampling approach was used, and as a result, not all program areas described above were reviewed in equal detail.

The general approach to this portion of the assessment was to review DOE Orders and regulatory requirements, and background documents provided by SURA and the CEBAF Site Office prior to the onsite portion of the assessment. Onsite activities focused on interviewing key personnel involved with environmental and radiation protection programs within SURA's Accelerator Division, Physics Division, Administration Division, and Office of Technical Performance. DOE personnel from the CEBAF Site Office were also interviewed to determine their roles in directing and overseeing environmerital protection programs. 
Overall, SURA has a clear understanding of Federal, state, and local regulatory requirements which affect its environmental protection programs. However, SURA has not consistently taken a comprehensive and formal approach to developing and implementing its environmental programs. The more dynamic activities that will take place at CEBAF, with users from around the world taking advantage of the facilities, necessitate additional formality and a more structured approach to environmental management to assure continued compliance with environmental regulations and protection of public health and the environment. The scope of environmental activities at CEBAF can be described as follows.

The hazardous waste program is managed out of the Superconducting Radiofrequency (SRF) unit. CEBAF is a small quantity generator, and the major sources of hazardous wastes are acid and solvent wastes associated with manufacture of niobium cavities.

At this time, minimal amounts of material are being activated with little, if any, resultant radioactive waste. Also, hazardous materials are utilized onsite which generate waste. There is an additional potential for the generation of radioactive mixed waste. The current CEBAF Radiation Safety Handbook (CEB130) discusses the classification, handling, labeling, and storage of radioactive materials and waste.

A state required backflow prevention program has been instituted in conjunction with the City of Newport News to protect the water supply from contamination. This program is well developed and there appears to be good control on modifications to the drinking water system through the work request process.

Direct environmental radiation monitoring is being performed at CEBAF for neutron and photon radiations at the site boundary. Six real-time automated boundary monitors have been installed, and background data have been collected for statistical analysis.

Additionally, there are plans to place a number of passive neutron integrating thermoluminescent detectors (TLDs) at the site boundary. Presently, there are 18 photon TLD monitors in place. However, the anticipated photon contribution will be minimal. The management approach in using these two individual systems is to verify the dose design criteria.

The groundwater and surface water monitoring program has been designed and managed to satisfy state permit requirements. A subcontractor is periodically sampling the monitoring and dewatering wells for radiological, chemical, and physical parameters. These data are being compiled for a determination of baseine conditions. The site is in a nondegredation region and CEBAF cannot alter groundwater quality from its original condition beyond the site boundary.

Sanitary and process wastewater is discharged to the Hampton Roads Sanitation District. The process wastewater treatment system consists of a neutralization system for acidic wastewater from the cavity cleaning process. Permit sampling is conducted by a subcontractor with oversight from CEBAF.

Dperation and maintenance activities were reviewed as they pertain to industrial pretreatment and air pollution control systems. Operation manuals have been prepared, rnaintenance activities have been scheduled, and records of maintenance and calibration ictivities are maintained. 
The approach to the management of the radiological air pollution control program to date has involved the submission for a National Emission Standards for Hazardous Air Pollutants (NESHAPs) approval to EPA for construction of the linear accelerators (LINACs). A NESHAPs permit to construct was issued in 1987. This involved a calculation of the source term and estimation of offsite dose. These calculations appear to be well thought out, reviewed, documented, and in conformance with regulatory requirements. This approval application will soon be modified for consideration of the experimental halls. Once operational, the potential radiological air effluents will be activated air.

Spill Prevention Control and Countermeasure (SPCC) regulations were reviewed to determine the applicability to CEBAF. It was determined that the quantities of oil onsite exceeded the thresholds that require preparation of an SPCC Plan. Oil sources at CEBAF include numerous oil-filled transformers, a diesel fuel tank, and the waste oil storage area.

Toxic and chemical material programs appear to be adequate as they relate to polychlorinated biphenyl (PCB) management, underground storage tanks, and asbestos. There are no remaining PCBs at CEBAF, all underground storage tanks have been removed, and most of the asbestos has also been removed from the buildings.

CEBAF has developed an overall Quality Assurance Program Plan which has guided the development of over 50 specific Quality Assurance Plans. Environmental quality assurance was reviewed with respect to oversight of sampling contractors. Oversight activities include accompanying contractors during sampling events and occasional audits of contract laboratories.

There was one finding in the area of Environmental Protection Programs relating to the development of comprehensive and formal environmental programs. 


\subsubsection{Finding \\ EP-1: $\quad$ Formalization and Development of Environmental Protection Programs and Plans}

Performance Objective: Programs should be in place to assure compliance with Federal, state, and local envircnmenta! laws and regulations and the protection of public health and the environment. This is demonstrated by comprehensive and formal environmental protection programs which contain documented regulatory requirements, formal policies and plans, implementation procedures, personnel responsibilities, recordkeeping and reporting mechanisms, identification and characterization of emission sources, training requirements, and mechanisms for program evaluation and oversight.

DOE 5480.19, "Conduct of Operations Requirements for DOE Facilities," requires operations to be conducted in a formal manner, and DOE 5400.1, "General Environmental Protection Program," provides guidance for establishing various environmental programs.

Finding: Although elements are in place, CEBAF has not fully developed and implemented formal and comprehensive environmental protection programs and plans.

Discussion: Environmental protection programs at CEBAF are described in the CEBAF Environmental Protection Program Plan (CEBO21). This document combines the Environmental Protection in., ,ementation Plan, Pollution Prevention Awareness Program, Groundwater Protection Management Plan, Waste Minimization Plan, and Long Range Environmental Plan into one document. This program plan discusses many of the mandated environmental protection statutes and elements of the environmental protection programs in a general fashion. It does not, however, provide a detailed discussion of site-specific requirements for each program. Specific deficiencies of the radiological and nonradiological environmental programs are discussed in more detail below.

\section{Nonradiological Programs}

Nonradiological environmental protection programs are administered through various organizations within SURA. For the most part, these programs appear to be properly managed and responsible personnel have demonstrated a high level of commitment to the programs. These programs, however, have not typically employed a comprehensive approach that includes formal documents which outline the objectives and requirements associated with each program. A more comprehensive and documented program, including identification of relevant regulatory requirements, definition of compliance strategies and roles and responsibilities, and development of mechanisms for oversight and control, would provide a higher level of assurance regarding environmental performance. In fact, the assessment team identified one environmental program (Spill Prevention Control and Countermeasure (SPCC) Plan) that had not been developed or implemented. The need for more formal programs is also important to provide continuity in the event of turnover and in light of future changes as CEBAF becomes fully operational. Weaknesses in programs reviewed during the assessment include the following:

- $\quad$ SPCC Plan: An SPCC plan has not been prepared for CEBAF. There are numerous transformers located throughout CEBAF that contain varying amounts of oil (typically $\mathbf{4 4 0}$ gallons each). Moreover, there are other 
sources of oil, such as a diesel fuel storage tank near the acid transfer building and containers in the waste oil storage area. Although an inventory of all oil sources onsite has not been conducted, the transformers around the accelerator proper contain an aggregate of over 4000 gallons of oil (CEBO85), which exceeds the 1320 gallon threshold for the preparation of an SPCC plan. In addition, the definition of navigable waters includes wetlands and tributaries to waters used for navigation, which leads the assessment team to believe that there is a reasonable potential for discharged oil to reach a navigable water. This portion of the finding was brought up in a 1989 Oak Ridge Assessment and was considered closed as of the January 1991 Oak Ridge Assessment. The Office of Environment, Safety and Health (EH) assessment team did not receive sufficient documentation to determine the reasons for closure, and based on the information reviewed, believe that an SPCC Plan is required at CEBAF.

Hazardous Waste Program: The Superconducting Radiofrequency (SRF) unit generates the majority of hazardous waste produced at CEBAF, and personnel within this unit are assigned laboratory-wide responsibility for hazardous waste disposal (I-D-05, I-D-10, and I-D-11). Although the program appears to be operating well, the specific requirements have not been formally documented. Areas that require further documentation include: overall objectives of the hazardous waste program, roles and responsibilities of SURA personnel, training requirements for personnel generating and handling hazardous waste, satellite accumulation and hazardous waste storage area management practices, and manifest preparation and tracking.

Environmental Quality Assurance Program: Sampling and analysis programs at CEBAF are conducted by subcontractors to SURA (I-D-05, I-D-07, and I-D-09). SURA's role in this process is to provide oversight of these functions. Specific oversight activities have included accompanying the contractor during sampling activities and occasional audits of the contract laboratories. This quality assurance program has not been formalized to include the frequency of oversight activities, identification of proper sampling procedures, chain-of-custody requirements, laboratory quality assurance procedures, and documentation requirements.

- Toxic and Chemical Material Program: Toxic and chemical materials are utilized by various personnel at CEBAF. Procedures that address the need for Material Safety Data Sheets (MSDSs) have been developed for materials purchased by the SURA procurement office and received by the shipping/receiving department (CEB105). The Accelerator Division has recently issued a directive requiring all purchases of liquid chemicals in excess of 1 gallon to be reviewed prior to submitting a requisition (CEB127). However, there is not a formal laboratory-wide policy or procedure that addresses all components of hazardous materials management (e.g., product substitution, waste disposal options) for all hazardous materials, including samples and small quantities brought onsite by visiting scientists. 


\section{Radiological Programs}

The professional radiation protection staff at CEBAF are knowledgeable in accelerator health physics and have a good understanding of applicable Federal and state regulatory requirements. The environmental radiation protection program elements reviewed appear to be adequate for meeting regulatory requirements for pre-operational activities. That is, the offsite dose calculations and groundwater sampling are being performed to meet permitting conditions. However, SURA has not completely developed, implemented, and/or documented the programs listed below. A more comprehensive approach would provide a higher level of assurance regarding environmental performance that all relevant requirements are being met, and would provide a clearer and more defensible position in the event of radiation concerns raised by organizations such as local interest groups.

- Air Pollution Control Program: The site currently holds appropriate Environmental Protection Agency (EPA) National Emission Standards for Hazardous Air Pollutants (NESHAPs) approvals. CEBAF has developed numerous technical documents that incorporate many of the individual elements of an air program. However, these have not been incorporated into a comprehensive summary plan that includes elements such as: identification and location of sources of activated gases, expected activity production rates under normal and abnormal operating conditions, control and release mitigation approach, effluent performance standards, monitoring methods, analytical requirements, documented procedures, site meteorological conditions with a review of daily and seasonal variability, program quality assurance, records and reports, and organizational responsibilities (I-C-04 and I-C-06). Additionally, there is some question as to the need for future confirmatory monitoring. CEBAF does plan to conduct some form of continuous air monitoring.

- Groundwater Monitoring Program: CEBAF has considered the activation of groundwater in accelerator detector hall design documents. Further, the site currently holds appropriate state groundwater permits. Some elements of an effective program exist under the permit (e.g., baseline sampling wells). However, a summary document has not been prepared that specifically discusses: the identification of expected locations of sources of activated radionuclides in soil and water, expected activity production rates under normal and abnormal operating conditions, control and release mitigation approach, effluent performance standards, monitoring methods, analytical requirements, sampling procedures, description of current site geohydrology, basis for locating sampling wells, approach for evaluating baseline conditions, program quality assurance, records and reports, and organizational responsibilities (I-C-04 and I-C-06).

- Environmental Radiation Protection Program: The site is currently in a pre-operational phase and presents little, if any, risk of offsite radiation dose to the public. However, once operational, direct radiation exposure from skyshine will likely be the highest contribution of offsite dose from the CEBAF facility. Presently, CEBAF is anticipating the need for direct radiation 
monitoring and addresses this in several technical notes. However, the program lacks a summary document that specifically discusses:

performance standards for offsite doses to the public, radiological environmental surveillance, pathway analysis, evaluation of planned and unplanned releases of radioactive materials, evaluation of direct radiation exposure to the public, sampling and monitoring design criteria, justification for sampling and monitoring locations, technical approach for baseline evaluations, data analysis and statistical treatment, dose calculation methods, parameter assumptions and justification, program quality assurance, records and reports, and organizational responsibilities (I-C-04 and $(-\mathrm{C}-06)$.

- Radioactive and Mixed Waste Management Program: The site is currently in a pre-operational phase and is generating little, if any, radioactive waste. However, once operational, low-level radioactive waste streams, and potentially mixed waste, will be generated. Presently, CEBAF anticipates some of these upcoming needs and addresses them in the draft CEBAF Radiological Control Manual (CEB059). However, the existing programs lack a summary document that specifically discusses: purpose and policy, performance objectives, waste generation, waste minimization, waste characterization, waste acceptance criteria, surface and volumetric unrestricted release limits, waste treatment, offsite shipment procedures, short- and long-term storage criteria, disposal options, decommissioning and other post-operational activities, performance assessments, reports and records, and organizational responsibilities (I-C-04 and I-C-06).

Site personnel are aware that a greater level of formality is necessary as CEBAF's mission changes from a construction orientation to operations. This is noted in the FY 1993 CEBAF EH\&S Self-Assessment (CEBO74). However, some programs require more immediate attention (e.g., waste management, SPCC) in light of the current level of site activity. Initiatives are being put in place to revise the Safety Manual to include many of the environmental programmatic elements described above. However, it is not expected that these improvements will be in place before the end of 1993.

The apparent causal factors contributing to this finding are policy implementation, in that the formality requirements of DOE Orders have not been implemented; a lack of procedures to formally document the approach which implements existing environmental programs; and change, in that the growth and changing nature of CEBAF have rendered the existing informal programs inappropriate for the anticipated uses of the facility. 
This page intentionally left blank. 


\subsubsection{Overview}

The review of Formality of Environmental Programs focused on CEBAF's systems and processes to assure ongoing environmental compliance and achievement of environmental performance goals. The assessment was designed to evaluate whether environmental protection activities are conducted in accordance with formal programs supported by controlled documentation. An important aspect of the assessment was to assess CEBAF's adherence to best management practices as embodied in DOE 5480.19, "Conduct of Operations Requirements for DOE Facilities." Specifically, the assessment focused on the following areas:

- Regulatory Tracking and Translation - the systems to track and interpret environmental regulations and DOE Orders and incorporate them into policies, standards, and procedures;

- $\quad$ Procedures - the mechanisms by which environmental programs and procedures are developed and effectively implemented throughout the organization;

- Routine Facility Inspections - the systems for conducting routine inspections to assure facility compliance with applicable environmental requirements and identifying and correcting potential problems; and

- Recordkeeping and Reporting - the systems for maintaining and retaining records, and for assuring timely completion of environmental regulatory and management reporting requirements.

The general approach to this assessment was to review DOE Orders, environmental regulatory requirements, and background documents provided by SURA and the CEBAF Site Office prior to arrival onsite. Onsite activities included additional document review and interviews with management and staff within the Office of Technical Performance, the Administration Division, the Physics Division, the Accelerator Division, the Associate Director of the Office of Project Management, and environmental and upper management personnel within the CEBAF Site Office.

\section{Regulatory Tracking and Translation}

The regulatory tracking and translation system at CEBAF is generally consistent with the intent of DOE 5480.19. The CEBAF Site Office has drafted a procedure for the transmittal of DOE management directives and requirements to SURA (CEBO11). The process involves a review of DOE Orders for applicability to CEBAF. If the Order is determined to be relevant to CEBAF, it is officially transmitted to SURA.

The EH\&S Reporting Department within SURA's Office of Technical Performance is responsible for tracking and determining the applicability of specific provisions contained within DOE Orders, as well as Federal, state, and local environmental regulations (DOE Orders are addressed in Section 3.9, Special Issue). To stay abreast of emerging regulatory issues, the EH\&S Reporting Department regularly reviews the Federal Register 
and the Bureau of National Affairs (BNA) summary of regulatory developments and trends. The EH\&S Reporting Department then notifies any SURA department or individual to whom a requirement is relevant. It is the responsibility of the Office of Technical Performance to translate regulations (and provisions of DOE Orders) into laboratory-wide policies, while the development of division-specific procedures is the responsibility of line management within the relevant division.

\section{Procedures}

The EH\&S Policy and Manuals Group located in the Office of Technical Performance has responsibility to generate laboratory-wide environment, safety, and health (ES\&H) policies and procedures. Currently, there is a lack of laboratory-wide environmental policies (see Finding EP-1). The EH\&S Policy and Manuals group, which has been meeting weekly since its creation in January 1993, is undertaking a focused effort to develop a comprehensive laboratory-wide environmental, health and safety policies and procedures manual (I-E-01). Draft laboratory-wide policies and procedures are reviewed and approved by all associate directors and the laboratory director before they are implemented by line management throughout the organization.

Division-specific policies and procedures are developed by the relevant division with assistance as needed by environmental specialists or staff within the Office of Technical Performance. Line management is responsible for fully understanding laboratory-wide policies and procedures and for assuring that division-specific policies and procedures are consistent with laboratory-wide directives. Consistency is further assured by the fact that many individuals drafting division-specific policies and procedures are the same individuals who draft the laboratory-wide policies and procedures (I-E-16).

SURA has not fully developed and implemented formal and comprehensive environmental protection programs and plans (see Finding EP-1). Similarly, there is a lack of development of specific procedures for many of those same environmental programs. CEBAF recognizes this and is in the process of formalizing division-specific and laboratory-wide policies and procedures (I-E-01 and I-E-06).

\section{Routine Facility Inspections}

SURA has instituted a routine facility inspection program involving frequent environmental walkthrough inspections of all the buildings and operations onsite. Currently, the Physics and Administration Divisions do not have fully developed and implemented checklists to guide and prompt inspectors. The Accelerator Division has developed a draft checklist, though it contains little detail on environmental issues. The CEBAF Site Office is planning to implement the Facility Representative Program to enhance the routine inspection process (I-E-15). The concept of the program is to establish a CEBAF Site Office and SURA representative for each building or operation at CEBAF. These representatives will then be assigned responsibility for assuring that all aspects of operations remain in compliance with all applicable requirements. In addition to providing for better information flow between the CEBAF Site Office and SURA, the program will also provide greater assurance to CEBAF Site Office and SURA management that best management practices are employed in all aspects of CEBAF's operations. Implementation of this program will require coordination with SURA. 
Followup of issues identified during routine walkthroughs and inspections is the responsibility of line management within the divisions. The system for followup of corrective actions identified during routine walkthrough inspections is essentially the same for all three divisions. If a deficiency is noted during an inspection, a responsible party, corrective action, and timetable for implementation are identified. The responsible party notifies the division EH\&S Department when the corrective action is closed. EH\&S continues to inspect an issue until the deficiency is addressed. Within the divisions, the systems are adequate to assure that corrective actions have been implemented for environmental issues that surface during the inspections. However, inspection deficiency corrective action tracking is not currently monitored by the Office of Technical Performance, but is expected to be monitored in the future (CEB111; 1-E-05).

\section{Recordkeeping and Reporting}

SURA's document control system provides a basic level of assurance that the Laboratory's most important documents are maintained and updated as appropriate. The Self-Assessment/Quality Assurance (SA/QA) Officer maintains the list of control documents in the appendices to the Quality Assurance Program Manual (CEB104). The following information is listed for each control document: approval authority, authorship, custodial responsibility of the master copy, and location of the master copy. In consultation with staff in the Office of Technica! Performance and line management within the divisions, the SA/QA Officer maintains and appends the control document list as appropriate. The master copy of the control document is located in the division or office where it was generated. The SA/QA Officer receives and maintains current copies of all control documents.

Changes to control documents ars approved by the associate directors, while the author is responsible to inform all registered document holders of the changes. Typically, the author will send the revised material with a memorandum detailing specifically where the material is to be inserted. Most authors request a receipt for the material, although there is no formal CEBAF policy on this (I-E-11, I-E-13, and I-E-16). The design of the system is understood by line management throughout SURA (I-E-01, 06, 10, 13, and 16). However, interviews and document reviews revealed a concern with respect to the system's implementation. The most up-to-date CEBAF Environmental Protection Program Plan (CEBO21) was not included in the CEBAF Site Office, nor in the CEBAF library copy of the Safety Manual. Centralized maintenance and administration . tistribution lists may be more effective in assuring all relevant personnel get updated documents in a timely manner.

The SURA EH\&S Reporting Office is another central document repository. The documents maintained there pertain to official daily correspondence with external parties (e.g., regulators), DOE relations, permit reporting, environmental planning, and special issues. These documents are logged alphabetically onto a master list and made available to interested parties as needed.

The EH\&S Reporting department coordinates all external reporting for SURA. Information relevant to environmental permit reporting is forwarded to that department from line management. That information is then transmitted to the CEBAF Site Office where it is sent to the relevant regulators. The following reports are produced routinely: wastewater discharge to the Hampton Roads Publicly Owned Treatment Work (monthly); groundwater 
pumpage for the State Water Control Board (annually and quarterly); groundwater monitoring for the State Water Control Board (quarterly); Superfund Amendments and Reauthorization Act (SARA) Title III Right-to-Know Report (annually); and air emission report to the State Department of Air Pollution Control (annually) (I-E-19).

After review of Occurrence Reports dating back to May 1990, it was noted that there were two incidents of late reporting notice of violations (NOVs); one to the Virginia State Water Control Board and the other to the Hampton Roads Sanitation District (CEB175). In both instances, appropriate corrective actions have been taken to assure both timely reporting and receipt of the necessary documentation in the future.

The Formality of Environmental Programs portion of this assessment identified one finding relating to the routine facility inspection program. 


\subsubsection{Finding}

\section{FP-1: $\quad$ Routine Facility Inspection Program}

Performance Objective: Best management practices suggest that a routine site and equipment inspection program be in place to manage day-to-day environmental issues and assure compliance with relevant environmental regulations, applicable DOE Orders, and overall environmental performance goals.

Finding: The routine facility inspection program for CEBAF lacks an adequate level of formality and focus on environmental issues.

Discussion: SURA has implemented routine facility inspection programs for each of its three divisions (i.e., Accelerator, Physics, and Administration). However, the inspection programs for the Administration and Physics Divisions are informal to the extent that no standard checklists of items to inspect have been developed (I-E-03, I-E-06, and I-E-09). In the Accelerator Division, the routine inspection program lacks an adequate level of detail on environmental issues.

The Plant Engineering Department of the Administration Division is responsible for conducting routine inspections on all civil construction activities at CEBAF. Plant Engineering conducts routine walkthrough inspections on a daily basis (I-E-14). Currently, the inspectors rely on a draft version of the Maintenance Management Plan and their knowledge of environmental issues and regulations to guide the inspections. Although environmental issues are considered in the walkthrough inspections, there is no finalized checklist for inspectors to use (I-E-03). Plant Engineering is in the process of developing such a list with input from environment, safety, and healthy (ES\&H) specialists and others within SURA. The Maintenance Management Plan, including a checklist which specifies environmental issues to monitor on a routine basis, is scheduled for completion by May/June 1993 (I-E-03).

The Physics Division is responsible for conducting routine inspections of a number of facilities at CEBAF including the Counting House, the Experimental Equipment Laboratory, the experimental halls, and the CEBAF Center. At a minimum, the experiment halls are inspected once per week and the CEBAF Center is inspected once per month (I-E-O6). Those present at the inspections include some or all of the following staff: the safety warden from the building being inspected, ES\&H staff and responsible line managers within the Physics Division, and frequently a representative from the CEBAF Site Office. Presently, the inspection team does not use a checklist, rather the inspectors rely on their knowledge of the facility and their expertise to guide the inspection (I-E-06). The EH\&S/QA Department within the Physics Division indicated that a comprehensive checklist was under development. The checklist will be based, in part, on an analysis of ES\&H hazards and risks within the Physics Division. EH\&S/QA staff within the Physics Division indicated that the checklist would be comp!eted by April 1993 (I-E-06).

The Accelerator Division conducts routine inspections on a number of facilities at CEBAF, including the Test Laboratory and the accelerator tunnel. However, these inspections, as reflected in the recently developed draft inspection checklist, do not provide an adequate level of detail on environmental issues (CEB170; I-E-17). For example, the chemical category of the checklist does not specifically address items such as inspection of 
hazardous material log books or other documentation related to the hazardous waste manifest system, existence of accumulation start dates on the storage containers, or length of time of storage of hazardous materials. In the environment section of the checklist, there are no specifics on maintenance and proper operation of pollution abatement equipment and/or chemical handling systems or spot checking solid waste receptacles for aerosol cans, oily or solvent soaked rags, or any other hazardous or special wastes. Finally, the checklist does not provide linkage between the areas to be inspected (e.g., chemical storage areas, chemical use areas, and satellite and central hazardous waste accumulation areas), and the relevant environmental issues of concern at those locations.

CEBAF site personnel within all three divisions are generally aware of the need to better formalize the routine inspection program through developing comprehensive checklists based on a thorough analysis of all ES\&H risks and hazards (I-E-03, I-E-06, and I-E-10). As such, all divisions are working on improving the inspection program. Completion of the checklists and associated training for the inspectors will provide a higher level of assurance that all relevant environmental issues are adequately inspected on a routine basis.

The apparent causal factors contributing to this finding are inadequate procedures, in that checklists for comprehensive routine inspection programs covering all relevant environmental issues have not been fully developed and implemented for the Administration and Physics Divisions; and design, in that the current routine inspection program, as reflected in the draft inspection checklist for the Accelerator Division, does not assure ongoing attainment of environmental performance goals. 


\subsubsection{Overview}

The purpose of the Internal and External Communication portion of the Environmental Management Assessmeric was to evaluate the extent and effectiveness of routine management reporting of environmental performance and issues; the communication of environmental management activities and best management practices between staff and line personnel and laterally across divisions; and the communication of information with external organizations such as regulatory agencies, environmental groups, and the community.

The general approach to this portion of the assessment included a review of background documents provided by SURA and the CEBAF Site Office and onsite interviews with key personnel. Documents reviewed included employee newsletters, agendas and minutes of meetings, internal memoranda, routine status reports, briefing and presentation material, and material describing CEBAF activities with the general public. Interviews were conducted with DOE personnel from the CEBAF Site Office and selected line managers; environment, safety, and health (ES\&H) staff; and employees with communications and environmental responsibilities in SURA's Director's Office, Office of Technical Performance, Office of Project Management, Accelerator Division, Physics Division, and Administration Division.

SURA relies primarily on regular management and staff meetings for routine management reporting of environmental performance and issues (I-A-01, 10,11, 12, 15, 16, and 17), and uses a variety of mechanisms including newsletters, memoranda, meetings, briefings, procedures manuals, training materials, and committees to share environmental information throughout the organization. Much of the communication between SURA and the CEBAF Site Office is formal and structured with environmental-related information requests and responses channeled through key CEBAF Site Office staff and SURA's Director, Associate Directors, or the Manager of EH\&S Reporting (1-A-08, 12, 14, 15, and 18). Communication of site-specific environmental information with external organizations consists largely of formal communication to determine or satisfy regulatory requirements $(1-A-05,08,12,13$, and 15). CEBAF has received few requests from the general public for environmental information (I-A-01, I-A-05, and I-A-17). SURA has a variety of excellent mechanisms for communicating with the general public, including a well-attended open house, a science lecture series, a SURA speakers bureau, and several education programs including onsite programs for elementary school students and professional development programs for teachers. These programs address environmental issues in a general fashion, however, currently there is little information communicated on SURA-specific environmental management.

SURA does not have a formal internal mechanism for employees to report environmental concerns anonymously, but it does publicize the availability of an anonymous reporting mechanism through the CEBAF Site Office (CEB126). The SURA Safety Trouble Report and the Plant Engineering phone line (extension 7400) are two additional ways for employees who are willing to identify themselves to report ES\&H concerns, although relatively few of the issues raised through these mechanisms have dealt with environmental issues (CEB141 and CEB152; 1-A-12 and I-A-13). 
There are many mechanisms for SURA staff to acquire or share environmental information and, in general, the staff interviewed for this assessment seemed to have good access to this information. However, SURA recognizes that communication with employees is a process that needs constant attention and has recently instituted several new initiatives including the formation of a work group to examine ways to improve communications on a variety of topics including ES\&H (I-A-19). Additionally, small group meetings are held between the SURA Director and staff (I-A-01).

Two concerns were identified regarding CEBAF's communications programs. The first, which is discussed in Finding IC-1, addresses the lack of a formal process for communicating routine status information on environmental management activities both within SURA and between SURA and the CEBAF Site Office. The second concern relates to the relatively limited information on site-specific environmental issues that is shared with the general public. This issue does not appear to be a problem at the current time, as there seems to be little public interest in CEBAF's environmental management activities. However, the development of a strategy for communicating site-specific environmental issues to the public would be useful in the event that interest in this topic increases in the future.

There was one finding in the area of Internal and External Communication relating to communication of routine environmental status information. 


\subsubsection{Finding}

IC-1: Communication of Routine Environmental Status Information

Performance Objective: Best management practices suggest that formal communication of routine environmental status information should be used to provide management with assurance that environmental programs are effectively implemented and to enhance top-down, bottom-up, and lateral communication of environmental information.

Finding: SURA has not fully developed and implemented a formal process for communicating routine status information on environmental management activities both within SURA and between SURA and the CEBAF Site Office.

Discussion: Currently, SURA relies primarily on regular management and staff meetings to communicate information on environmental management issues and performance. Much of this communication is verbal, frequently focuses on problems or "exceptions" rather than status or performance information, and is documented, if at all, largely through meeting minutes $(I-A-10,11,12,15,16,17)$. The weekly Director's Council meetings are the primary mechanism for senior management to share information on a wide variety of topics including routine environmental status information (I-A-01, I-A-14, and I-A-15). The CEBAF Site Office Manager frequently attends these meetings. In addition, environment, safety, and health (ES\&H) issues are discussed at the weekly and monthly SURA project management meetings (I-A-17) and documented in the weekly Project Progress Summary (CEB 147) and Monthly Technical Report (CEB144) produced by the Office of Project Management. Several people indicated that the new EH\&S Committee and the EH\&S Policy and Manuals Group should provide additional mechanisms for sharing routine environmental status information within SURA (I-A-10, I-A-12, and I-A-15).

Although the existing approaches provide some mechanisms for communicating environmental management information, SURA lacks a formal, comprehensive, and documented process to collect, summarize, and distribute this information on a routine basis. This process is particularly critical now as SURA begins to implement a more decentralized ES\&H organization and several new environment, safety, and health (ES\&H) initiatives. Environmental status information of interest to management may include summaries of inspection and self-assessment results, status of corrective actions, status of training and policy and procedures manual development activities, division/organization performance versus defined goals, etc. A more formal process will enable SURA to provide better assurance to management and oversight organizations that environmental programs are being carried out effectively, and to better document environmental accomplishments and performance for both internal and external audiences. Areas for improvement include:

- Development of a clear process for transmitting environmental status information from line organizations (i.e., divisions) through the Office of Technical Performance to senior managers and outside organizations. This process should specify what types of information will be collected, how often it should be reported, who will provide it, and who will receive it.

- More emphasis on formal written reports rather than verbal status updates. 

"exception-based" reporting.

Most of the existing communication mechanisms between SURA and the CEBAF Site Office are "reactive" rather than "proactive" and focus on providing information in response to either regulatory requi ements or to specific DOE information requests that either originate from or are transmicied by CEBAF Site Office staff. This type of communication is typically very formal and strictured with information requests and responses channeled through the Director, the Associate Directors, or the Manager of EH\&S Reporting (I-A-08, 12, 14, 15, and 18).

There are relatively few merhanisms for sharing routine environmental status information between SURA and the CEBAF Site Office. Three mechanisms that provide some environmental management status reporting on a rogular basis are: the weekly SURA Director's Council meeting, which the CEBAF Site Office Manager often attends (I-A-01 and I-A-14); the SURA Monthly Technical Report (CEB144), which is submitted to the CEBAF Site Office as one of the requirements of the Project Management Plan (1-A-17); and SURA ES\&H inspection reports (CEB11 1 ). None of these mechanisms provide comprehensive environmental status information. The Director's Council meetings cover a wide variety of topics, and as noted above, often deal with "exception" based information rather than comprehensive status reporting. The Monthly Technical Report is designed to provide information on construction activities and, based on a sample of recent reports reviewed by the assessment team, currently focuses primarily on health and safety, rather than environmental issues. The inspection reports also focus largely on health and safety issues, and there is no formal mechanism for providing the site with information on the status of corrective actions, or summary or trending information about inspection results (see Finding FP-1).

Comprehensive routine environmental status reporting can provide information to assure the CEBAF Site Office that SURA has satisfactory processes for identifying environmental requirements, developing programs and procedures to implement these requirements, assi iring that staff who carry out these programs are knowledgeable and well trained, and quickly identifying and correcting any deficiencies. The CEBAF Site Office has expressed concern to SURA about the level of routine status information it receives and has discussed several possible avenues for obtaining this information. These include more frequent meetings between the CEBAF Site Office and SURA staff and additional opportunities to observe or be informed about the ac vities of the recently formed CEBAF EH\&S Committee and subcommittees. (A CEBAF Site Office representative currently sits as a non-voting member of the Emergency Management Subcommittee, but CEBAF Site Office staff do not expect to observe, or receive minutes from, the other committees/subcommittees (e.g., the EH\&S Committee or EH\&S Training Subcommittee) $(1-A-08$ and $\mid-A-14)$.

To address these concerns, SURA and CEBAF Site Office staff have recently decided to hold regular meetings to discuss ES\&H issues that might be of concern to either party. The first meeting was held in early March 1993. The participants are still working out the frequency of meetings and the process for deciding what topics to discuss (I-A-08, I-A-12, and $(-A-14)$. While this is a good first step, additional measures are necessary to assure that the CEBAF Site Office obtains adequate environmental status information. This includes developing a more formal written status report(s), and clarifying what SURA 
documents will be provided to the CEBAF Site Office and the process for obtaining this information. The assessment team noted several environmental documents that the CEBAF Site Office was not aware existed, including supporting information documenting the conclusions reached in the SURA self-assessment contained in the Environment, Health and Safety Quality Assurance Plan (1993) (CEBO24, CEB158, CEB159, and CEB160);

procedures regarding chemical procurement and disposal (CEB127); and a chart showing the allocation of ES\&H staff among the various ES\&H functions and SURA divisions.

The apparent causal factor contributing to this finding is design, in that existing communication systems are not structured to provide routine environmental management information to all individuals with a need to know. 
This page intentionally left blank. 


\subsubsection{Overview}

The Staff Resources, Training, and Development portion of the assessment was reviewed to assess systems that assure staffing resources and training are sufficient to meet CEBAF's environmental goals. Emphasis was placed on the quality and quantity of staff responsible for environmental activities, the identification of necessary environmental training needs for each job classification, and the systems for maintaining training records and evaluating the training program itself.

The general approach to this portion of the assessment was to review CEBAF's background documents prior to the onsite portion of the assessment. Onsite activities included review of additional documentation pertaining to staffing and training, and interviews with knowledgeable and responsible CEBAF personnel. Documents reviewed included CEBAF ES\&H Five-Year Plan, FY95-FY99 (March 2, 1993) (CEB109), organizational unit descriptions, individual training records, and job vacancy announcements. Training documents reviewed included safety training reports, training materials and descriptions, and training records of individual employees. Interviews were held with the CEBAF Site Office Manager and the EH\&S Manager. Within SURA, interviews were held with the five associate directors; the managers of EH\&S Reporting and Policy and Manuals; two EH\&S/OA division managers; the managers for finance, human resources, and training; and other selected SURA personnel.

In reviewing SURA's staffing resources for environmental programs, it was found that staffing levels for currently defined responsibilities will be sufficient once they have filled the three open environment, safety, and health (ES\&H) positions. However, resource issues may need to be reassessed upon the resolution of the applicability of DOE Orders (see Section 3.9, Special Issue). Environmental staffing levels for the CEBAF Site Office are of concern. The EH\&S Manager requires a significant amount of overtime and relies heavily on support from Oak Ridge and other outside contractors to perform responsibilities. The CEBAF Site Office has requested 0.5 full-time equivalent (FTE) to permit greater attention to environmental responsibilities.

SURA is in the process of hiring a much needed central resource for nonradiological environmental expertise. With regard to radiological control (the area with the most significant environmental implications) the current level and depth of expertise is outstanding, and the department has plans to further bolster that experience as the facility approaches an operational status.

With regard to training activities, SURA has not yet implemented a complete and comprehensive environmental training program. Such a program would include a formal assessment of environmental training needs for all personnel, assure courses offered are appropriate to the backgrounds of their target audiences, and provide a complete and current recordkeeping system which would enable managers to identify quickly the status of required environmental training for their staff.

It should be emphasized, however, that the initiatives which SURA has already begun to implement will likely satisfy the concerns raised, if their implementation is performed effectively. 
There were two findings identified in the Staff Resources, Training, and Development portion of the assessment relating to the need for more nonradiological environmental management expertise and an inadequate environmental training program. 


\subsubsection{Findings}

\section{SR-1: $\quad$ Staffing Expertise}

Performance Objective: Best management practices suggest that staff resources should be sufficient to develop and implement the organization's environmental protection programs consistent with environmental performance objectives.

Finding: The current depth of nonradiological environmental expertise at CEBAF is insufficient to assure the effective implementation of environmental protection programs.

Discussion: The recent reorganization of the environment, safety, and health (ES\&H) function has strongly reinforced line management responsibility and accountability for ES\&H matters, with the Office of Technical Performance (OTP) providing a central role as the primary resource for environmental support and expertise. Presently, there is no one in OTP with strong technical training and experience in nonradiological environmental management. This is primarily due to the recent departure of the environmental engineer who was frequently sought for advice on environmental issues (I-F-08, 09, 12, 15, 18, 21 , and 23). OTP presently has two job vacancies. The backgrounds of the people OTP hires will be critical because of OTP's laboratory-wide environmental management support role, especially in light of key initiatives being developed in the areas of accelerator readiness review, policy and procedures development, training, and self-assessment (including inspection programs). These initiatives will require input from an experienced and knowledgeable environmental professional.

The strong reinforcement of line responsibility highlights the need for a broader base of environmental knowledge and support within each of the three main divisions (in addition to centralized expertise). There is currently no one in the divisions' EH\&S departments with strong technical training and experience in nonradiological environmental management, although a few have a good working knowledge of hazardous waste management. This need has been recognized and is being addressed through a number of environmental training courses which have been scheduled (I-F-15 and I-F-23).

Furthermore, the training subcommittee plans on conducting a formal needs assessment (I-F-06), In addition to increased training, each of the three SURA divisions is in various stages of seeking individuals with strong environmental credentials to fill open positions (I-F-21, I-F-24, and I-F-25).

The addition of central environmental expertise in OTP, combined with a broadening of expertise in the divisions through environmental training and additional hires, will enhance SURA staff expertise and will foster effective implementation of environmental protection programs.

The apparent causal factor contributing to this finding is change, in that the organization was decentralized and the experienced environmental engineer departed. 


\section{SR-2: $\quad$ Environmental Training Program}

Performance Objective: Best management practices suggest that a complete and comprehensive environmental training program be in place which identifies the necessary environmental training required for all personnel, provides courses which are relevant and tailored to meet the needs of the audience, and utilizes a recordkeeping system with effective tracking capabilities to allow managers to monitor training accomplishments versus training requirements.

Finding: SURA has not completed the development of a comprehensive environmental training program.

Discussion: Presently, assessment of environmental training needs is primarily performed on an informal basis (CEBO98). Managers, with input from other key SURA personnel, determine the training needs for their staff (I-F-02,06,08, and 11). This informal approach has led to the development of specific training objectives in specific parts of the organization. For example, the chemical assessment team determined all of its members should receive a 24-hour Occupational Safety and Health Administration (OSHA) First Responder Awareness and Operations Level training course (I-F-08 and I-F-15). The Radiation Control Manager reviews all future activities and determines the training his staff will need to perform those activities (I-F-16). Further, it is a laboratory-wide policy that all staff receive hazard communications and radiation protection orientation (CEBO98). However, there has not been a forma! process to assure laboratory-wide that all environmental training needs are defined for each position or job activity which may impact environmental performance. Such a process would provide for more effective planning and implementation of necessary environmental training.

In the past, some environmental training courses have been targeted at a level inappropriate for the audience to which it was directed. For example, physicists have attended radiation courses that they perceived to be much longer in duration than needed to cover the relevant material. Environmental training courses which are not relevant and tailored to the backgrounds of the participants are less likely to be effective in enhancing the employees' knowledge, skills, and ability.

Employee environmental training records are maintained on a personal computer, which are downloaded daily into CEBAF's Information Systems (CIS) data base. The Employee Relations and Development Section produces the Safety Training Report (CEB100) monthly. This report is a useful management tool which displays, for all employees, the regularly scheduled in-house training courses that have been taken, as well as the data indicating when certain courses must be updated. However, this report presently tracks only regularly scheduled in-house training courses. The only courses tracked with some elements of environmental training are hazard communications and radiation protection orientation. All other environmental training records are found in each employee's individual training file (CEB106).

In some instances, records are not kept up-to-date. On October 30 and December 9 , 1992, a 2-hour environmental management seminar was given by the former SURA environmental engineer. A total of approximately 100 people attended. Signup sheets were collected. However, the information has not yet been transferred to the training data base (CEB042). Formal written evaluations are tracked for in-house courses, while 
managers and attendees are contacted verbally for evaluations of all external courses (I-F-03 and I-F-17).

SURA records indicate SURA-required training has not yet been completed. Of 934 individuals tracked on the Safety Training Report, the report indicated 184 had not completed radiation protection orientation and 297 had not completed hazard communication (CEB100). The fact that many of these individuals only worked briefly at CEBAF and should no longer be on the report underscores the need to revise the recurdkeeping system. It should be noted that the Training Department sends memoranda to managers and employees informing them of CEBAF-wide required courses not taken (CEB148).

SURA has identified the issues described above, and has recently formed an EH\&S Training Subcommittee to address these and other training issues. Interviews with some members of that committee revealed the following objectives: conduct a comprehensive environment, safety, and health (ES\&H) training needs assessment; tailor courses to be relevant and commensurate with the backgrounds of their audience; update recordkeeping system to provide a matrix of all ES\&H courses; highlight required or recommended training which has not been completed; conduct formal evaluations of all training courses; and perform 90-day or 180-day followup interviews to monitor the training's effectiveness (I-F-03, 06, 11, 17, and 19). SURA will have an excellent environmental training program if they succeed in accomplishing these goals.

The apparent causal factors contributing to this finding are policy, in that SURA only recently established a policy to institute a complete comprehensive training program; design, in that CEBAF's training systems currently do not provide for formalized needs assessment by job activity; and a historical lack of appreciation of the risk associated with a management system not designed to assure appropriate environmental training is conducted. 
This page intentionally left blank. 


\subsubsection{Overview}

The assessment of Program Evaluation, Reporting, and Corrective Action focused on whether the CEBAF Site Office and SURA have effective oversight and self-assessment programs in place. More specifically, the assessment evaluated the types of oversight and self-assessment programs, reporting of identified concerns to appropriate managers, and tracking and implementation of corrective actions that address root causes.

The general approach used to perform the assessment included interviews with CEBAF Site Office and SURA personnel responsible for conducting oversight and developing and implementing self-assessment programs, as well as senior manágers in both organizations. Extensive document reviews were conducted prior to the onsite assessment, and additional documents were obtained and reviewed throughout onsite activities.

Overall, the developing oversight and self-assessment programs established by the CEBAF Site Office and SURA provide an adequate level of environmental assurance. These programs will improve as environmental expertise is enhanced throughout CEBAF by implementing planned training initiatives (for both the CEBAF Site Office and SURA) and appropriately filling job vacancies (SURA only, see Finding SR-2). SURA's program will continue to improve as the Self-Assessment/Quality Assurance (SA/QA) function (a relatively new position) continues to focus heavily on program development.

In light of resource limitations at the CEBAF Site Office, oversight of SURA is largely conducted with the assistance of direct support from the Oak Ridge Field Office (OR). This arrangement has proven effective to date, and should remain effective provided there is easy access to OR support on an ongoing basis. Further; CEBAF Site Office staff are scheduling needed training to improve their environmental skills, and possibly reduce their dependence on external appraisal resources such as OR.

The CEBAF Site Office has a well-developed environmental self-assessment program. It includes a detailed Self-Assessment Plan, which describes specific assessment criteria and supporting lines of inquiry. The CEBAF Site Office has developed a list of planned assessments and set priorities for conducting them. Many have been conducted over the last year and a half. In addition, their assessments generate findings which result in corrective actions which are tracked through completion on a computer-based system. The one deficiency in the CEBAF Site Office's environmental self-assessment approach is its apparent focus on procedures. Self-assessments are organized by "procedure" rather than work process or function (although many processes/functions are covered by procedures). In addition, a review of the findings resulting from assessments indicate a focus on the procedure itself, rather than its implementation.

SURA's environmental oversight and self-assessment activities are described in its Quality Assurance, Self-Assessment, and Continuous Improvement Program documentation. In addition to its overarching Quality Assurance Program Manual (CEB104), SURA has developed over fifty "Specific Quality Assurance Plans," including one for environment, safety, and health (ES\&H). The Environment, Health and Safety Quality Assurance Plan (1993) (CEBO24) includes an annual self-assessment of SURA's ES\&H activities. 
SURA continues to develop its environmental self-assessment program, which is being led by the SA/QA function. The basic design of their program is sound, but elements are still under development and being implemented. Nonetheless, SURA has conducted several self-assessments. Corrective action tracking is performed by the assessor (whether the SA/QA group or individual divisions) and is performed manually within the Office of Technical Performance. The assessment team was not provided with documentation illustrating lessons learned analyses in the environmental area. The status of their self-assessment program is detailed in Finding PE-1.

SURA has been embracing a philosophy of continuous improvement. Senior management have been visible in reinforcing this concept to all SURA employees. Just recently, SURA developed a Continuous Improvement Program Implementation Plan which lays out the principles and an overall approach in implementing a continuous improvement program. The actual implementation of this plan is in its infancy.

There was one finding in the Program Evaluation, Reporting, and Corrective Action portion of the assessment related to SURA's self-assessment program. 


\subsubsection{Finding}

\section{PE-1: $\quad$ Self-Assessment Program}

Performance Objective: Best management practices suggest and DOE Secretarial guidance directs line organizations to develop and implement comprehensive self-assessment programs to identify and characterize environment, safety, and health (ES\&H) concerns, as well as to identify, report, and correct environmental deficiencies.

Finding: SURA has not yet completed the design and implementation of its Self-Assessment Program.

Discussion: SURA is in the midst of designing and implementing a comprehensive Self-Assessment Program. This program includes several layers of assessment: SURA-Corporate assessment of SURA; SURA Self-Assessment/Quality Assurance (SA/QA) Department assessment of SURA's line organizations (e.g., Accelerator, Physics, and Administration Divisions); self-assessments within the line organizations; routine inspections; and routine management "walkthroughs." In the last year, SURA-Corporate has conducted one environmental compliance review and SURA/CEBAF has conducted two internal assessments of SURA's ES\&H activities (although the most recent "self-assessment" reads more like a status report on environmental programs and it did not result in any formal corrective actions beyond existing initiatives). Routine inspections and walkthroughs are conducted on an ongoing basis and are covered in another section of this report (see Section 3.4). All of this is in addition to DOE environmental oversight activities.

SURA's SA/QA Department has recently revised the initial Self-Assessment Program Implementation Plan (CEB081). It contains many of the elements of an effective self-assessment program (including corrective action tracking forms, listing of possible deficiency causal factors, proposed format for division self-assessment programs, etc.). However, it addresses many other issues in only a generic fashion, including: training requirements; corrective action implementation and tracking; report content, format, and distribution; and trending and lessons learned.

In addition, assessment tools have not yet been fully developed by SURA. For example, while performance objectives for the overall ES\&H assessment have been approved, supporting assessment criteria have not. The question list developed for the initial self-assessment performed by the new SA/QA Manager is a good start (CEB167). A data base to be used as a repository for assessment criteria, question lists, and corrective action tracking is currently being reviewed for its applicability and subsequent implementation. Also, procedures addressing many of the specific items described above have not been developed. Assessment tools and procedures are expected to be completed shortly after the new SA/OA staff position is filled. In addition to providing additional quantity of resources, this new position should also provide needed environmental expertise to the development of the assessment criteria and for the conduct of the assessments themselves.

One critical gap in the Self-Assessment Program Implementation Plan is the absence of a defined schedule for performing independent environmental assessments within the Accelerator and Physics Divisions in the coming years. The plan notes that such 
assessments will be coordinated with the Accelerator Readiness Review (ARR). However, environmental assessments are not addressed in the most current version of the CEBAF Readiness Review Plan (CEB107), nor are they well-defined in the ARR process description documentation provided to the assessment team (CEB140).

The line organizations have not yet developed formal self-assessment programs, although walkthroughs and inspections are routinely performed. To address this issue, the newly formed EH\&S/QA functions within the line organizations are planning to develop formal self-assessment programs in the coming months. Planned environmental training initiatives and staff increases should support division staff in designing and implementing their self-assessment programs.

The apparent causal factors contributing to this finding are policy implementation, in that the self-assessment program has not been fully developed or implemented; and risk associated with a less than optimal environmental assurance function. 


\subsubsection{Overview}

The Environmental Planning and Risk Management portion of the assessment addressed the extent to which technical and financial environmental planning is conducted and integrated into the overall planning process at CEBAF. The environmental risk management portion addressed the adequacy of systems used by CEBAF to identify, evaluate, and mitigate environmental risks.

The general approach to this portion of the assessment was to review documents provided to the assessment team by SURA and the CEBAF Site Office prior to arrival onsite. Once onsite, interviews were conducted and additional documents were reviewed. Key personnel interviewed for this protocol area included associate directors; environment, safety, and health (ES\&H) staff throughout SURA; members of the Accelerator Readiness Review Panel; and planning and budgeting staff within the Administration Division. Key documents reviewed for the environmental planning portion included the Nuclear Science Advisory Council (NSAC) Subcommittee Review of CEBAF Operations and NSAC's response to CEBAF, the CEBAF ES\&H Five-Year Plan, FY95-FY99 (March 2, 1993) (CEB109), and various budget documents. Key documents reviewed for the environmental risk management portion of the protocol included the CEBAF Environmental Assessment, the Preliminary Safety Assessment Document (PSAR), the draft safety assessment document (SAD), and the Accelerator Readiness Plan and supporting documentation.

The Accelerator Readiness Review (ARR) process is a key component of the overall planning and risk management activities at CEBAF. This process is intended to provide assurance that risks and concerns related to pre-operational testing and commissioning are effectively managed. The methodology used in the ARR process includes a self-assessment by the responsible line manager of the system under review, an objective review by a member of the ARR Team with the appropriate area of expertise, and a fully independent peer review panel. An aspect of the ARR and overall risk management process at CEBAF is completion of the SAD. ARR documents were reviewed to understand to what extent environmental issues were addressed.

One goal of the ARR self-assessment is to determine whether ES\&H requirements have been met. While the documents reviewed fail to fully demonstrate that all environmental issues are covered by the ARR process, the thoroughness of the ARR process appears to assure environmental requirements are met so long as they have been identified (CEB036, $140,168,169,172,173$, and 174).

Another important aspect of the overall environmental risk management program at CEBAF is the ongoing process of identifying ES\&H risks associated with day-to-day operations in the Physics and Accelerator Divisions. Both divisions are currently in the process of soliciting input from line managers, operating staff, and ES\&H specialists on all ES\&H risks inherent to the operations. A master list of these risks and mitigation strategies for each division will serve as a management tool to assure that environmental performance goals are met and to provide input into the development of routine inspection checklists (CEB150 and CEB139; I-E-06 and I-E-17). 
From a budgetary standpoint, CEBAF has an impressive record of committing substantial financial resources to its environmental activities. Some "beyond compliance" examples include increasing the thickness of the accelerator tunnel walls from 9 inches to 18 inches, removing asbestos from the Test Laboratory instead of encapsulating it, removing remaining underground storage tanks, and using triple containment for the acid baths. Managers consistently indicated they have had virtually no concern funding could be obtained to address identified deficiencies in their environmental programs (e.g., training).

The only concerns in the area of planning relate to findings in other areas which may impact managemix $t$ 's ability to make informed decisions. This includes the lack of formal routine environmental status information communications to senior managers (see Finding IC-1), the need for more nonradinlogical environmental expertise (see Finding SR-1), and deficiencies in SURA's training and seif-assessment programs (see Findings PE-1 and SR-2).

There were no findings in the area of Environmental Planning and Risk Management. 
Although there is a clear and strong commitment to full regulatory compliance by the CEBAF Site Office and SURA, there is a difference of opinion between the two organizations as to the applicability of DOE Orders. The CEBAF Site Office believes it has the authority to require SURA compliance with DOE Environment, Safety, and Health (ES\&H) Orders it deems applicable and appropriate. SURA does not contest DOE'S authority to employ the use of Orders to direct DOE operations. However, SURA believes that the imposition of requirements under DOE Orders on contractors is beyond DOE's authority, unless the requirements are: (1) explicitly detailed in contractual language, or (2) codified through the formal Federal rulemaking process. As stated in SURA's Response to the ES\&H/QA Appraisal of CEBAF by the Oak Ridge Field Office in January 1991 (CEBO22), SURA has "agreed to give a good faith assessment of all additional proposed requirements [beyond regulatory requirements, e.g. DOE Orders] and discuss with DOE those items that could be implemented without an adverse impact on cost, schedule, mission, or programmatic priority." In addition, SURA's position is to use a "graded approach" and comply with environmental-related Orders it feels truly "add value " (I-1-03). SURA considers the concept of "added value" to be an important factor of "applicability" under Article 35 of the management and operating (M\&O) contract entitled "Environment, Safety and Health."

SURA entered into this contractual agreement with DOE in October 1987. Under Article No. 35, Paragraph a., SURA agreed to "comply with all applicable safety and health regulations and requirements (including reporting requirements) which are transmitted to the contractor in writing" (CEBO16). The CEBAF Site Office transmitted a memorandum on October 12,1990, stating that they "have conducted a review of these [DOE ES\&H] Orders and made a preliminary determination as to which are appropriate for implementation and compliance in the relatively near term. In many cases we have also identified specific provisions [within the Orders] which should be applied here . . . Accordingly, these Orders are hereby transmitted in accordance with the provisions of Article No. 35 of our contract" (CEB132). Although SURA has complied with many elements of the Orders DOE deemed applicable, it has not complied with all of the elements noted in the memorandum referenced above.

SURA believes that Article 16(c) of the contract supports their position. This provision states "Any references to FAR, DEAR, DOE-PR, DOE Orders or Code of Federal Regulations (CFR) in the text of the provisions of this contract refer to the text of these provisions as constituted on the date of the execution of this contract. Except for changes effective by operation of law, changes to the referenced provisions effective after the date of execution of this contract shall affect the contract only to the extent agreed to in writing by the Contractor and the Contracting Officer. "

The SURA M\&O contract expired on September 30, 1992, and they are currently operating under a contract extension. Although the issue of Order applicability has been recognized for several years, it has yet to be resolved. Further, it is not expected to be resolved in the near future. This is partly due to the fact that this issue has implications well beyond CEBAF and will require senior DOE management involvement. Given the recent change in the DOE administration and other DOE priorities, it is uncertain whon DOE 
Headquarters guidance will be available. A date for completion of contract negotiations between DOE and SURA is partly contingent upon such guidance and therefore is also uncertain.

There are two primary concerns associated with this unresolved disagreement over DOE Order applicability. First, the CEBAF Site Office is not able to direct SURA to implement all of the Orders or provisions of Orders it deems applicable to CEBAF. Second, it is a continuing distraction for the CEBAF Site Office and SURA management as discussions and negotiations have continued for an extended period of time. Finally, the lack of a common understanding between DOE and SURA regarding the applicability of DOE Orders or a process for determining the applicability of Orders prevents the establishment of a baseline against which the facility can be appraised for compliance with DOE requirements. 


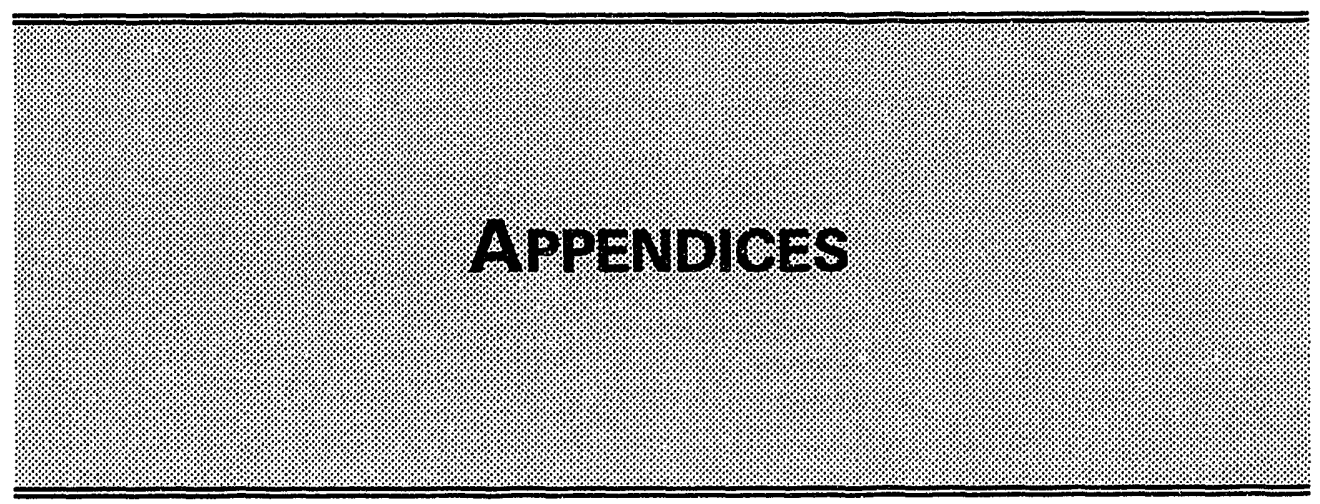


This page intentionally left blank. 


\section{APPENDIX A}

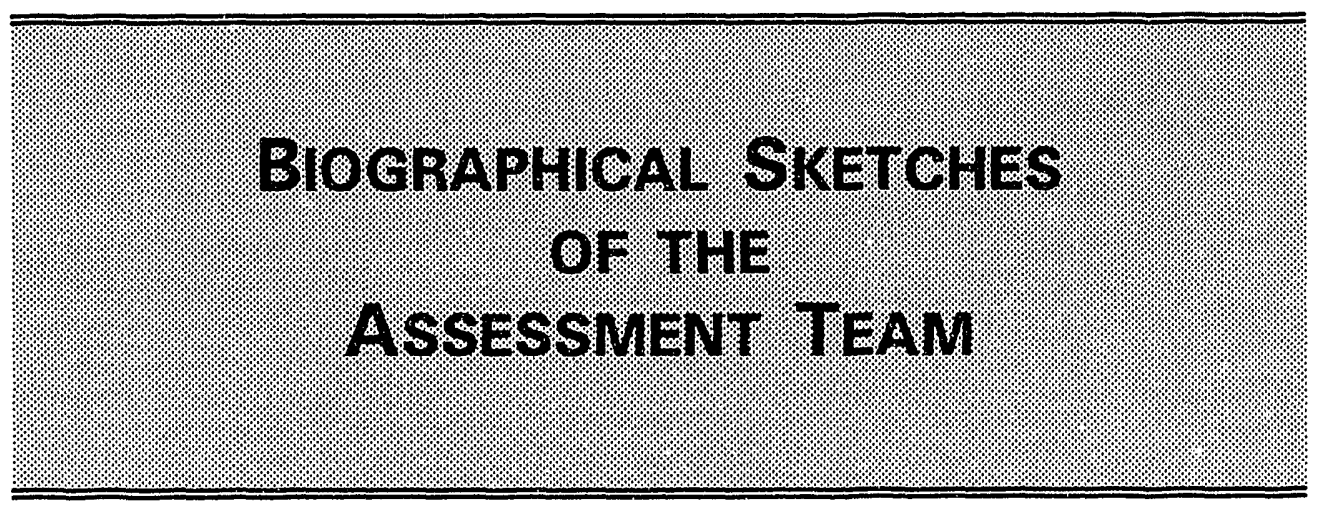


This page intentionally left blank. 


\section{APPENDIX A:}

\section{BIOGRAPHICAL SKETCHES OF THE ASSESSMENT TEAM}

NAME: $\quad$ William A. Eckroade

AREA OF RESP: Team Leader

ASSOCIATION: U.S. Department of Energy

EXPERIENCE: $\quad 6$ Years

- U.S. Department of Energy, Office of Environmental Audit

- Environmental Team Leader/Environmental Engineer. Principal responsibilities include leading multidisciplinary teams of professionals in performing Environmental Audits; Environmental Assessments; and Environment, Safety and Health (ES\&H) Progress Assessments at DOE facilities.

- Served as Team Leader for the Western Area Power Administration Environmental Management Audit.

- $\quad$ Served as the Deputy Team Leader for the Coal-Fired Flow Facility Environmental Audit; Alaska Power Administration Environmental Audit; the Maywood, New Jersey, FUSRAP Site Environmental Audit; the Energy Technology Engineering Center Tiger Team Assessment; the Grand Junction Environmental Audit; the Bonneville Power Ad'ministration Environmental Management Audit; and the Ames Laboratory Tiger Team Assessment.

- Technical specialist for the ES\&H Progress Assessment of the Hanford Site responsible for the conduct of a programmatic assessment of Hanford's Environmental Restoration Program.

- U.S. Department of Energy, Office of Environmental Compliance

- Environmental Engineer responsible for conducting independent oversight of environmental compliance activities at the Savannah River Site.

- U.S. Environmental Protection Agency, Office of Waste Programs Enforcement

- Environmental Engineer responsible for providing assistance in technical case development to assigned EPA regional offices. Additionally, responsible for conducting oversight of regional activities involving activities at enforcement lead Superfund sites.

EDUCATION: $\quad$ M.S., Civil Engineering, University of Maryland

B.S., Geophysics, Virginia Polytechnic Institute 
NAME:

Richard S. Green

AREA OF RESP: Deputy Team Leader

ASSOCIATION: U.S. Department of Energy

EXPERIENCE: $\quad 20$ years

- U.S. Department of Energy, Office of Environmental Audit

- Deputy Team Leader responsible for conducting audit activities and providing guidance, direction, and assistance to a multidisciplined group of professionals performing environmental audits and Tiger Team Assessments at DOE facilities.

- Served as the Deputy Team Leader for the Fermilab Tiger Team Assessment and as Environmental Specialist for the EM-20 sponsored INEL Agreement-in-Principle Review.

- U.S. Department of Energy, Office of Environmental Compliance

- Environmental Protection Specialist (EPS) responsible for conducting independent oversight of environmental compliance activities at the Savannah River Site.

- U.S. Environmental Protection Agency, Office of Waste Programs Enforcement

- EPS responsible for providing assistance in technical case development to EPA Region 6 and conducting oversight of Region 6 enforcement lead Superfund sites.

- U.S. Environmental Protection Agency, Office of Compliance Monitoring

- EPS responsible for the development of Toxic Substances Control Act (TSCA)/Federal Insecticide, Fungicide, and Rodenticide Act (FIFRA) enforcement penalty policies and monitoring strategies, and for the revisions to the TSCA and FIFRA Good Laboratory Practice Regulations.

- U.S. Environmental Protection Agency, Office of Toxic Substances

- EPS responsible for the management of a multidisciplined group of professionals tasked to assess the risks and the appropriate regulatory dispositions of chemical substances subject to TSCA.

- U.S. Environmental Protection Agency, Office of Pesticide Programs

- EPS responsible for the management of a multidisciplined group of technical professionals tasiked to assess insecticide products subject to the FIFRA registration process.

EDUCATION: $\quad$ B.S., Entomology, University of Maryland 
NAME: $\quad$ James Margolis

AREA OF RESP: Group Coordinator

ASSOCIATION: Arthur D. Little

EXPERIENCE: $\quad 9$ Years

- $\quad$ Arthur D. Little, Inc.

- Served as Environmental Management Specialist for the Environmental Management Audit of the Western Area Power Administration and the Formerly Utilized Sites Remedial Action Program covering the areas of Organizational Structure, Culture and Attitude, Internal and External Communication, and Planning.

- Served as a Special Assistant for the Environmental Management Audit of the Uranium Mill Tailings Remedial Action Program.

- Served as Environmental Management Specialist in the Environmental Audit of the Weldon Spring Remedial Action Project and West Valley Demonstration Project.

- Assessed environmental management systems at the corporate, division, and plant levels for a major diversified international industrial products manufacturer. The work focused on organization structure, staffing, review and oversight activities, and managing for compliance.

- Evaluated the corporate organization structure and roles and responsibilities related to environmental, health, and safety management for a major international natural resources company to best serve the needs of its various business units.

- Assessed the environmental, health, and safety management systems for a large international computer manufacturer.

- Assessed the management systems in place for a leading pharmaceutical manufacturer at the company's largest U.S. facility with a particular focus on water pollution control.

- Assessed hazardous materials management programs in place at all twenty campuses of a major State University system. Recommendations focused on the adequacy of management controls and opportunities for automation.

EDUCATION: $\quad$ B.S., Civil Engineering, Tufts University

M.M., Management, Kellogg Graduate School of Management, Northwestern University 
NAME:

David J. Allard

AREA OF RESP: Environmental Protection Programs

ASSOCIATION: Arthur D. Little, Inc.

EXPERIENCE: $\quad 15$ Years

- $\quad$ Arthur D. Little, Inc.

- Senior Consultant and Certified Health Physicist providing technical support for DOE Tiger Team Assessments and various commercial client cases dealing with radiation issues, such as environmental monitoring, waste management, emergency planning, training, applied technical services, and radiation protection management.

- $\quad$ Participated in the Tiger Team Assessments of the Morgantown Energy Technology Center, Idaho National Engineering Laboratory, Los Alamos National Laboratory, and the Environmental Audit of the Fossil Energy Sites in Wyoming.

- TGM Detectors, Inc.

- Vice President with responsibilities for radiation protection and gas-filled detector design, engineering, and marketing.

- Nuclear Metals, Inc.

- Supervisor of Health Physics with responsibilities in the areas of environmental monitoring, external and internal dosimetry, shielding, radiation surveys waste disposal, and regulatory affairs regarding various uranium and thorium manufacturing operations.

- $\quad$ Albany Medical Center

- Medical/Health Physicist with responsibilities involving external and internal dosimetry, laboratory radiation protection, $x$-ray equipment quality assurance, shielding, surveys, and waste disposal.

EDUCATION: M.S., Radiological Sciences and Protection, University of Lowell B.S., Environmental Sciences, State University of New York at Albany A.A.S., Environmental Health Technology, Hudson Valley Community College 
NAME: $\quad$ Lisa Baci

AREA OF RESP: $\quad$ Organizational Structure

Internal and External Communication

ASSOCIATION: Arthur D. Little, Inc.

EXPERIENCE: $\quad 13$ Years

- $\quad$ Arthur D. Little, Inc.

- Served as Waste Management Specialist for the Tiger Team Assessments of the Stanford Linear Accelerator Center and the Strategic Petroleum Reserves.

- Helped a major diversified international manufacturing and service company assess its existing environmental, health, and safety organization and identify changes to better align the EHS organization with the company's new global business structure.

- Assessed environmental management systems at the corporate, division, and plant levels for many companies including major chemical manufacturers, leading consumer and industrial products manufacturers, and a natural gas pipeline operation. Areas examined in these studies included policies and procedures, organizational structure and resources, internal and external communication, and audits/self-assessment mechanisms.

- Managed a project for a large state environmental agency to identify state and local permitting requirements that affect hazardous waste cleanup and to assess options to streamline and better coordinate the permitting process.

- Analyzed the potential economic benefits to various parties at a Federal Superfund site from past waste disposal practices at the site.

- Analyzed the economic and financial impacts of several major environmental regulations for the U.S. Environmental Protection Agency. These analyses included a study of the impacts on municipalities of proposed new regulations on solid waste landfills and a study of the impacts on generators, transporters, and recyclers of proposed regulations on facilities that handle used oil.

EDUCATION: Masters of City and Regional Planning (MCRP), Harvard University B.S., Urban and Environmental Planning, Worcester Polytechnic Institute

A.B., Economics, College of the Holy Cross 
NAME: $\quad$ Joseph Delaney

AREA OF RESP: Environmental Protection Programs

ASSOCIATION: Arthur D. Little, Inc.

EXPERIENCE: $\quad 9$ Years

- $\quad$ Arthur D. Little, Inc.

- Surface Water/Drinking Water Specialist for the Tiger Team Assessments of the Naval Petroleum Reserves in California, the Pittsburgh Energy Technology Center, the Strategic Petroleum Reserve, and the Fermi Laboratory; Inactive Waste Sites Specialist for the Naval Petroleum and Oil Shale Reserves Tiger Team; and assisted on the Stanford Linear Accelerator Center Tiger Team Assessment.

- Revised Performance Objectives and Criteria (POCs) for the Department of Energy Environmental Audit Program. Responsibilities included revising surface water, sediment, and biota POCs.

- Participated in numerous environmental audits for commercial clients. Specialized in the assessment of compliance with provisions of the Clean Air Act, Clean Water Act, Resource Conservation and Recovery Act, and Safe Drinking Water Act.

- Prepared a Toxic Substanses Control Act (TSCA) training manual to address the major provisions of TSCA, including asbestos and polychlorinated biphenyl (PCB) management.

- Environmental Consultant

- Conducted a variety of studies assessing the impact of process wastewater discharges on receiving water quality. These studies included characterization of waste streams, thermal impact assessment, and water quality modeling in support of National Pollutant Discharge Ellimination System permit applications.

- Participated in several sampling programs for the Army Corps of Engineers to assess PCB discharges and dredge material disposal sites.

- Prepared and updated Spill Prevention Control and Countermeasure Plans and Emergency Response Plans to address oil and hazarcious materials spills from several industrial sites.

EDUCATION: $\quad$ B.S., Civil Engineering, Northeastern University

OTHER: Registered Professional Engineer 
NAME:

Peter Gascoyne

AREA OF RESP: Staff Resources, Training, and Development Environmental Planning and Risk Management

ASSOCIATION: Arthur D. Little, Inc.

EXPERIENCE: $\quad 9$ Years

- $\quad$ Arthur D. Little, Inc.

- Participated in the Environmental Management Audit of the Western Area Power Administration as a Management Specialist covering the areas of Staff Resources, Training, and Environmental Planning.

- Prepared a protocol for use in conducting management audits of Federally-owned energy facilities.

- Estimated the implied benefits to government and private parties resulting from the failure to treat adequately significant quantities of numerous types of hazardous wastes. The analysis required designing a treatment facility and estimating treatment costs.

- Estimated the economic impact to the recreational boating and construction materials industries resulting from a proposed EPA change in air emissions standards.

- Conducted a cradle-to-grave input-output analysis comparing the environmental impact from the manufacture, use, and disposal of certain paper products versus their cloth counterparts.

- $\quad$ PMI Mortgage Insurance Co.

- Centralized and directed accounting, claims, pricing, legal, and marketing functions of mortgage pool and reinsurance products; volume: $\$ 18$ billion.

- Designed computer system to manage accounting, claims, reporting, and profitability.

EDUCATION: $\quad$ M.A.L.D., Fletcher School of Law \& Diplomacy M.A., Economics, San Francisco State University

B.A., Political Science, University of California at Berkeley 


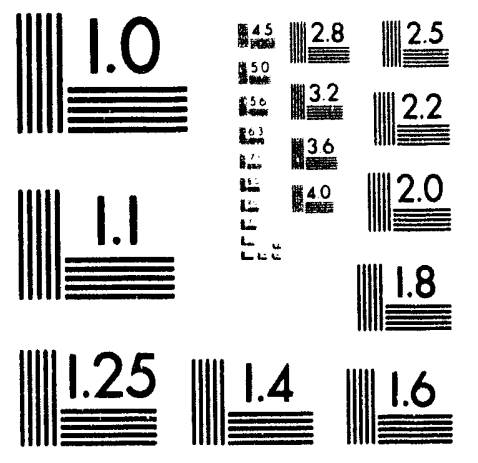



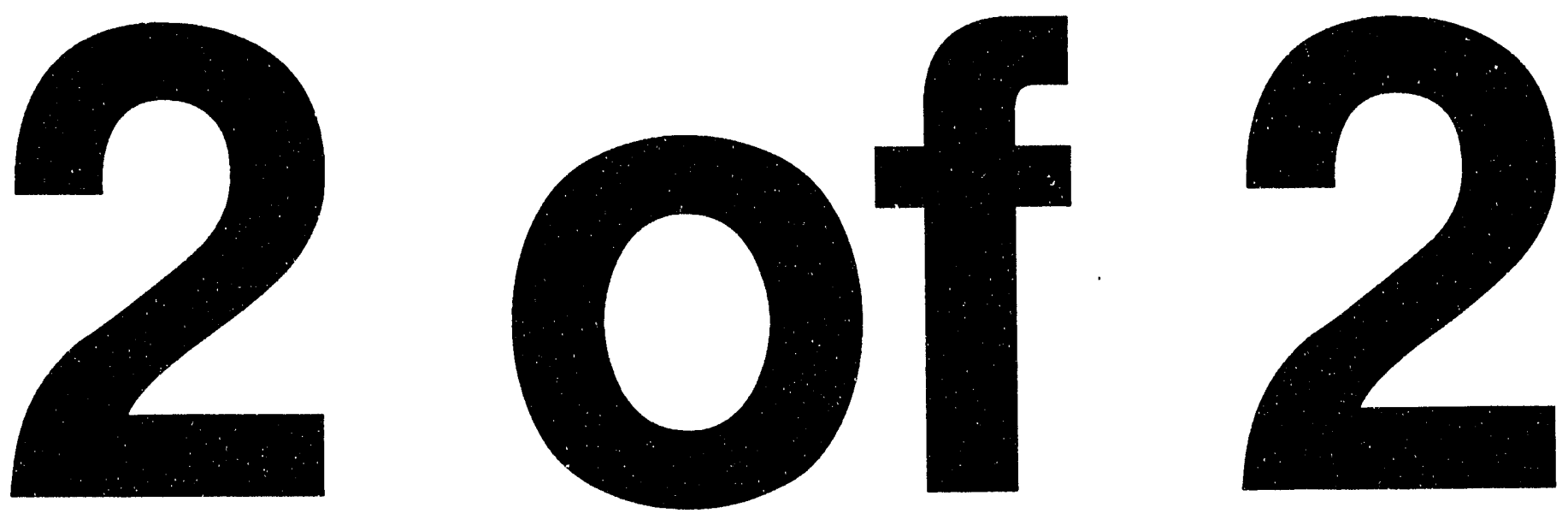
NAME: $\quad$ Kathy Loving

AREA OF RESP: Program Evaluation, Reporting, and Corrective, Action

Environmental Commitment

ASSOCIATION: $\quad$ Arthur D. Little, Inc.

EXPERIENCE: $\quad 8$ Years

- $\quad$ Arthur D. Little, Inc.

- Served as Group Coordinator for the Environmental Management Audit of the Bonneville Power Administration. Also served as a Management Specialist reviewing the area of Environmental Protection Programs.

- Served as Group Coordinator for the Environmental Management Audit of the Southwestern Power Administration.

- Developed the DOE guidance protocol for Environmental Management Audits.

- Developed and conducted a training seminar for DOE staff on environmental management systems audits.

- Participated in the Environmental Management Audit of FUSRAP, reviewing the areas of Environmental Protection Programs and Formality of Programs.

- Participated in numerous environmental audits and assessments in the U.S., Canada, and Europe. Served as both team leader and team member in these reviews. Areas of expertise in environmental auditing include management systems, solid and hazardous waste management, PCB management, spill control, and emergency response.

- Conducted legislative and regulatory reviews of existing and proposed environmental requirements in the U.S. and Europe. Reviewed the regulatory compliance status of over 40 hazardous waste treatment, storage, and disposal facilities, as part of Arthur D. Little's Site Watch program.

- Leads various environmental management cases at Arthur D. Little.

EDUCATION: $\quad$ M.B.A. candidate, Boston University

B.A., Environmental Studies, University of Kansas 
NAME: Joseph P. Selle

AREA OF RESP: Formality of Environmental Programs

Environmental Planning and Risk Management

ASSOCIATION: Arthur D. Little, Inc.

EXPERIENCE: $\quad 8$ Years

- $\quad$ Arthur D. Little, Inc.

- As a member of the company's Environmental Business and Strategy Unit, assists private and public sector clients, including Federal and state government entities and quasi-public institutions in developing environmental strategies and policies. Key services provided include government regulatory and procedural analysis, legislative and regulatory policy analysis, economic and market analysis, and environmental strategy analysis. Currently a member of the Department of Energy environmental management audit team. Past involvement in management system environmental benchmarking studies focusing on the chemical and oil industry.

- Assisted in the development of Department of Energy standard operating procedures for the conduct of environmental management systems assessments.

- Massachusetts Department of Environmental Protection

- As a regional Planner in the Division of Solid Waste Management, co-authored the Massachusetts Solid Waste Masterplan. In support of the plan, performed quantitative analysis of solid waste generation rates and management methods. Planned and analyzed the state's long-range strategy for solid wast? management.

- Worked to revise the state permit procedure for solid waste facilities, and crafted strategy to ensure use of integrated solid waste planning and management for new and existing facilities.

- Worked with hydrogeologists to design a risk assessment screening procedure for solid waste landfills. The procedure was designed to dovetail with Federal and State hazardous waste assessment and remediation programs.

- As a program coordinator for the Office of Program Development and Evaluation, provided ongoing management consulting support to the Commissioner of the Department. Examples of projects include analysis and revamping of the Department's formal budgeting procedures, redesign of the Department's internal communication and priority setting procedure, and ongoing support in the preparation of annual Department budgets submitted to the Governor.

EDUCATION: Masters of Public and Private Management (MPPM), Yale University B.A., Geography and Environmental Studies, Dartmouth College 
NAME: Lynne Day

AREA OF RESP: Administrator

ASSOCIATION: META, Inc.

EXPERIENCE: $\quad 16$ Years

- $\quad$ META, Inc.

- Information Management Specialist. Provides administrative support for Environmental Audits; Environmental Management Assessments;

Environment, Safety and Health (ES\&H) Progress Assessments; and the Environmental Subteam on Tiger Team Assessments at DOE sites.

- Participant in the Component Development and Integration Facility, Environmental Measurements Laboratory, Alaska Power Administration, and the Coal-Fired Flow Facility Environmental Audits; the Uranium Mill Tailings Remedial Action Project Environmental Management Audit; the Fernald Environmental Management Project, Hanford Site, and Brookhaven National Laboratories ES\&H Progress Assessments; and the Solar Energy and Research Institute, Los Alamos National Laboratories, Strategic Petroleum Reserves, and Naval Petroleum Oil Shale Reserves Tiger Team Assessments.

- $\quad$ Provided administrative support for production of the ES\&H Progress Assessment Manual and attended Progress Assessment Training Program.

- Assisted in production of the draft Administrative Support Procedures and Guidance for the Office of Environmental Audit.

- INNOVA Communications, Inc.

- Office Administrator. Provided system, office automation, project management, database management, graphic, and documentation support for a local and wide area network integration firm.

- Sandler \& Greenblum

- Word Processing Departmental Manager. Developed and coordinated activities related to the word processing department for law firm specializing in patent/trademark law. Responsible for supervision and staffing of word processing department and hardware and software procurement and installations.

EDUCATION: $\quad$ A.A., Computer Science, Strayer College 


\section{APPENDIX B}

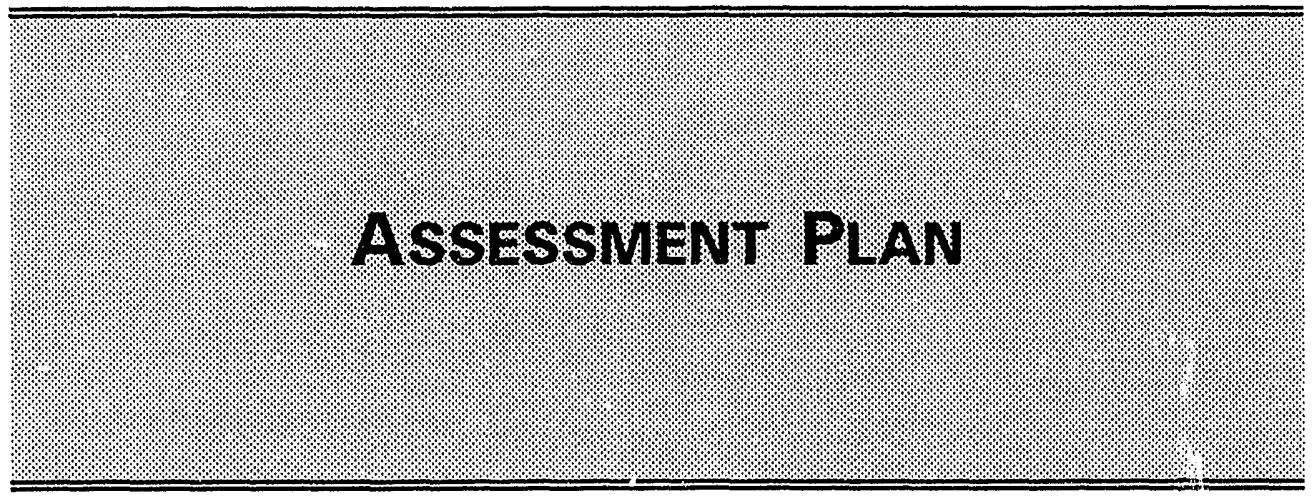


This page intentionally left blank. 


\title{
Plan for the
}

DOE Environmental Management Assessment

$$
\text { of the }
$$

\section{Continuous Electron Beam \\ Accelerator Facility (CEBAF)}

Newport News, Virginia

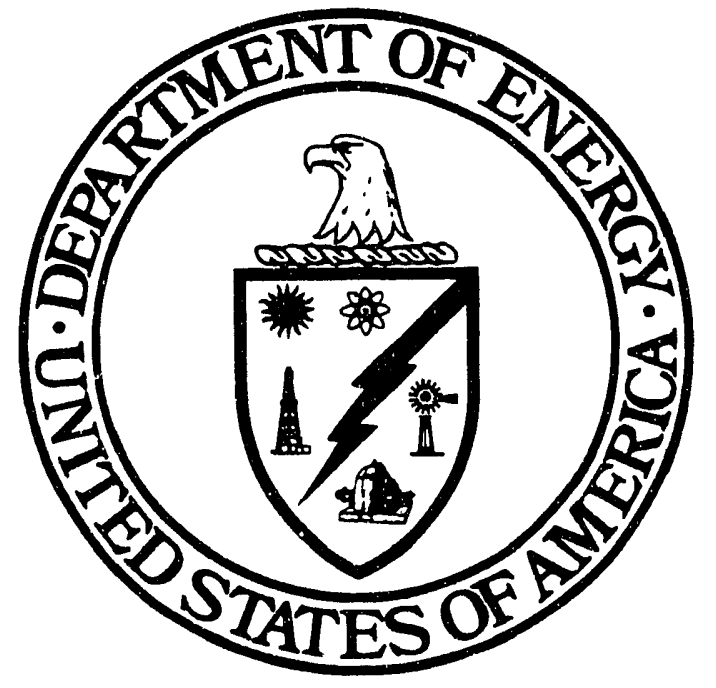

\author{
U.S. Department of Energy \\ Office of Environmental Audit
}

February 1993 
This page intentionally left blank.

B-2 


\section{TABLE OF CONTENTS}

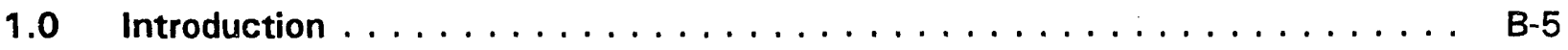

2.0 Environmental Management Assessment Implementation $\ldots \ldots \ldots \ldots \ldots$. . . . B-7

2.1 Pre-Assessment Activities . . . . . . . . . . . . . . . B B-7

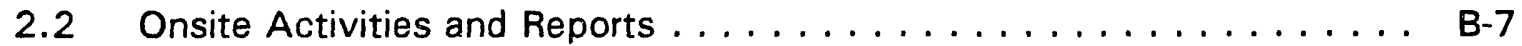

2.3 Post-Site Activities . . . . . . . . . . . . . . . . . B B-8

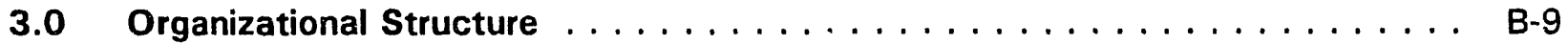

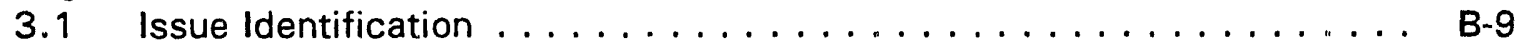

3.2 Records Required ....................... B-10

4.0 Environmental Commitment . . . . . . . . . . . . . . . . . . B-11

4.1 Issue Identification ....................... . . . 11

4.2 Records Required ...................... B-12

5.0 Environmental Protection Programs $\ldots \ldots \ldots \ldots \ldots \ldots \ldots \ldots$

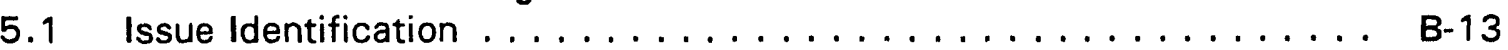

5.2 Records Required ....................... B-14

6.0 Formality of Environmental Programs . . . . . . . . . . . . . B-16

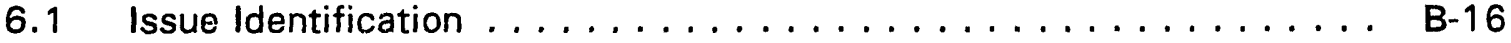

6.2 Records Required ...................... B-17

7.0 Internal and External Communication $\ldots \ldots \ldots \ldots \ldots \ldots \ldots \ldots \ldots$

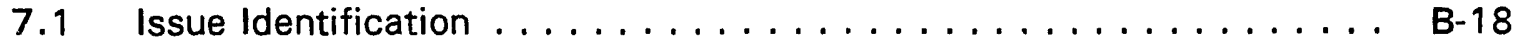

7.2 Records Required ....................... B-19

8.0 Staff Resources, Training, and Development . . . . . . . . . . . . . . . B-20

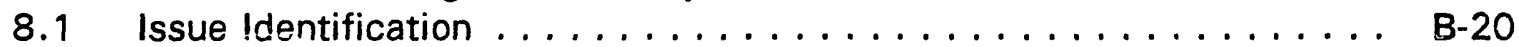

8.2 Records Required . . . . . . . . . . . . . . . B B-21

9.0 Program Evaluation, Reporting, and Corrective Action . . . . . . . . . . B-22

9.1 Issue Identification . . . . . . . . . . . . . . . . . B-22

9.2 Records Required . . . . . . . . . . . . . . . . . B-23

10.0 Environmental Planning and Risk Management . . . . . . . . . . . . . . . . B-24

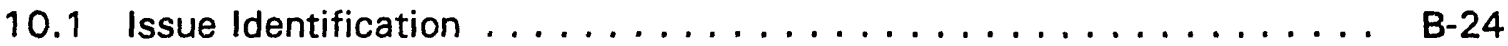

10.2 Records Required . . . . . . . . . . . . . . . . B-25 
This page intentionally left blank.

B-4 


\section{APPENDIX B:}

\section{PLAN FOR THE DOE ENVIRONMENTAL MANAGEMENT ASSESSMENT OF THE CONTINUOUS ELECTRON BEAM ACCELERATOR FACILITY (CEBAF)}

\section{INTRODUCTION}

The DOE Environmental Audit Program is carried out by the Office of Environmental Audit (EH-24) within the Office of Environment, Safety and Health (EH). The program was created in 1985 with a goal to provide a continuing program of internal, independent oversight of line management's environmental performance, in support of DOE's broader goal of achieving full compliance and excellence in the environmental area. The objectives of the program in achieving this goal include:

- $\quad$ Providing continued leadership in the environmental component of Tiger Team Assessments;

- Conducting comprehensive, baseline environmental audits of facilities that were not addressed in the Environmental Survey and are not expected to receive Tiger Team Assessments;

- Conducting assessments of environmental management within line programs, including adequacy of self-assessment programs;

- Conducting a continuing program of field/technical re-audits of major and other DOE facilities;

- $\quad$ Conducting focused, special issue audits to assess high priority issues at a particular site, or which cut across site and program lines; and

- $\quad$ Supporting line management self-assessment programs through continuing updates and automation of audit protocols, training, and other mechanisms of transferring the special auditing expertise of EH-24 to the field.

The assessment of the Continuous Electron Beam Accelerator Facility (CEBAF) during the period of March 8 through March 19, 1993 will be an Environmental Management Assessment. It will evaluate the effectiveness of environmental management programs established by DOE line organizations and their support contractors. The assessments are conducted in accordance with the DOE Environmental Audit Program Guidance (January 1992) and draft protocols developed for conducting Environmental Management Assessments (January 1993). The draft protocols are shown in Attachment A.

From an organizational perspective, the scope of the assessment will include environmental management issues at the Program Office, Field Office, and facility levels. The assessment team will focus on line management's performance in developing and implementing environmental programs, consistent with DOE expectations for environmental excellence. 
From a functional perspective, the scope of the CEBAF Assessment is comprehensive in that it covers a full range of relevant management systems. This includes:

- Organizational Structure;

- $\quad$ Culture and Attitude;

- Environmental Protection Programs;

- Formality of Environmental Programs;

- Internal and External Communication;

- Staff Resources, Trainir.g, and Development;

- Program Evaluation, Reporting, and Corrective Action; and

- Environmental Planning and Risk Management.

Issues such as the design and effectiveness of environmental self-assessment programs, implementation of policy and procedures, occurrence reporting, and use of performance indicators will receive special attention.

The information in this Environmental Management Assessment Plan is based on information received by the assessment team as of the end of the day on February 17, 1993. 


\subsection{ENVIRONMENTAL MANAGEMENT ASSESSMENT IMPLEMENTATION}

The CEBAF Environmental Management Assessment will be conducted by a team consisting of a Team Leader and Deputy Team Leader from the Office of Environmental Audit (EH-24) and a Group Coordinator and five management systems specialists from Arthur D. Little, Inc. (ADL). The names and assignments are listed below:

\begin{tabular}{|c|c|c|}
\hline Bill Eckroade & DOE & Team L eader \\
\hline Rick Green & DOE & Deputy Team Leader \\
\hline James Margolis & $A D L$ & Group Coordinator \\
\hline $\begin{array}{l}\text { David Allard/Joe Delaney } \\
\text { Lisa Baci }\end{array}$ & $\begin{array}{l}A D L \\
A D L\end{array}$ & $\begin{array}{l}\text { Environmental Protection Programs } \\
\text { Organizational Structure } \\
\text { Internal and External Communications }\end{array}$ \\
\hline Peter Gascoyne & ADL & $\begin{array}{l}\text { Environmental Planning } \\
\text { Staff Resources, Training, and Development }\end{array}$ \\
\hline Kathy Loving & ADL & $\begin{array}{l}\text { Priogram Evaluation and Reporting } \\
\text { Environmental Commitment }\end{array}$ \\
\hline Joseph Selle & ADL & $\begin{array}{l}\text { Formality of Environmental Programs } \\
\text { Risk Management }\end{array}$ \\
\hline Lynne Day & META & Administrative Support \\
\hline
\end{tabular}

\section{1}

PRE-ASSESSMENT ACTIVITIES

Pre-assessment activities for the CEBAF Environmental Management Assessment included the issuance of an introduction and information request memorandum, a site visit, and initial review of documentation which was sent to the assessment team by CEBAF as a result of the information request memorandum.

The pre-assessment site visit was conducted on January 11 and January 12, 1993 by the DOE Team Leader, the Deputy Team Leader, and the Group Coordinator from ADL. The purpose of the visit was to brief site personnel on the purpose and scope of the Environmental Management Assessment, to become familiar with CEBAF and its operations, to review information being supplied by CEBAF and request additional information, and to coordinate activities for the upcoming assessment. The visit also included presentations by the DOE CEBAF Site Office and selected managers from the primary CEBAF contractor, Southeastern Universities Research Association, Inc. (SURA). Also attending the pre-assessment site visit were team members from the Oak Ridge Office management appraisal team, who will be performing their appraisal from March 8 through March 12, 1993.

\subsection{ONSITE ACTIVITIES AND REPORTS}

The onsite activities for the Environmental Mar.agement Assessment will begin March 8 and continue through March 19, 1993. Onsite activities will include file/record reviews and interviews with CEBAF management and staff (including both DOE and SURA personnel). Selected interviews will be conducted with program and field office personnel with management and oversight responsibilities. 
The agenda for the assessment (including a preliminary interview schedule) is shown in Attachment B. The interview schedule reflects the assessment team's best attempt to identify relevant personnel to be interviewed, and is coordinated with the Oak Ridge Office management appraisal occurring during the first week of the Environmental Management Assessment. Based on past experience, these schedules will change as additional information is gathered by the assessment team members and based on availability of site personnel. Modifications to the interview schedule, or other elements of the agenda, will be coordinated with the designated CEBAF contacts.

During the assessment, the assessment team will conduct daily debriefing sessions with CEBAF management to review progress and concerns to date. A factual accuracy review of all findings will begin in the middle of the second week of the assessment. A closeout briefing will be conducted at the conclusion of the onsite portion of the assessment. A summary of the results of the assessment, including key findings, will be presented by the assessment Team Leader at that time. Also at the closeout, a draft assessment report will be provided to CEBAF for review and comment.

\section{$2.3 \quad$ POST-SITE ACTIVITIES}

Following the onsite activities, CEBAF will have the opportunity to submit final comments on the draft assessment report. After reviewing these comments, EH-24 will issue a final report. CEBAF will be responsible for preparing an action plan which will be reviewed by $\mathrm{EH}-24$. The following is a tentative schedule for completion of these post-site activities.

April 2 Site comments on draft report due

April $16 \quad$ Final assessment report issued by EH-24

April $30 \quad$ Draft action plan due (six weeks after closeout)

May $14 \quad$ EH-24 comments on draft action plan

May $28 \quad$ Final action plan due 


\section{$3.1 \quad$ ISSUE IDENTIFICATION}

The Environmental Management Assessment activities for Performance Objectives and Criteria (POC) EM.1, "Organizational Structure," will review and analyze whether CEBAF's environmental management organization is consistent with the overall organization structure and has clear lines of authority, well defined roles and responsibilities, and sufficient organizational stature.

The general approach to the assessment will include a review of documentation regarding organizational structure, and interviews with CEBAF management and staff. Areas of particular interest will include:

- The formal structure and working relationship among the Oak Ridge Field Office (ORO), the DOE CEBAF Site Office, and Southeastern Universities Research Association, Inc. (SURA), the management and operations contractor for CEBAF;

- The degree to which actual lines of environmental management authority and responsibility are consistent with formal documents that define organizational roles, responsibilities, and authority;

- The degree to which reporting relationships within the environmental management function are well defined and clearly communicated;

- The degree to which authority to make decisions related to environmental protection is assigned to the organizational levels that can provide the most timely and appropriate response;

- The reporting "distance" between the person with primary responsibility for the environmental support function and the overall manager of the organization;

- The definition and understanding of functional relationships between environmental support groups and line units;

- The existence of management systems and procedures to promote responsibility and maintain accountability;

- The degree to which the environmental management organization leverages managers effectively; and

- The occurrence and results of periodic reviews of the environmental organizational structure.

Coordination with other assessment team members will be routine and extensive. Special attention will be paid to coordination with Line Responsibility (EM.2), Internal

Communication (EM.5), and Staff Resources (EM.6). 


\section{2}

RECORDS REQUIRED

In addition to those documents reviewed prior to the assessment, the following records will be examined at CEBAF:

- Formal documents that define organizational responsibility, authority, and accountability for environmental protection programs;

- Formal job descriptions for field office and facility-level environmental staff, as well as other key line management and operating personnel;

- Formal measures of job performance;

- Descriptions of any environmental recognition, award, or incentive programs; and

- Environmental planning documents. 


\subsection{ISSUE IDENTIFICATION}

The Environmental Management Assessment activities for Performance Objectives and Criteria (POC) EM.2, "Environmental Commitment," will review and evaluate the organization's commitment to achieving environmental excellence. The assessment team will evaluate whether CEBAF demonstrates a positive attitude and proactive approach to environmental management. Some key indications of environmental commitment that will be evaluated are the following:

- Demonstration oi senior management's commitment to environmental protection through formal statements, managerial decisions and actions, attitude, and interest;

- Establishment of organizational policy, which places environmental protection equal to production operations and safety and health; and

- Awareness of and responsibility for environmental protection at all levels and across various functions of the organization.

The general approach to assessing this performance objective will include interviews with personnel at various levels and in several functions within the organization. The assessment will also be based on documentation that provides insight into the organization's environmental protection programs and activities. Furthermore, evidence and findings from all other aspects of the Environmental Management Assessment will be considered in the overall determination of the organization's level of environmental commitment. Areas of particular interest will include:

- Existence and organizational understanding of formal policy statement on the environment and issue-specific policies, as appropriate;

- Senior management interest and knowledge of environmental issues and programs;

- General understanding and acceptance of the importance of environmental protection by all CEBAF personnel;

- Line management's sense of responsibility for environmental performance;

- Environmental awareness of staff in other functional areas such as engineering, procurement, legal, and public affairs;

- Level of environmental protection program development and implementation;

- Existence of progressive environmental programs such as pollution prevention; and

- $\quad$ Allocation of adequate human, financial, and technical resources. 
The following documents will be reviewed to support the assessment of environmental commitment:

- Environmental policy statements;

- Environmental program descriptions, guidance manuals, and implementation plans;

- Senior management statements of support for environmental protection that are included in internal or external reports, speeches, newsletters, or other documents;

- Internal reports on environmental protection activities and issues;

- Examples of environmental awareness programs or activities;

- Environmental training program manuals and supporting materials; and

- $\quad$ Other relevant material identified during the course of the assessment. 


\subsection{ENVIRONMENTAL PROTECTION PROGRAMS}

5.1 ISSUE IDENTIFICATION

The Environmental Management Assessment activities for Performance Objectives and Criteria (POC) EM.3, "Environmental Protection Programs," will evaluate whether CEBAF has the environmental programs in place to ensure compliance with Federal, state, and local environmental laws and regulations. Further, the assessment will determine if the site provides for timely and correct implementation of those DOE Orders and Secretary of Energy Notices (SENs) designed to protect the environment and public health. The emphasis of the review will be on determining whether effective and comprehensive programs are in place and whether there is sufficient planning, oversight, and staff training regarding these programs. The key issues involve conformance of CEBAF environmental protection programs with the performance objectives and prescriptive requirements of the following DOE Orders and other applicable environmental protection statues (including the implementing regulations of these statutes):

- DOE Orders:

- $\quad$ DOE 5400.1, "General Environmental Protection Program";

- DOE 5400.2A, "Environmental Compliance Issue Coordination";

DOE 5400.5, "Radiation Protection of the Public and the Environment";

DOE 5400.9, "Sealed Radioactive Source Accountability";

DOE 5480.2A, "Radioactive Waste Management";

DOE 5480.4, "Environmental Protection, Safety, and Health

Protection Standards"; and

- DOE 5700.6C, "Quality Assurance."

- Environmental Statutes (not a comprehensive listing):

Clean Water Act (CWA);

Safe Drinking Water Act (SDWA);

Clean Air Act (CAA);

Resource Conservation and Recovery Act (RCRA); and

Toxic Substances Control Act (TSCA).

In addition, the CEBAF environmental protection programs will be evaluated for their adequacy in light of all agreements entered into with Federal, state, and local governments and associations. 
The general approach to the assessment will include interviews with the DOE CEBAF Site Office and Southeastern Universities Research Association, Inc. (SURA) personnel responsible for environmental program development and iriplementation. Prior to arriving onsite, and during the assessment, reviews will be perforrned of documentation supporting those programs or demonstrating their proper implementation. Areas of particular interest will include:

- Determination of regulatory requirements and incorporation of those requirements (regulatory drivers) into appropriate environmental protection programs;

- Determination that all activities and contractors are included in environmental protection planning documents;

- Identification and regular monitoring of current or planned environmental releases;

- Activities relative to long-term surveillance and maintenance programs;

- Prevention and minimization of environmental releases;

- Emergency response provisions;

- Groundwater monitoring;

- Ambient and effluent radioactivity monitoring;

- Direct radiation monitoring for offsite dose;

- $\quad$ Policies and procedures relating to quality assurance; and

- Effective and consistent implementation of environmental programs.

\subsection{RECORDS REQUIRED}

In addition to those documents reviewed prior to the assessment, the following records will be examined onsite:

- Individual project plans;

- Results of ongoing environmental effluent and release monitoring;

- Results of internal audits and self-assessments;

- Emergency response plans;

- National Emission Standards for Hazardous Air Pollutants (NESHAPs) documentation and correspondence;

- $\quad$ Preventive maintenance and inspection procedures; 
- Reports to management, DOE Headquarters, and regulatory agencies;

- Minutes of the Advisory Panel on Acceleration Radiation Safety; and

- Other records as determined onsite. 


\subsection{FORMALITY OF ENVIRONMENTAL PROGRAMS}

\section{1 ISSUE IDENTIFICATION}

The Environmental Management Assessment activities for Performance Objectives and Criteria (POC) EM.4, "Formality of Environmental Programs," are designed to determine whether environmental protection activities are conducted in accordance with formal programs supported by controlled documentation. Specifically, the assessment is designed to evaluate:

- The existence and effectiveness of formal systems to track and interpret regulations and DOE Orders and incorporate them into policies, standards, and procedures;

- The extent to which environmental programs and procedures are developed and effectively implemented throughout the organization;

- $\quad$ CEBAF's system for conducting routine inspections to assure facility compliance and identify potential problems; and

- Systems for maintaining and retaining records, and for assuring timely completion of regulatory and management reporting requirements.

The general approach to the assessment will include interviews with CEBAF personnel responsible for tracking new environmental requirements and incorporating them into policies and procedures, as well as staff and line managers, and other personnel responsible for implementing environmental programs. Areas of particular interest will include:

- The extent to which staff responsible for regulatory tracking is up-to-date on new, proposed, and emerging regulatory issues;

- The development of guidance documents for operational staff to assist them in assuring a high level of environmental compliance and protection;

- Systems to distribute regulatory information, procedures, and guidance to all relevant personnel and operational groLiDs within DOE and contractor organizations;

- The process of creating and approving new procedures, and the existence of procedures covering major areas of risk;

- The extent to which CEBAF's procedures and standards are reviewed and revised to address environmental considerations;

- $\quad$ Contractor oversight procedures and systems, including programs for routine site inspections and compliance checks;

- Systems for recordkeeping and document control; 
- Systems to prepare environmental reports for external oversight organizations and internal management; and

- Formal systems to identify, report, investigate, and track trends and to correct identified environmental problems.

\section{2}

RECORDS REQUIRED

The assessment will include review of key documents supporting environmental programs prior to and during the site visit. Documents of particular interest include:

- Program specific and general environment, safety, and health policies, procedures, and guidance manuals;

- Environmental protection plans and environmental management plans;

- $\quad$ CEBAF Readiness Plans;

- Self-assessment plans and reports;

- Regulatory tracking protocols and procedures, and related information on file;

- Inspection checklists, logs, and procedures;

- Reports of corrective action implementation;

- Incident reports;

- Examples of other environmental records and reports; and

- Documentation and records of environmental performance. 


\section{1 ISSUE IDENTIFICATION}

The Environmental Management Assessment activities for Performance Objectives and Criteria (POC) EM.5, "Internal and External Communication," will be designed to determine whether formal and informal channels of communication are effectively used to emphasize management commitment to environmental protection; to promote awareness and support of environmental policies and programs throughout the organization; and to share information with external organizations, such as regulatory agencies, envirorimental groups, and the community. The review will focus on the modes of communicat.nn used and their effectiveness. Key issues that will be addressed include the following:

\section{Internal Communication}

- Extent, effectiveness, and timeliness of CEBAF's communication of environmentai polisies, standards, guidance, and performance to employees;

- Extent and effectiveness of routine management reporting of environmental performance and issues;

- Communication of environmental activities and best management practices between staff and line personnel, and laterally across divisions;

- Employees' awareness of their individual environmental responsibilities;

- Mechanisms for "bottom-up" communications of environmental concerns; and

- Effectiveness of communication of environmental information between the DOE oversight organizations (Oak Ridge Field Office (ORO) and DOE CEBAF Site Office) and Southeastern Universities Research Association, Inc. (SURA).

\section{External Communications}

- $\quad$ Frequent and timely formal communication of environmental risks and protection efforts to external organizations;

- Provision for external parties to be involved in key decisions related to environmental protection;

- Responsiveness to environmental concerns expressed by external parties; and

- External recognition of CEBAF's commitment to environmental protection. 
The general approach to the assessment will include interviews with CEBAF personnel responsible for implementing environmental communication programs and with staff who are the audience or "customers" for these programs. (As appropriate, interviews will also be conducted with selected external parties (regulatory agencies, environmental interest groups, and representatives of the local community)l. The assessment will also include a review of documentation supporting internal and external communication programs.

The scope of internal communication programs is interpreted widely, and is viewed as including staff meetings, memoranda, management reports, task forces, training programs, newsletters, speeches, and other relevant forms of communication. Given this wide scope, and the overlap with other assessment functional areas, communication with other assessment team members will be routine and extensive.

\subsection{RECORDS REQUIRED}

In addition to those documents reviewed prior to the assessment, the following records will be examined at CEBAF:

- Samples of relevant management reports and staff meeting minutes;

- Forms and guidelines for internal anonymous reporting of environmental issues;

- Guidance documents for interpretation and implementation of environmental regulations and policies;

- Internal memoranda or newsletters that communicate and promote environmental awareness;

- Documentation of information and awareness programs for affected external parties;

- $\quad$ Files containing letters and/or other correspondence from external stakeholders regarding any comments or suggestions about CEBAF's environmental protection efforts; and

- $\quad$ Press releases relating to environmental activities and programs. 


\subsection{STAFF RESOURCES, TRAINING, AND DEVELOPMENT}

\subsection{ISSUE IDENTIFICATION}

The Environmental Management Assessment for Performance Objectives and Criteria (POC) EM.6, "Staff Resources, Training, and Development," will involve a review and analysis of CEBAF operations to verify that staff resources are sufficient to develop and implement environmental protection programs; that all personnel have received environmental protection training commensurate with their job responsibilities; and that professional development opportunities for environmental staff are equal to those of their peers in non-environmental positions. Specifically, the assessment will verify the following:

- Quantity of staff is sufficient to ensure environmental goals are met.

- $\quad$ Staffing levels today are adequate for achieving CEBAF's environmental performance goals.

- $\quad$ Planned staffing levels for when CEBAF becomes operational are adequate for achieving its environmental protection goals.

- There is a system for identifying CEBAF's short- and long-term staffing requirements.

- $\quad$ Staffing support for environmental protection activities is provided in a timely and responsive manner.

- Qualifications of staff are sufficient to ensure environmental goals are met.

- The environmental support staff's education, training, and experience are adequate to effectively conduct their assigned duties.

- $\quad$ Appropriate job qualifications are established and maintained for environmental positions.

- Environmental responsibilities are built into job descriptions of key line management and staff positions.

- Measurement of job performance for environmental positions is appropriate.

Environmental protection factors are included in performance evaluation standards.

- Superior work in the environmental field is rewarded.

- $\quad$ Poor performance is disciplined. 
- Training programs are in effect to ensure all staff obtain the environmental training necessary for their positions.

- There is a process to evaluate and establish environmental training needs.

- There is a mechanism to ensure training programs provide adequate coverage of DOE Orders, Federal, and state regulations, and internal policies and procedures.

- There is a sistem to ensure that all employees, including new employees and contractors, receive the training deemed appropriate.

- Records of environmental training are maintained in a satisfactory recordkeeping system.

- The training program is evaluated for effectiveness on a periodic basis.

- Envirnnmental staff are provided career opportunities and advancement, and are encouraged to develop supervisory and other professional skills.

The general approach to the assessment will include interviews with the DOE CEBAF Site Office and Southeastern Universities Research Association, linc. (SURA) personnel regarding staff resources, training, and development, as well as a review of relevant and available dccumentation.

\section{2}

RECORDS REQUIRE?

In addition to documents reviewed prior to the onsite assessment, documents to be examined at CEBAF may include the following:

- Documented requests for environmental staff;

- A sample of resumes or "171" forms for selected environmental staff and other staff with scme environmental responsibilities;

- Pertormance evaluation standards for both environmental and non-environmental personnel:

- Documentation of training courses;

- Training history and educational records for a sample of environmental staff and line managers; and

- $\quad$ Presentation materials for environmental protection training programs. 


\subsection{PROGRAM EVALUATION, REPORTING, AND CORRECTIVE ACTION \\ 9.1 ISSUE IDENTIFICATION}

The assessment activities for Performance Objectives and Criteria (POC) EM.7, "Program Evaluation, Reporting, and Corrective Action," will assess vithet the organization has self-assassment and oversight programs in place to effectively evaluate environmental protection activities, report environmental concerns, implement corrective actions, and progressively improve environmental management activities. The two key elements of the review are the following:

- Design of self-assessment and appraisal programs, including their objectives, scope, coverage, frequency, and assignment of responsibilities; and

- Followup from the assessments/appraisals, including reporting to management, corrective action planning, tracking, and implementation, performance trending and analysis, and continuous improvement actions based on lessons learned.

The general approach to assessing this performance objective will include interviews with staff who are responsible for environmental oversight and interviews with line management who are responsible for self-assessment. The assessment team will also review other relevant documentation not previously provided in the pre-assessment documents. Based on the review of pre-assessment information, the following issues will be further evaluated during the assessment:

- $\quad$ CEBAF's understanding of all program evaluation mechanisms, including self-assessments, audits, and appraisals;

- Scope and approach of self-assessments and appraisals;

- $\quad$ Adequacy of CEBAF's self-assessments in meeting the intent of DOE self-assessment policy and guidance;

- Cov : age of all activities with potential environmental impacts and the depth and frequency of the reviews;

- Assignment of responsibilities for self-assessments/appraisals and qualifications/training of those conducting the assessments;

- Distribution of assessment findings and reports to appropriate managers;

- System for setting priorities for corrective actions;

- Systems for tracking and ensuring completion of corrective actions;

- Existence of "lessons learned" initiatives or programs; 
- Assessment of late/incomplete corrective actions; and

- Identification of performance indicators.

\subsection{RECORDS REQUIRED}

The following documents will be reviewed as part of this component of the assessment:

- All self-assessment/appraisal reports;

- Reports for audits conducted by external organizations;

- $\quad$ Corrective action plans;

- Documentation of corrective action tracking system;

- List of and reports showing environmental performance indicators;

- Trending or lessons learned documentation; and

- Documentation of the qualifications/training of staff responsible for conducting environmental oversight activities. 
The Environmental Management Assessment activities for Performance Objectives and Criteria (POC) EM.8, "Environmental Planning and Risk Management," will include evaluating the effectiveness of project-wide environmental planning activities. The scope of the planning portion of the assessment will include environmental activities as well as more standard business planning activities, such as budgeting, priority setting, and allocation of resources. Short- and long-term planning will be addressed. In addition to planning, this portion of the assessment will evaluate the adequacy of systems designed to identify environmental hazards and to minimize and control environmental risks.

The general approach to the assessment will include interviews with the DOE CEBAF Site Office and Southeastern Universities Research Association, Inc. (SURA) personnel responsible for environmental planning and risk management, and a review of documentation supporting this area. Areas of particular interest will include the following:

\section{Environmental Planning}

- Technical and financial planning relating to environmental management and the extent to which such planning is conducted and integrated with overall organizational planning (including mechanisms for resource allocation and priority setting, and the extent to which actual resource allocation is consistent with environmental objectives);

- The adequacy of funding for environmental protection activities;

- The relative priority that environmental issues are given with respect to production in the planning and budgeting process;

- The organization's system for staying current with emerging environmental issues; and

- The adequacy of pollution control technologies and other equipment and services for supporting environrnental protection activities at CEBAF.

\section{Risk Management}

- $\quad$ Risk management program design and approach, including program scope and coverage, assignment of responsibilities to appropriate staff, procedural documentation, and the specific mechanisms for identifying hazards and associated risks, assessing the acceptability of identified risks, and implementing risk mitigation actions; and

- The existence and adequacy of a formal project/program review process which includes environmental considerations. 
The assessment will include review of key documents relating to environmental risk management and planning. Documents of particular interest include:

- Descriptions (if available) of budgeting mechanisms at CEBAF;

- Short- and/or long-term business plans;

- $\quad$ Latest budget requests from all organizational units of CEBAF, specifying purposes for all planned expenditures, and approved budgets for the same; and

- Descriptions of risk managernent programs and reports of risk assessments. 
This page intentionally left blank. 


\section{APPENDIX C}

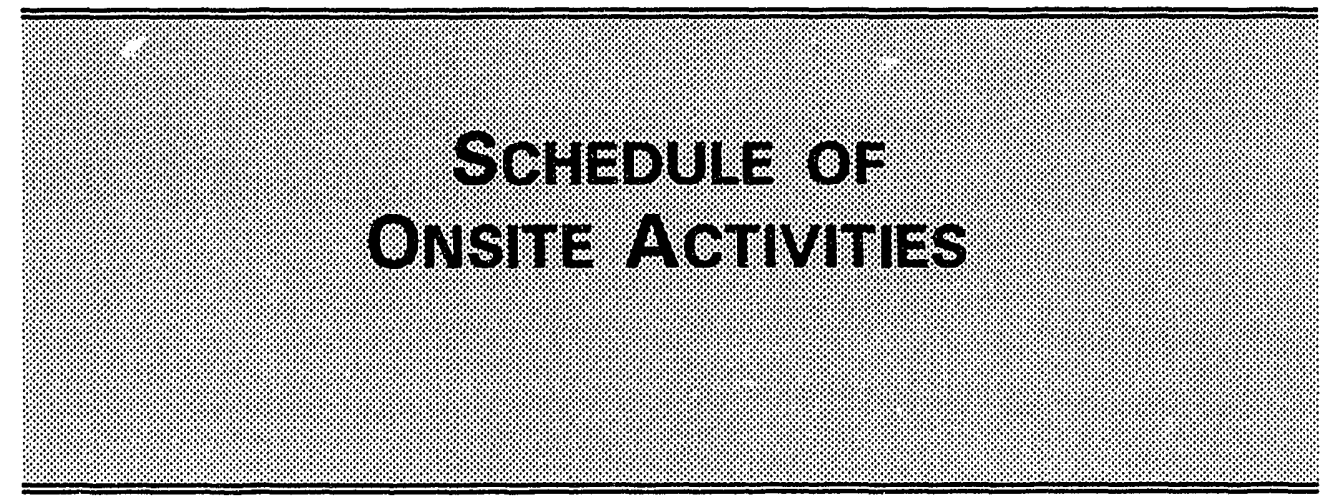


This page intentionally left blank. 


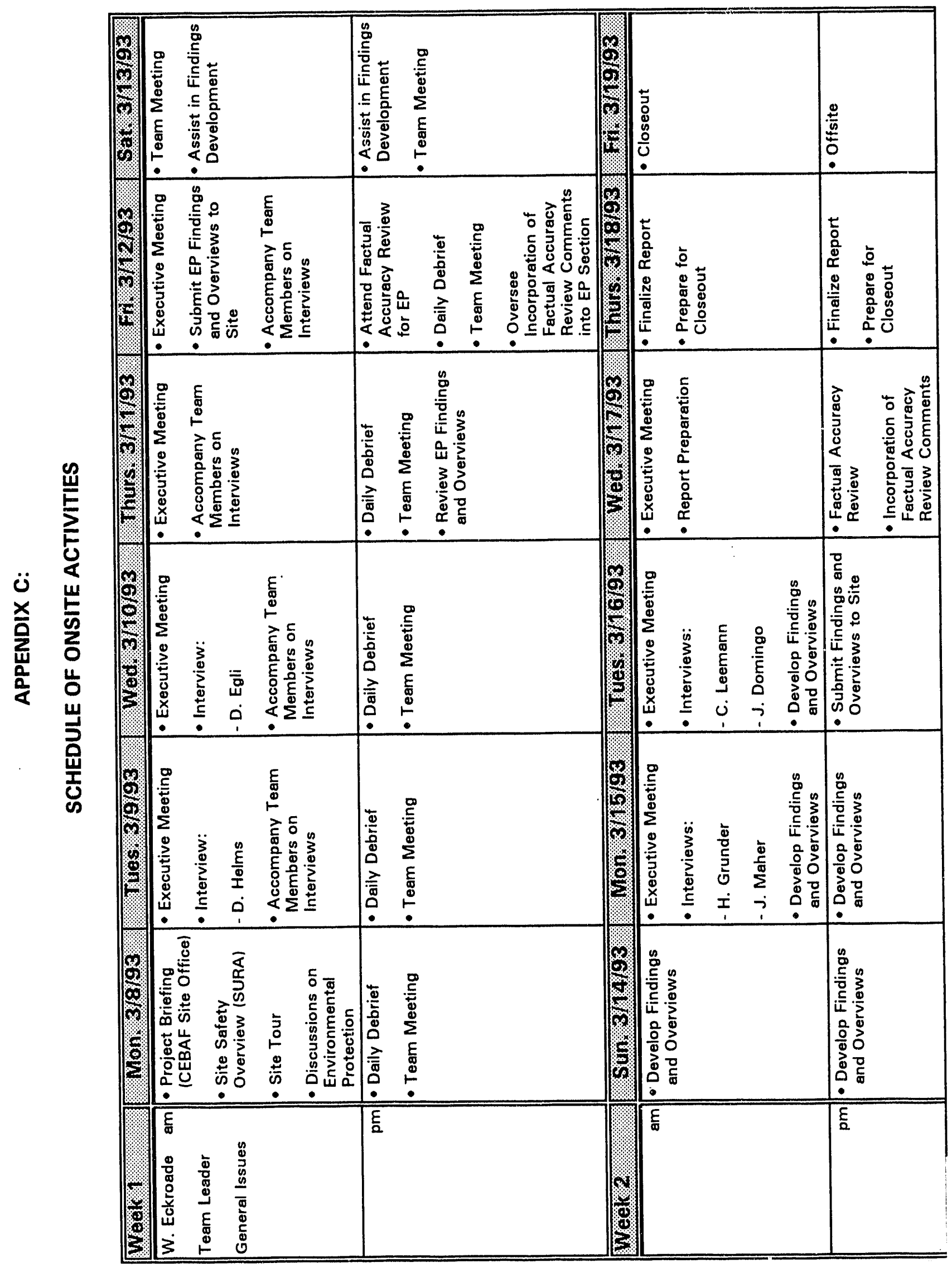

C-1 


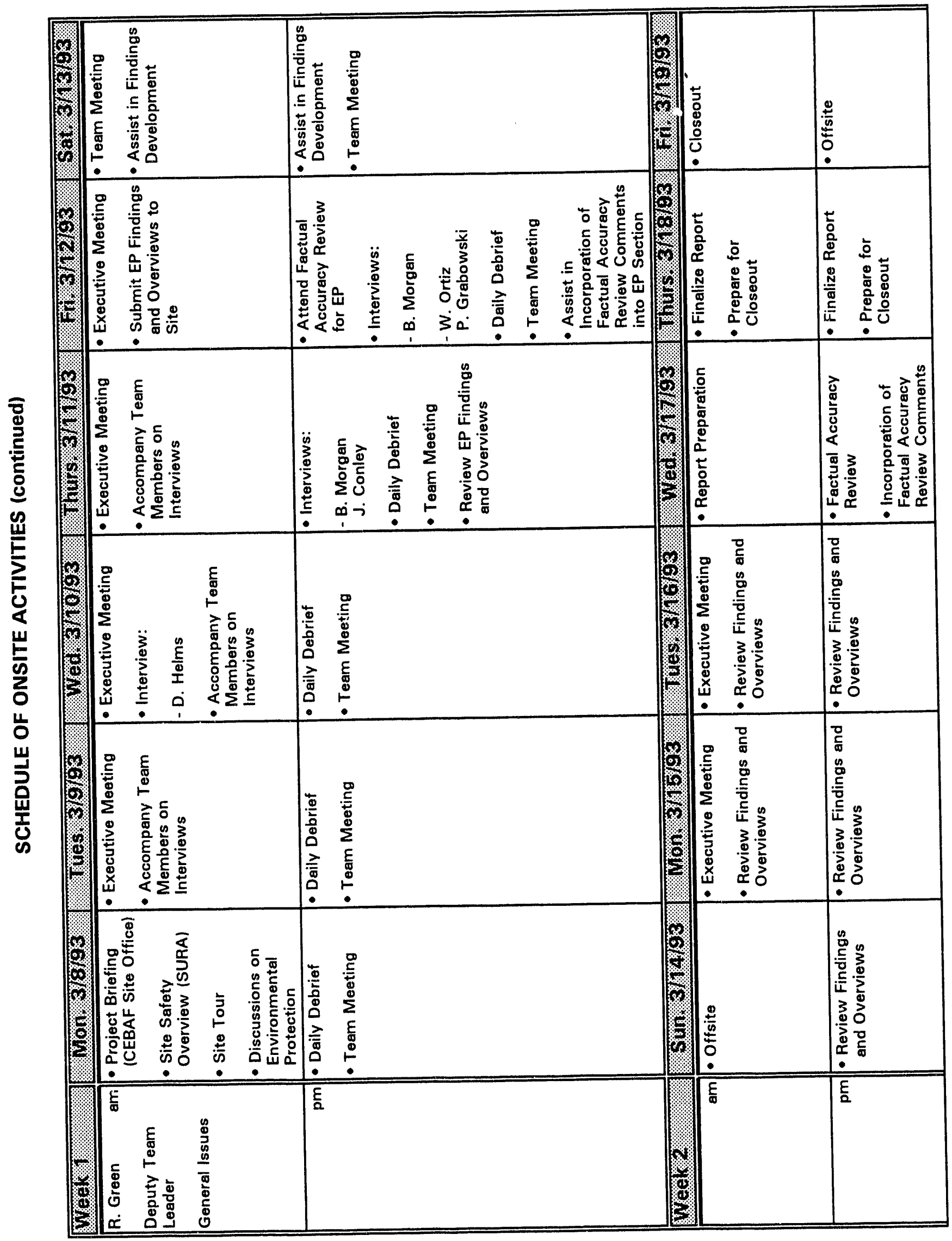




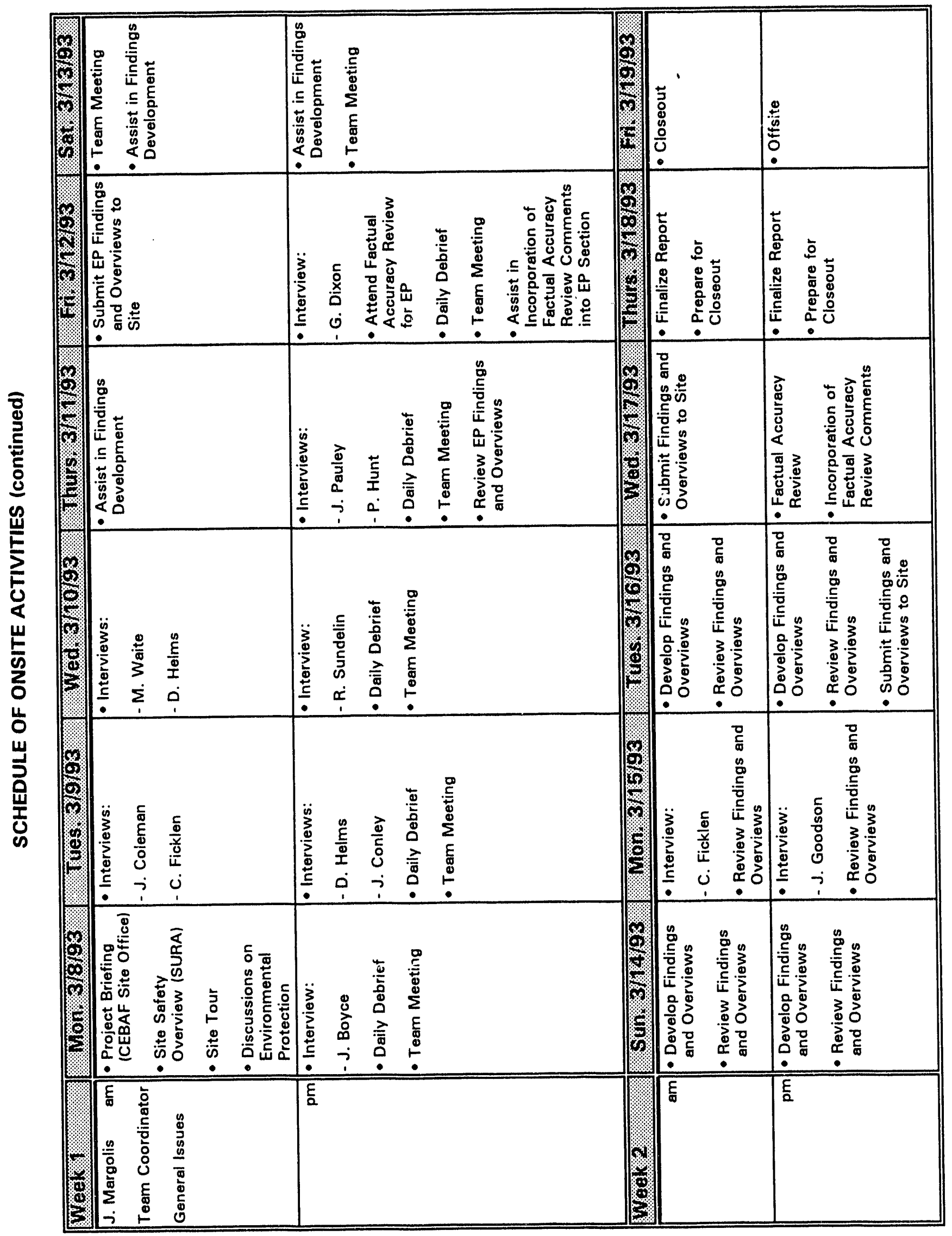




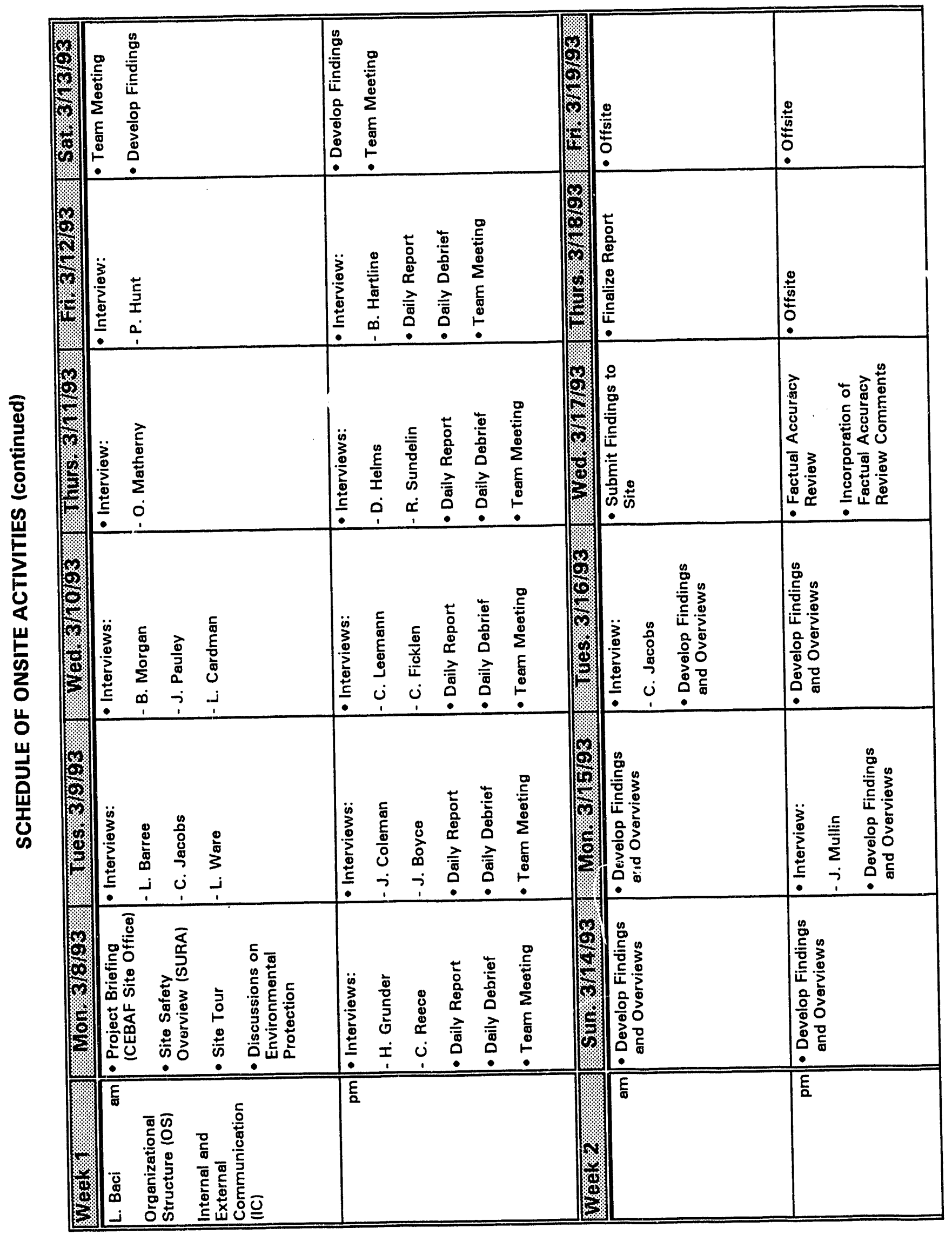




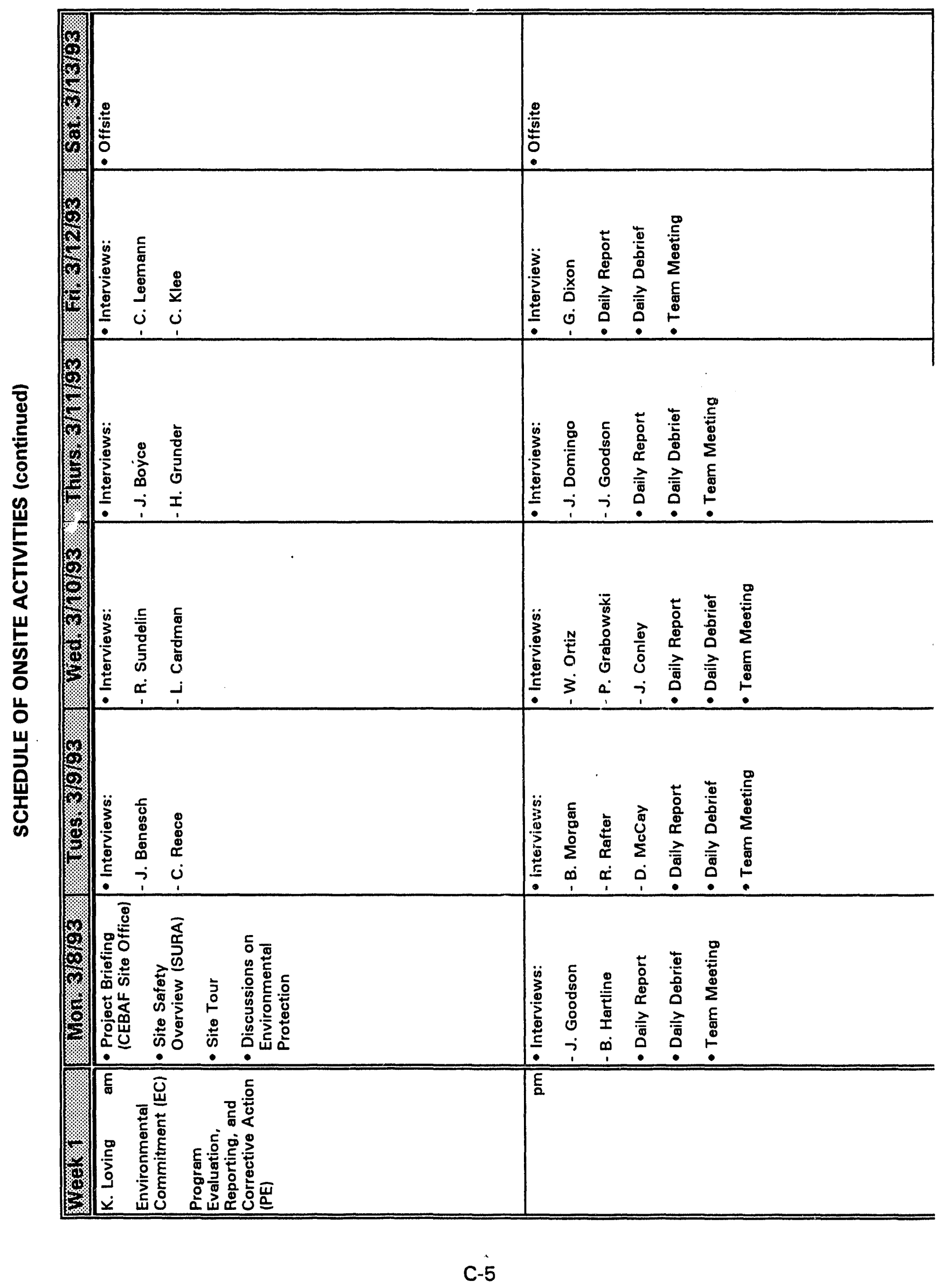




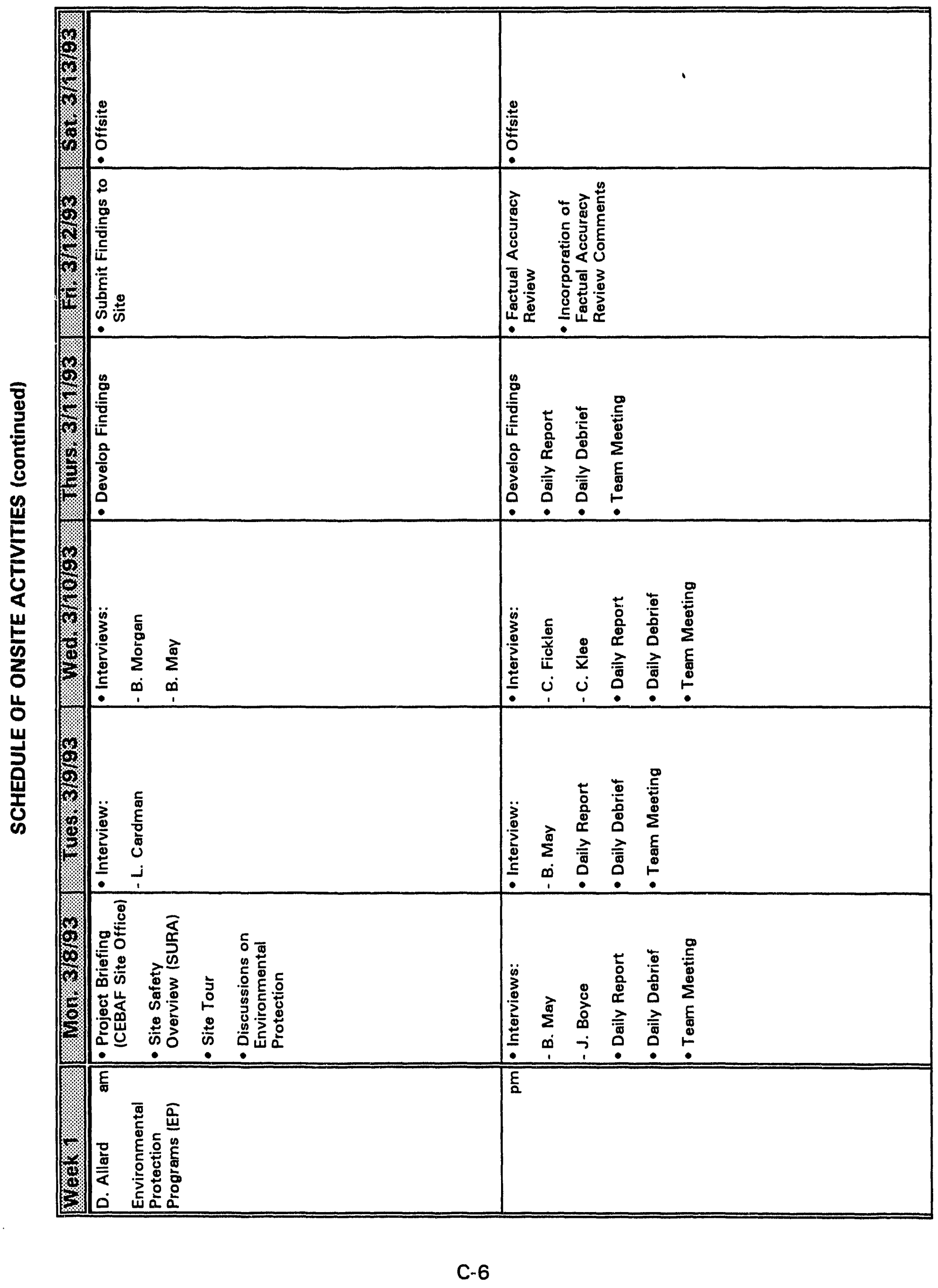




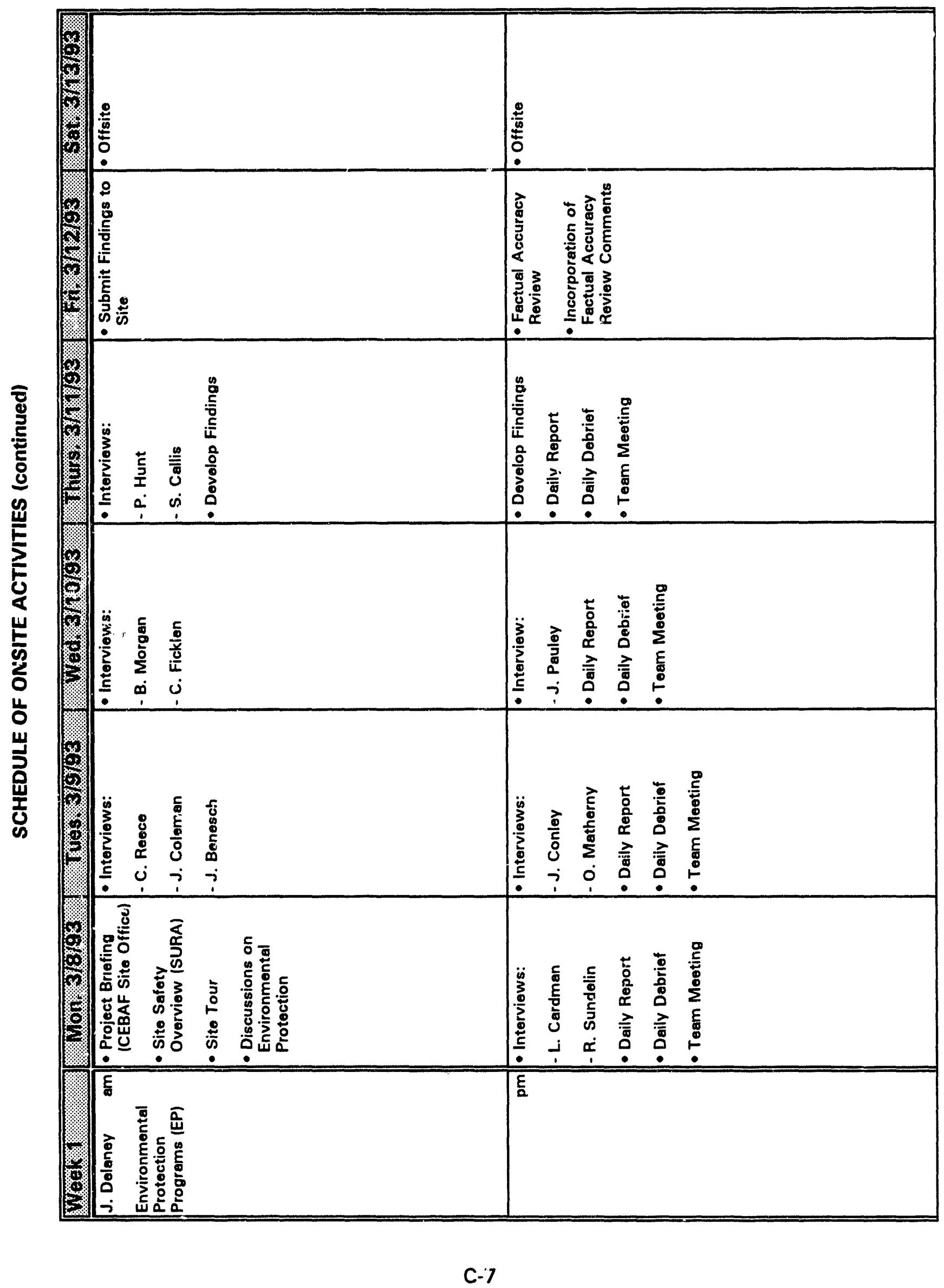




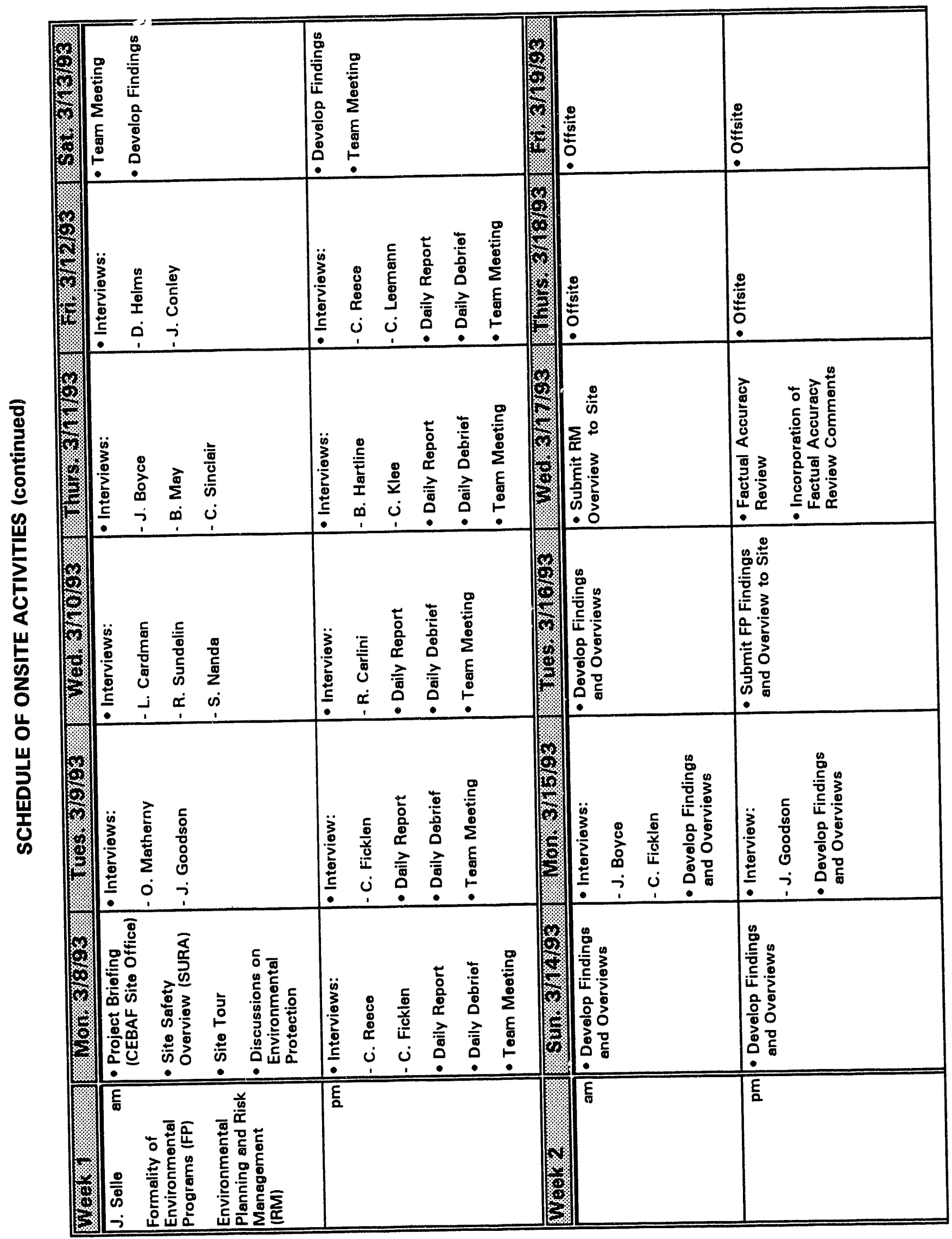




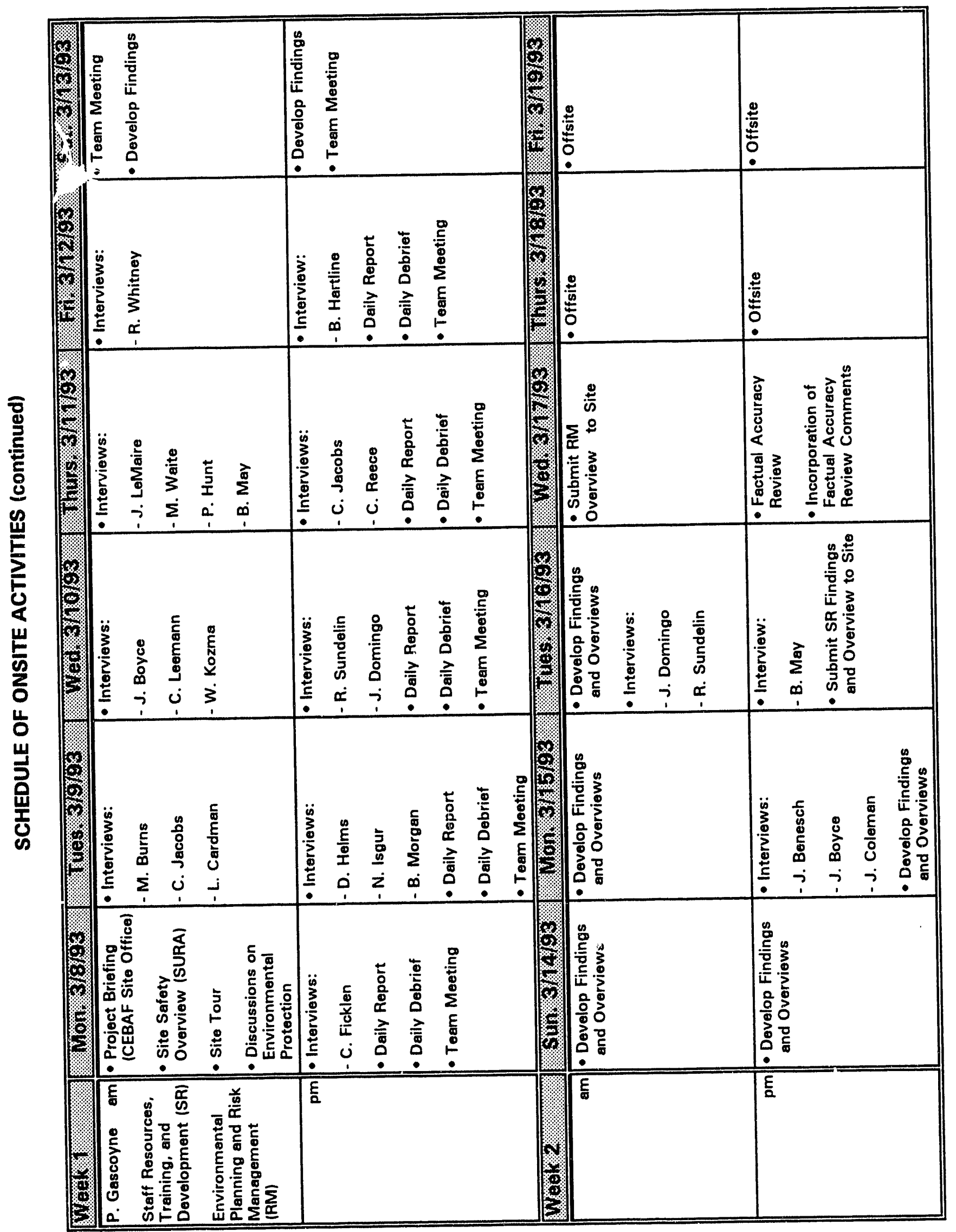


This page intentionally left blank.

C-10 


\section{APPENDIX D}

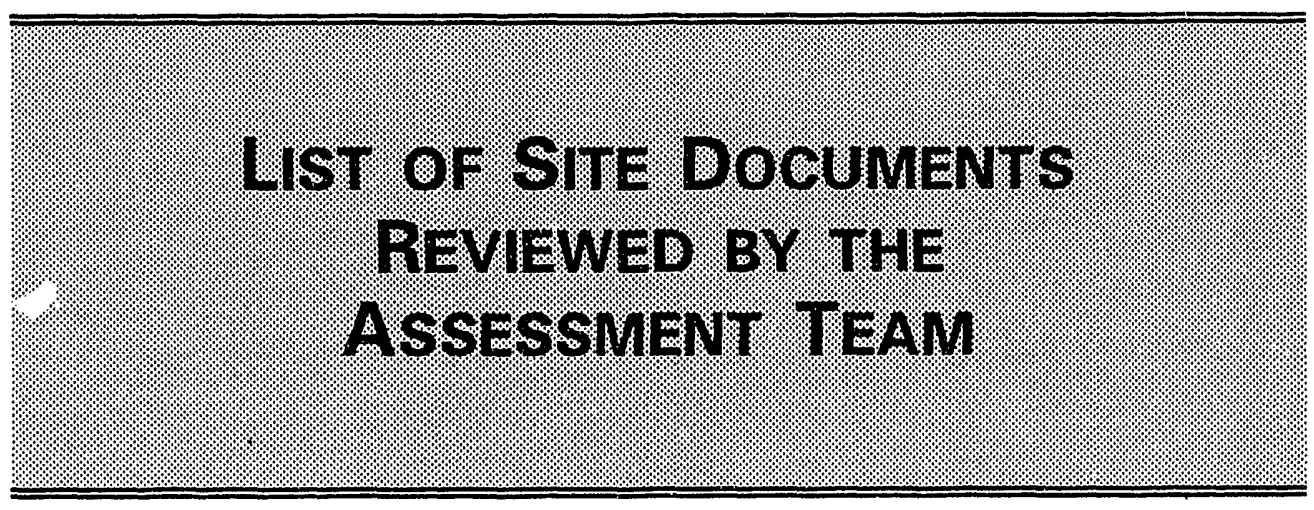


This page intentionally left blank. 


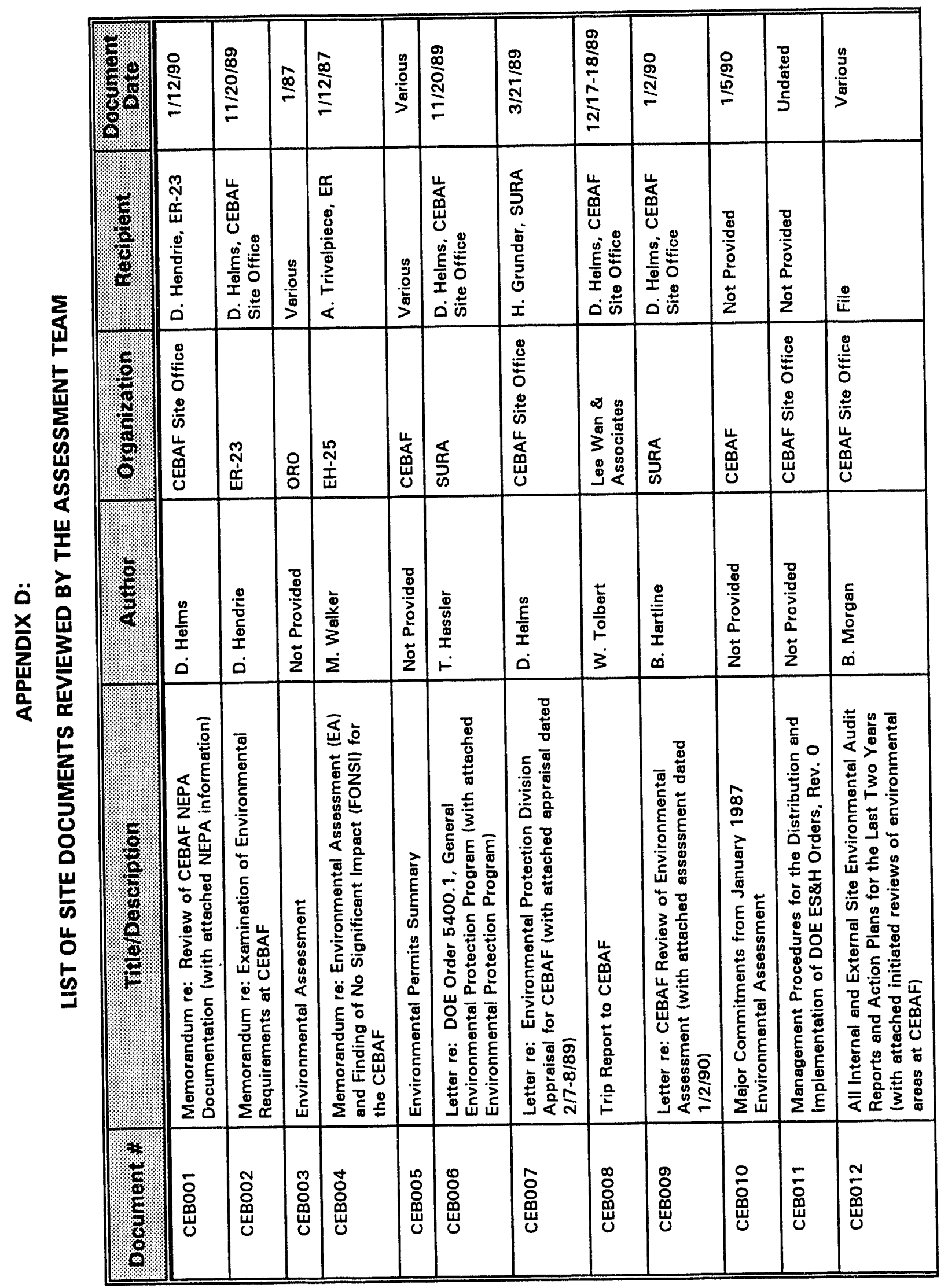




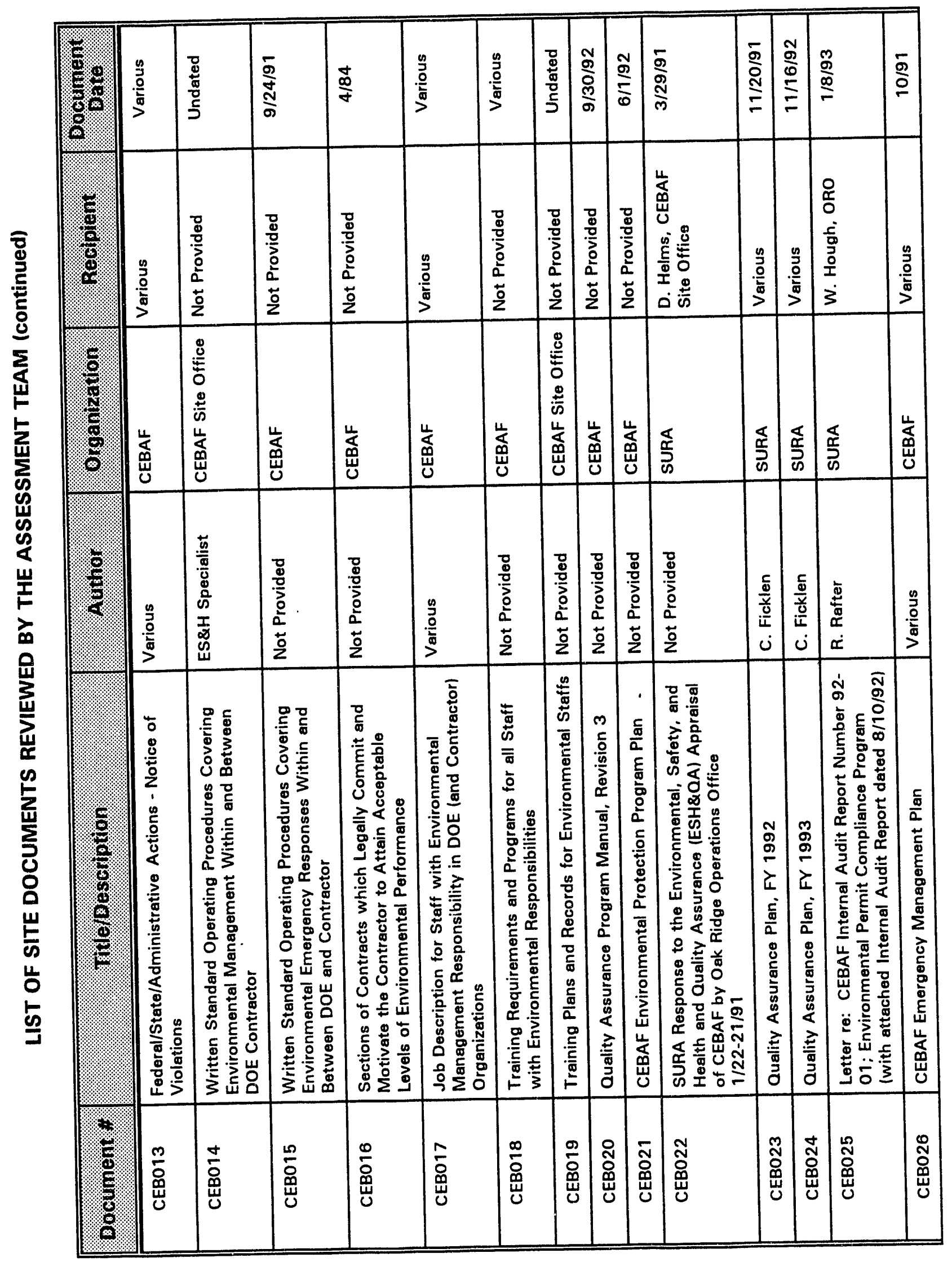




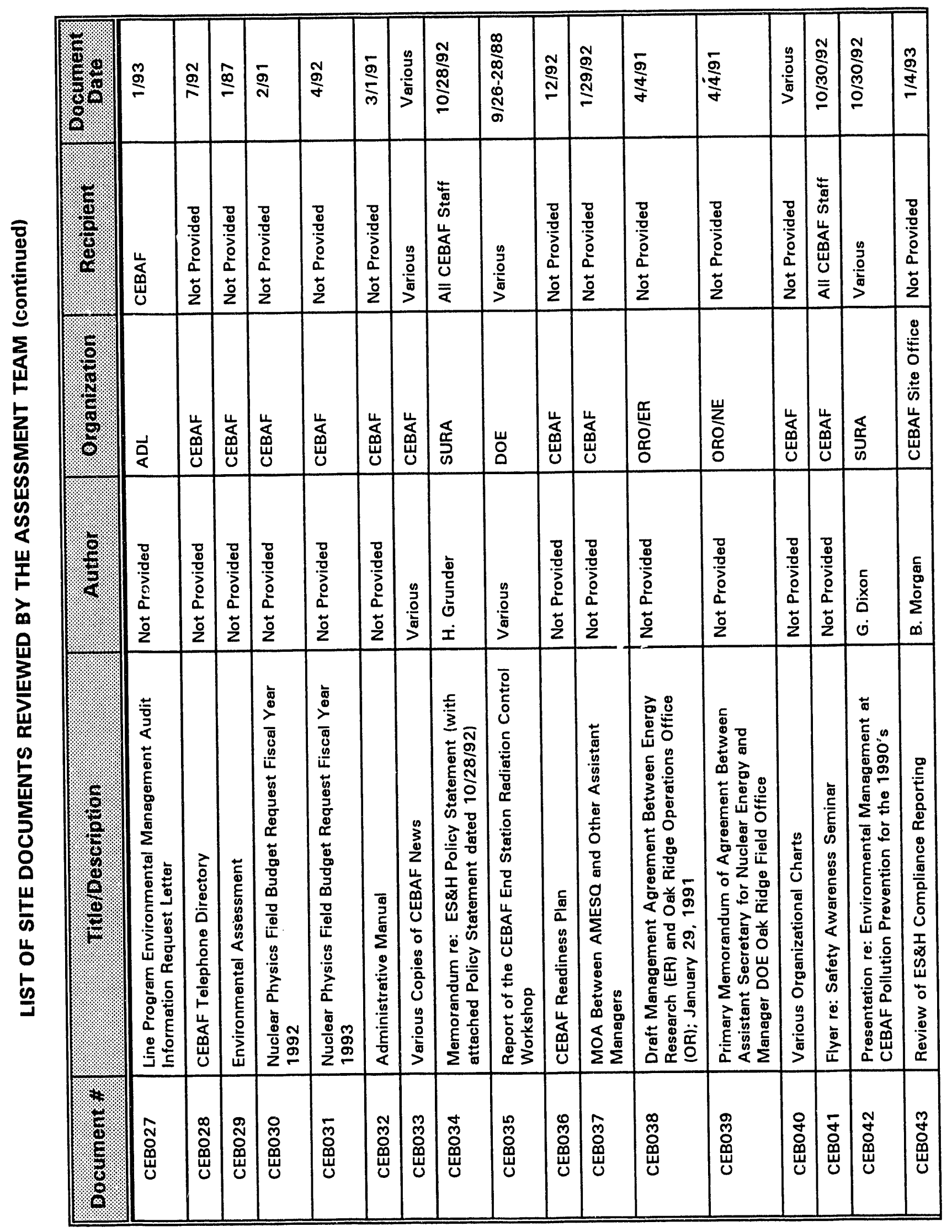




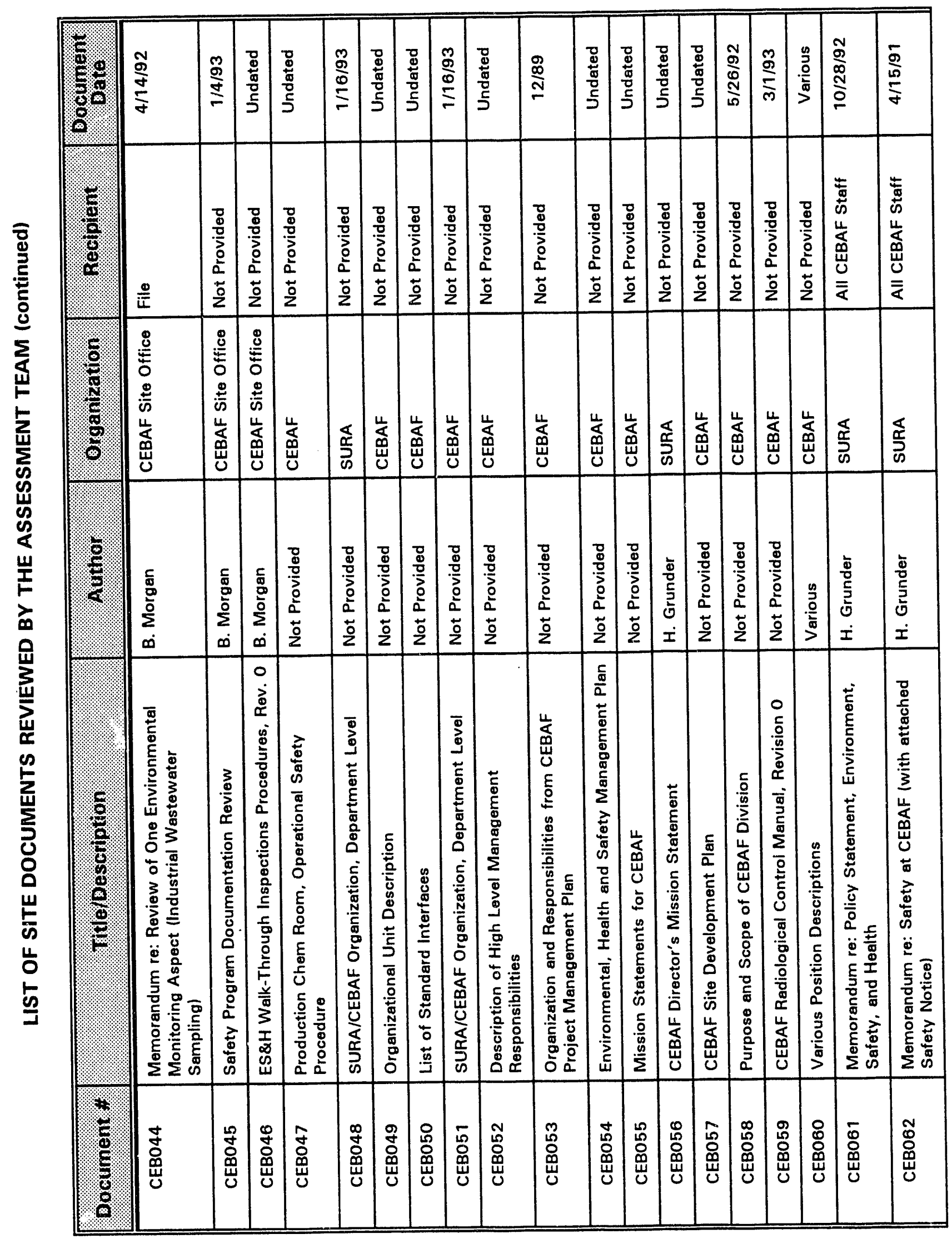




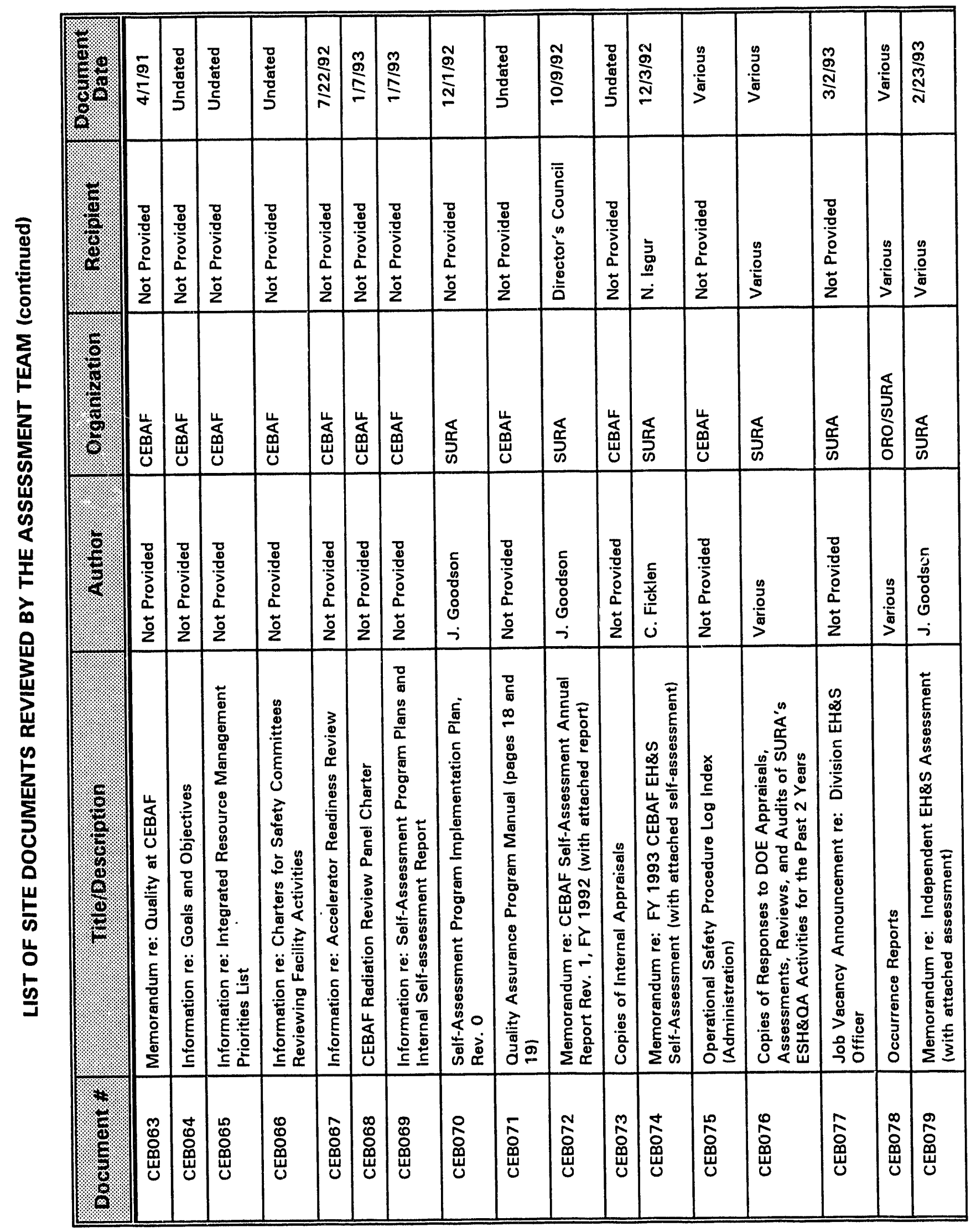




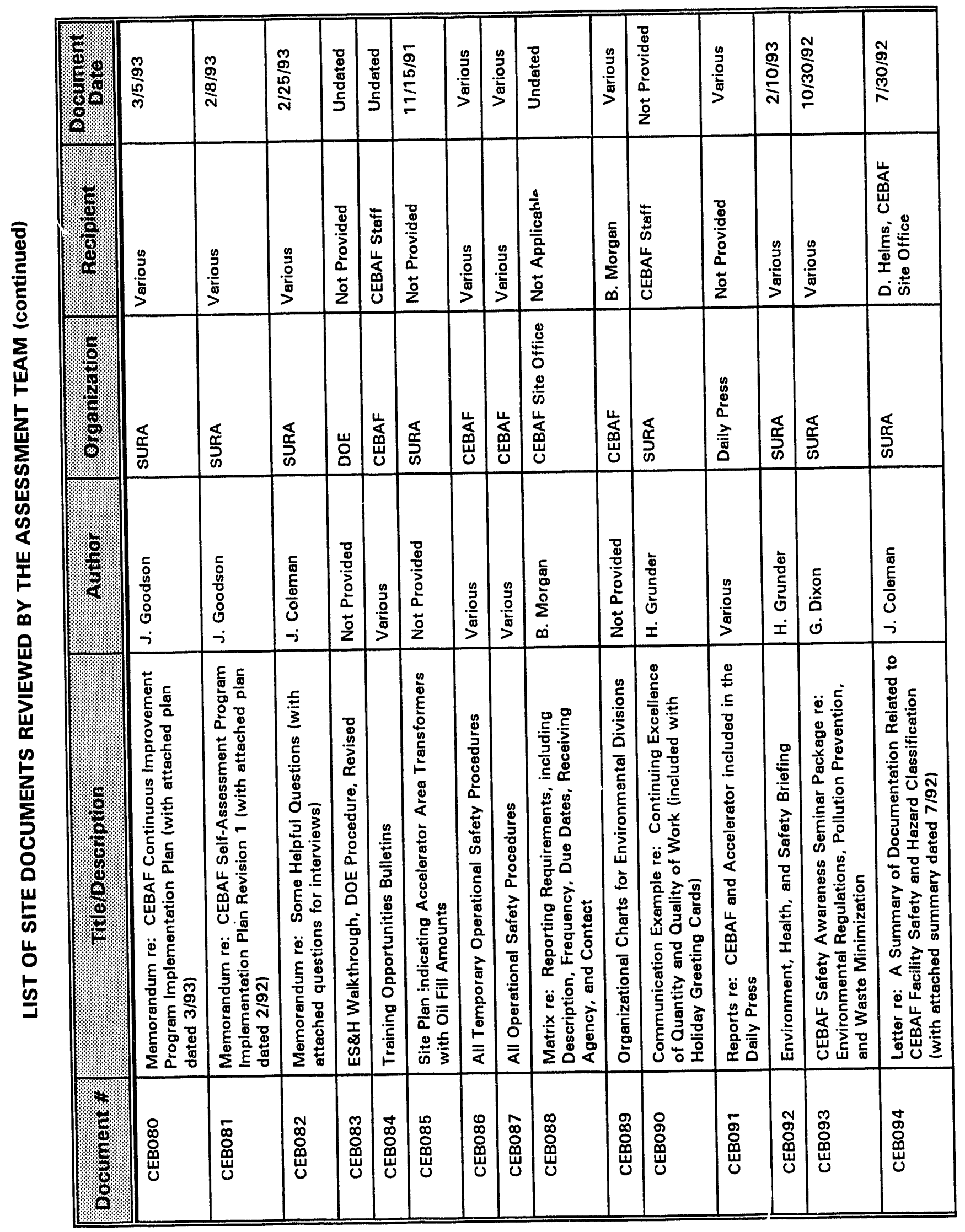




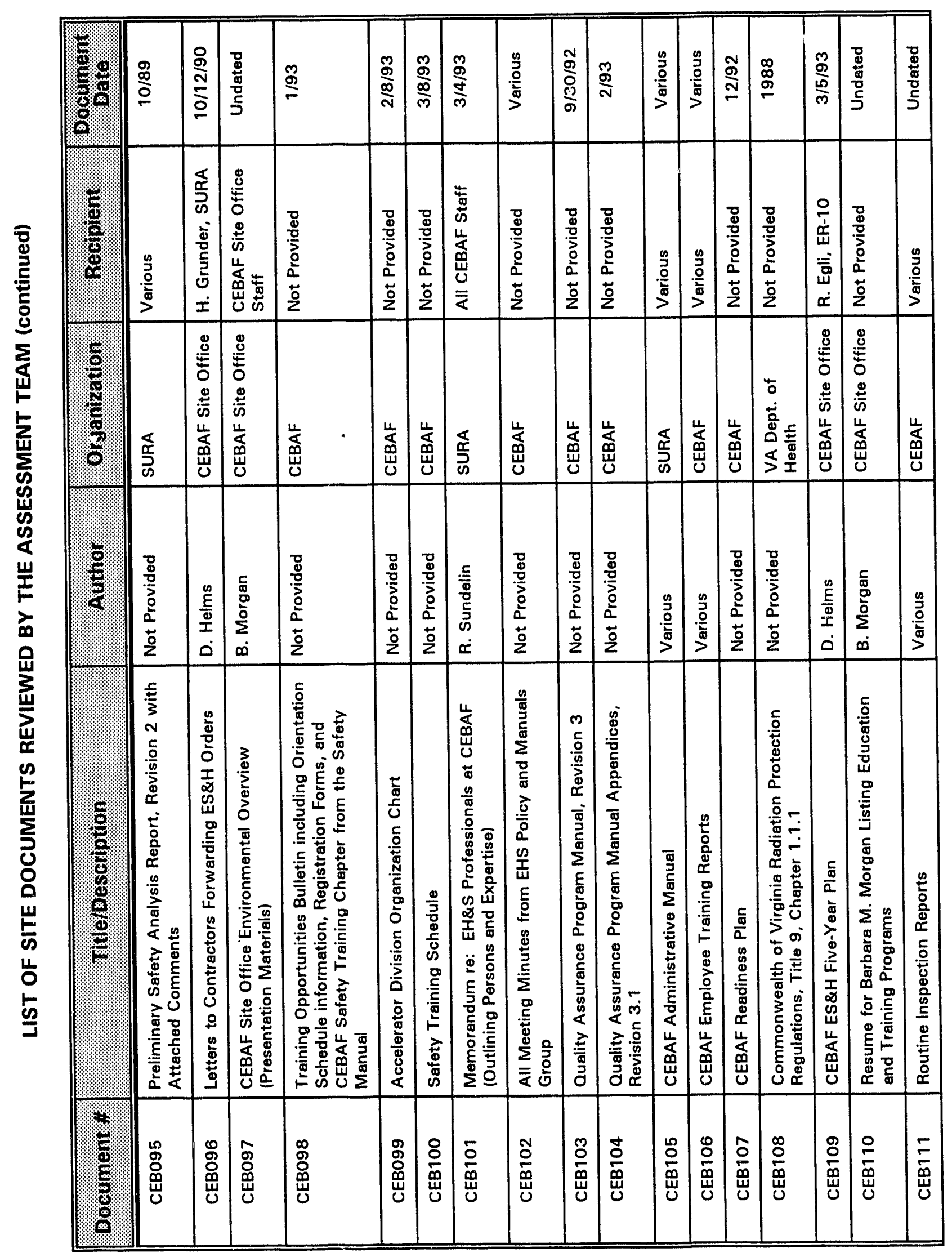




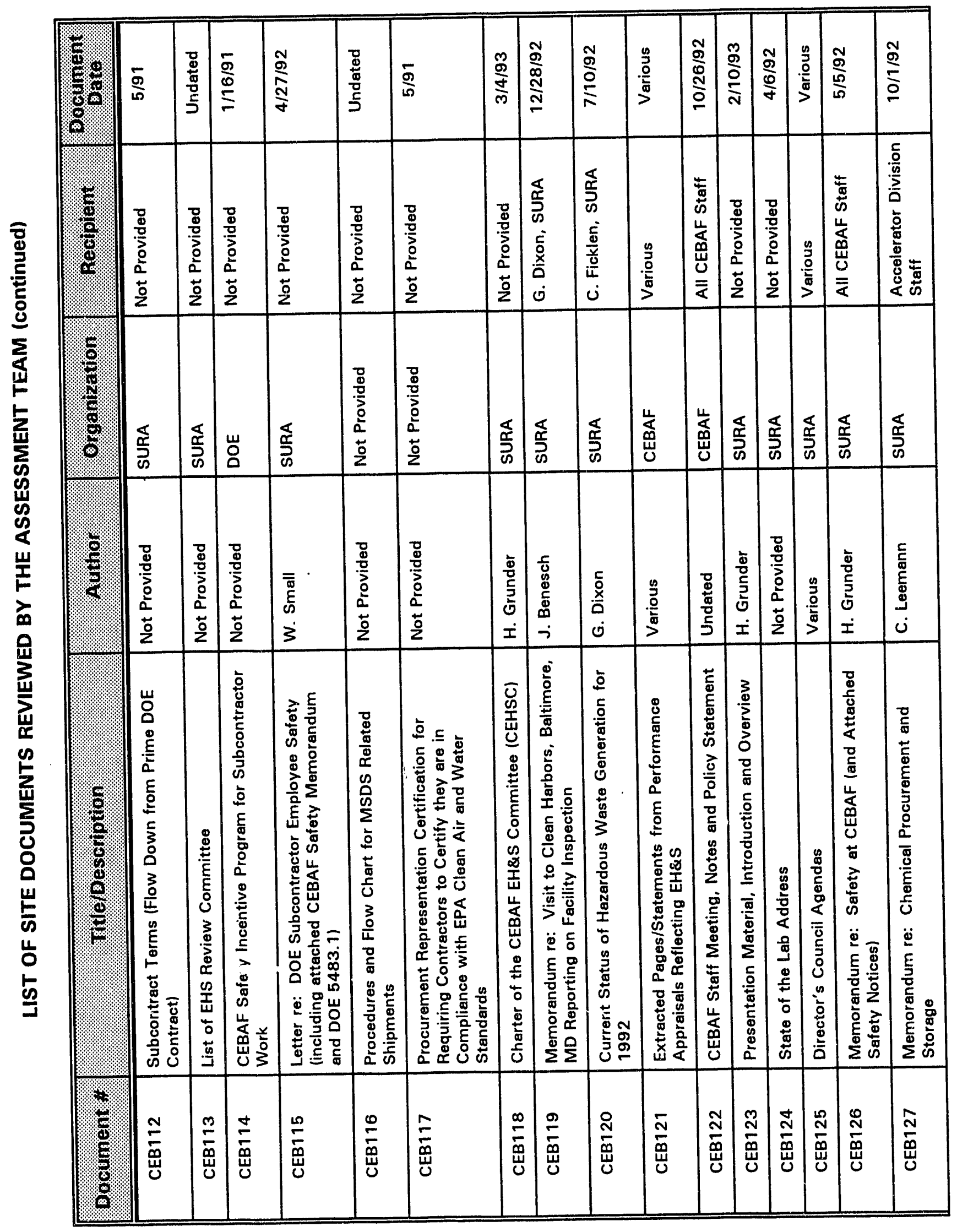




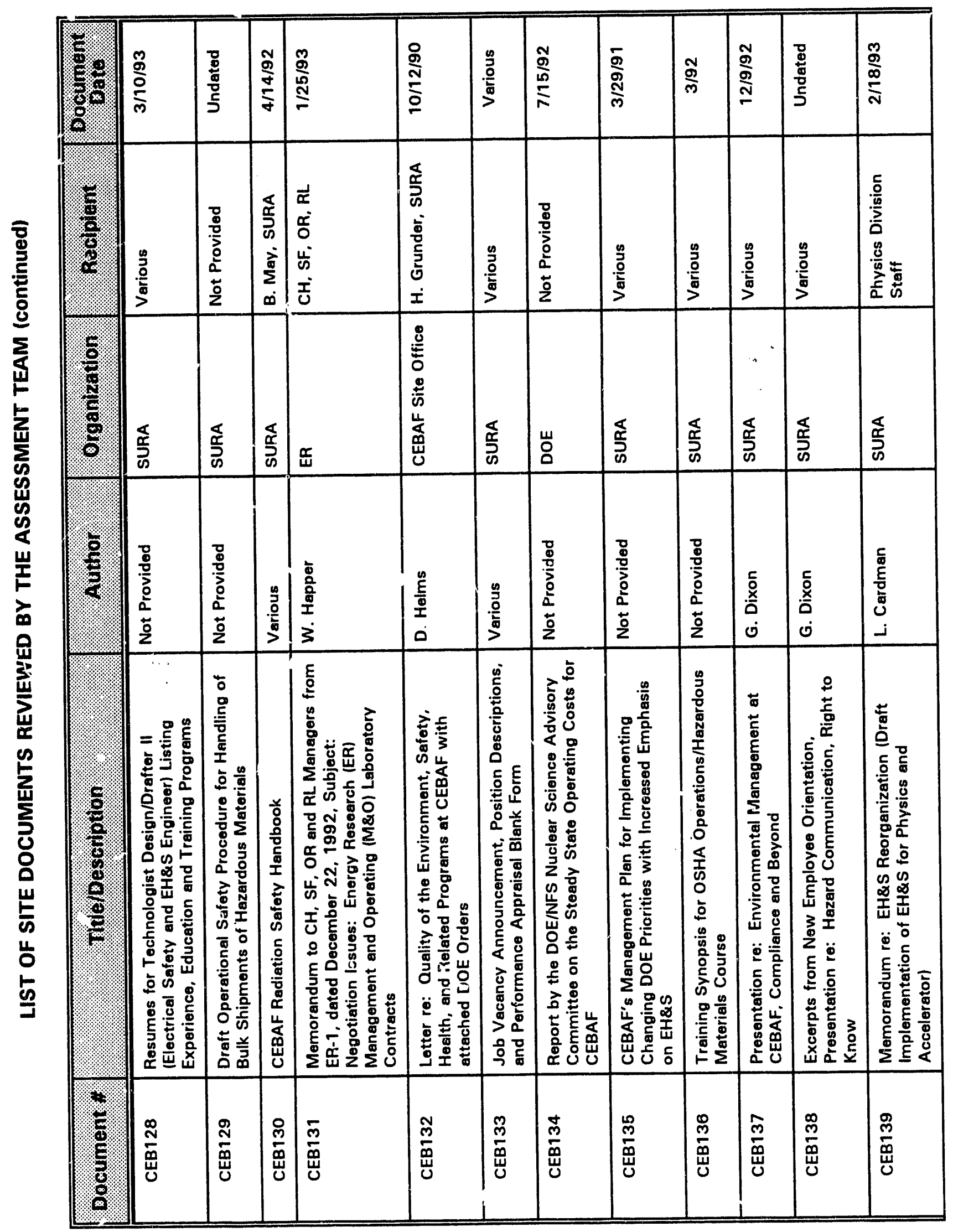




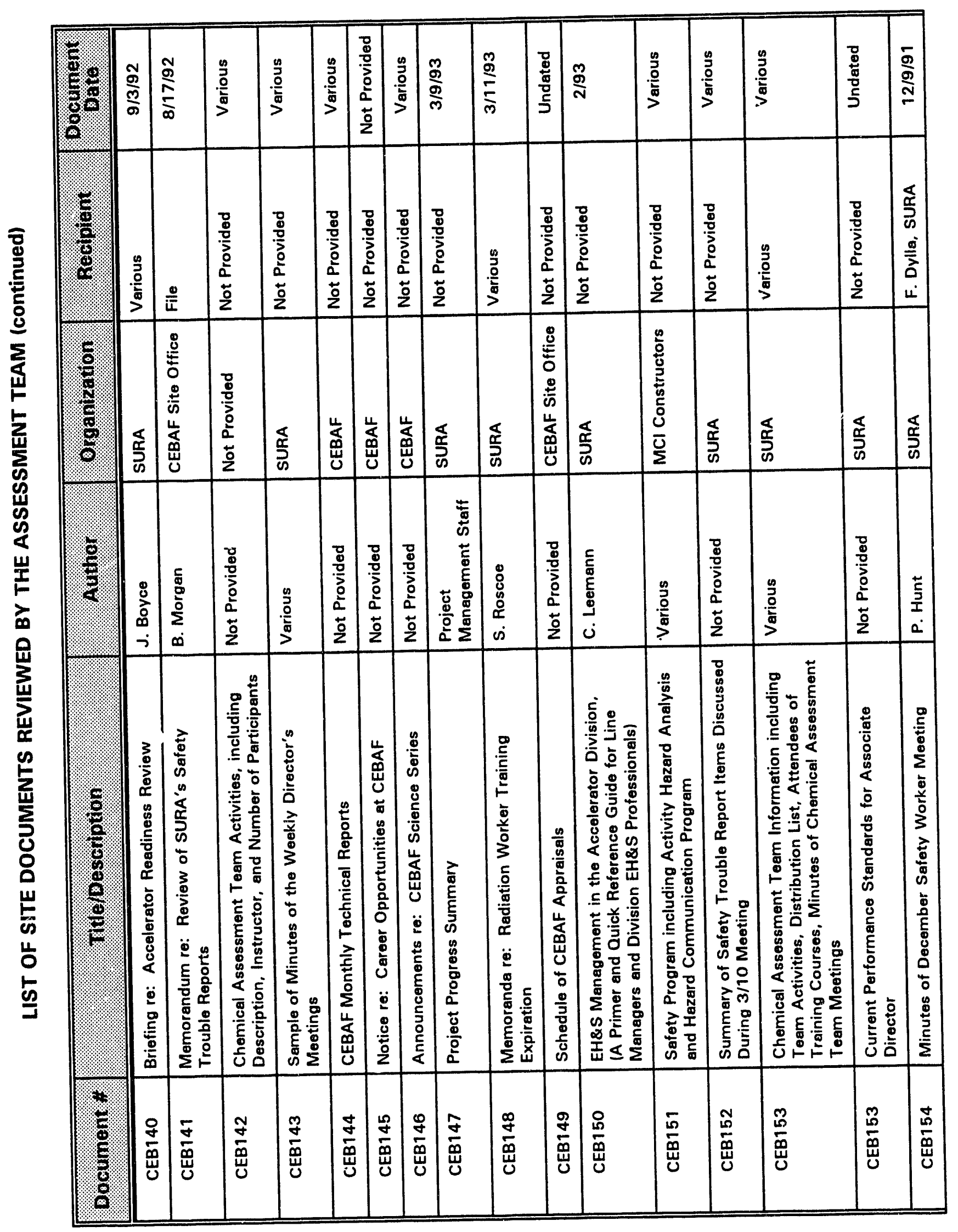




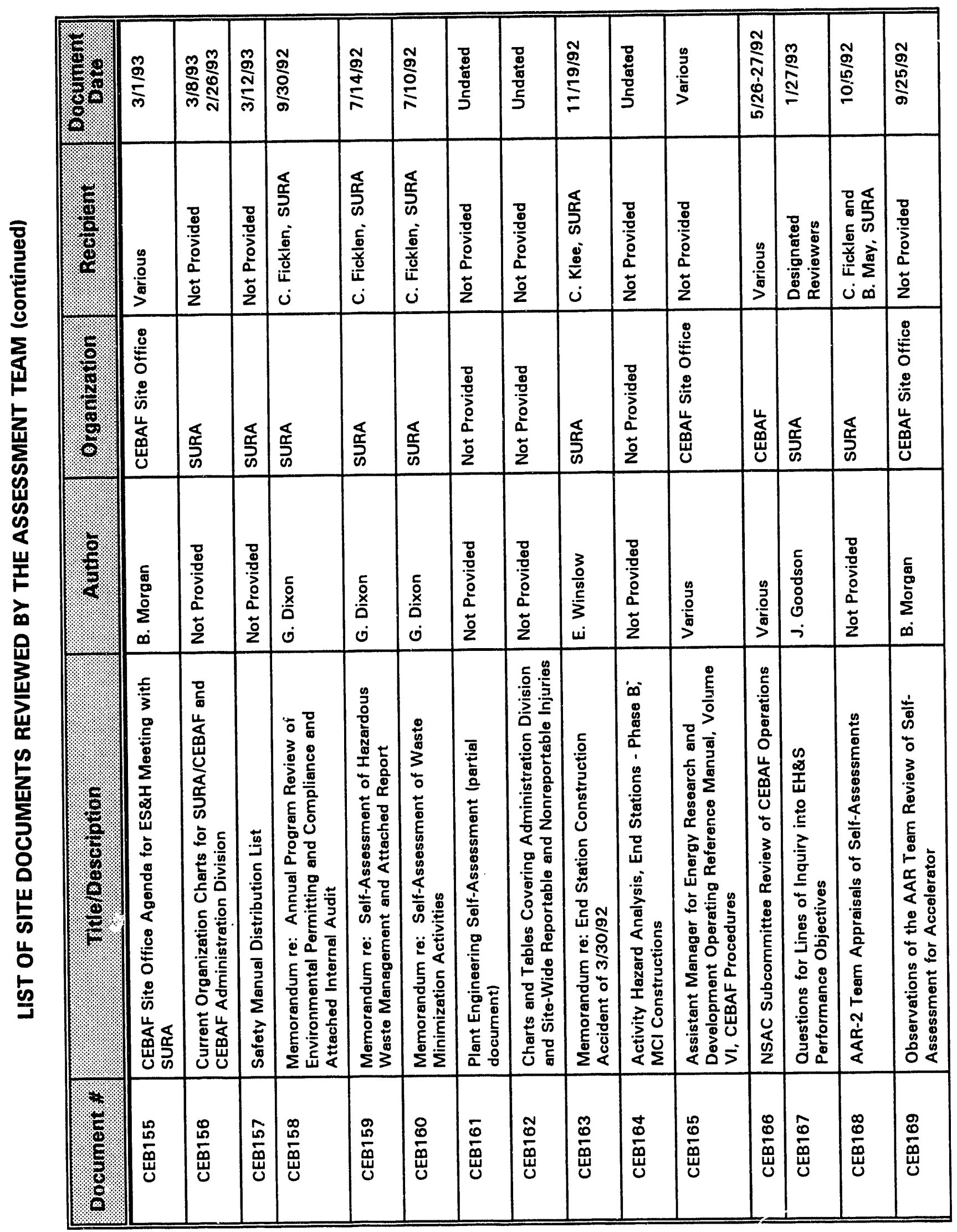




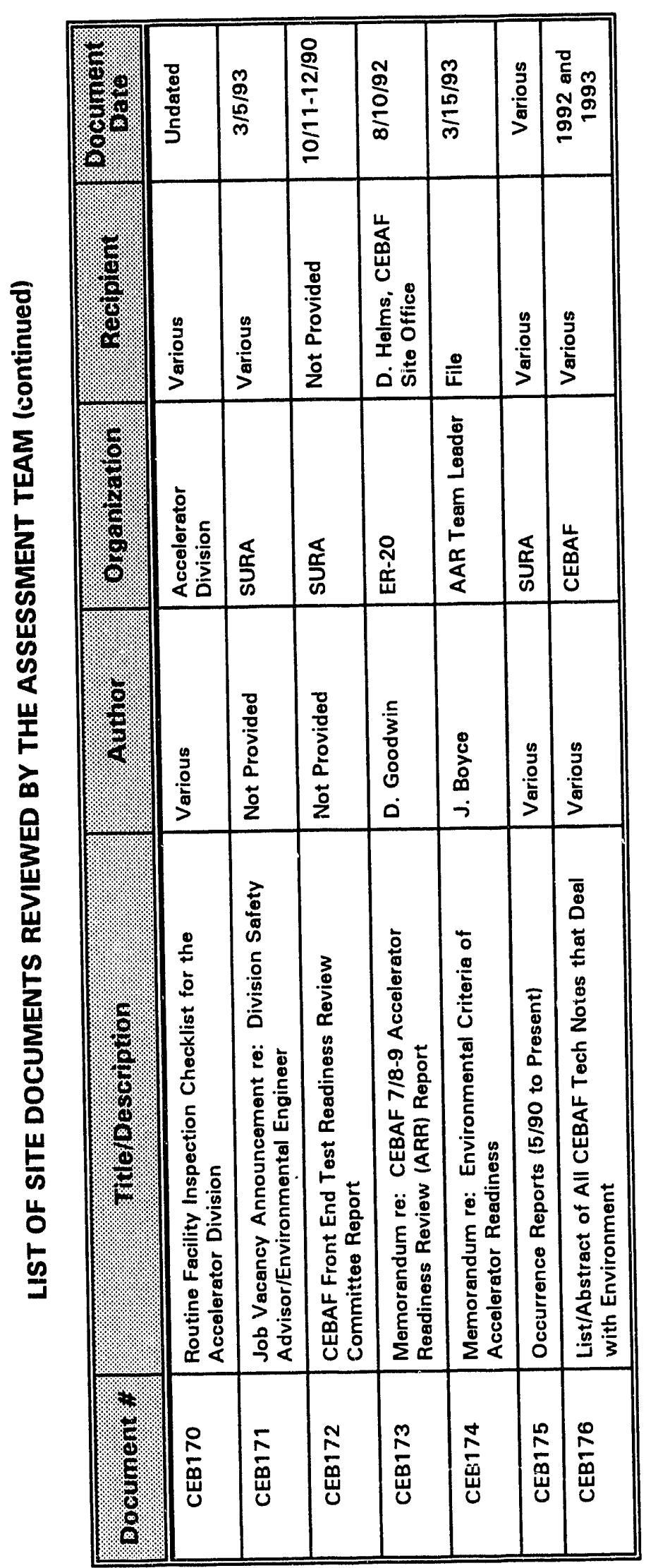

D-12 


\section{APPENDIX E}

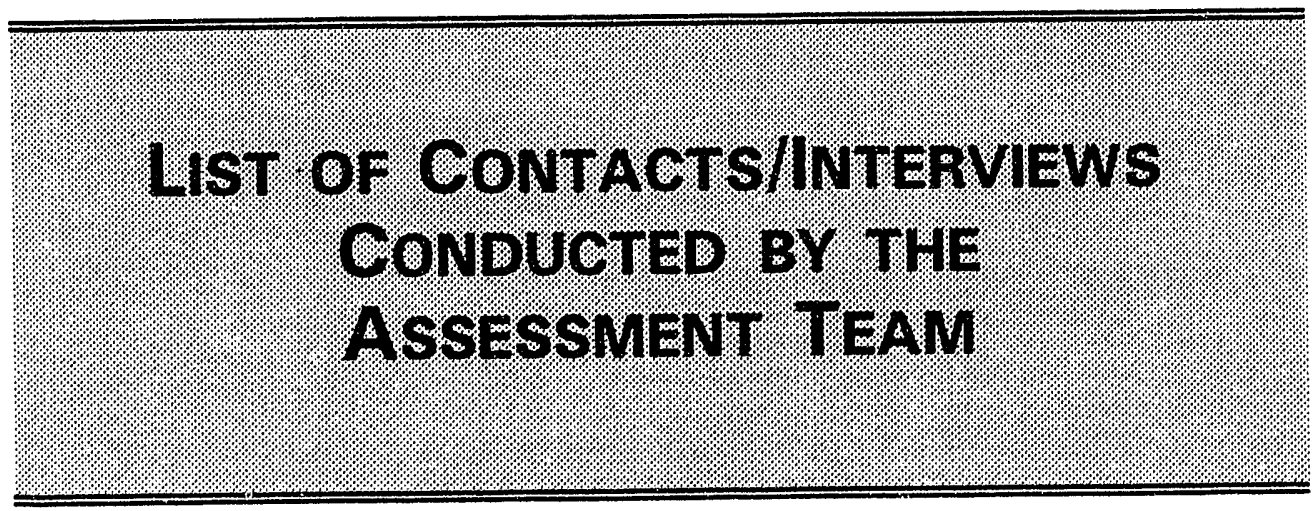


This page intentionally left blank. 


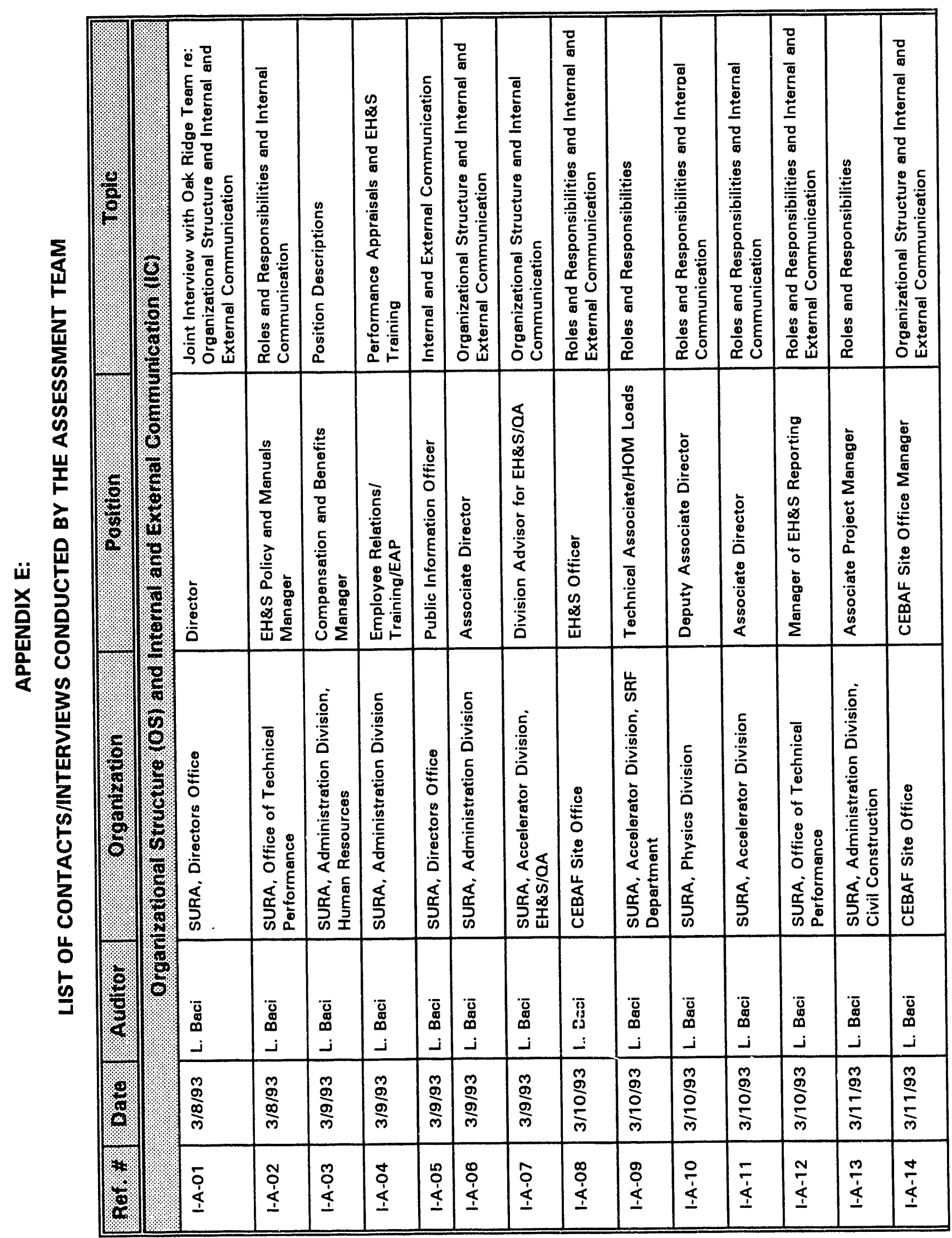




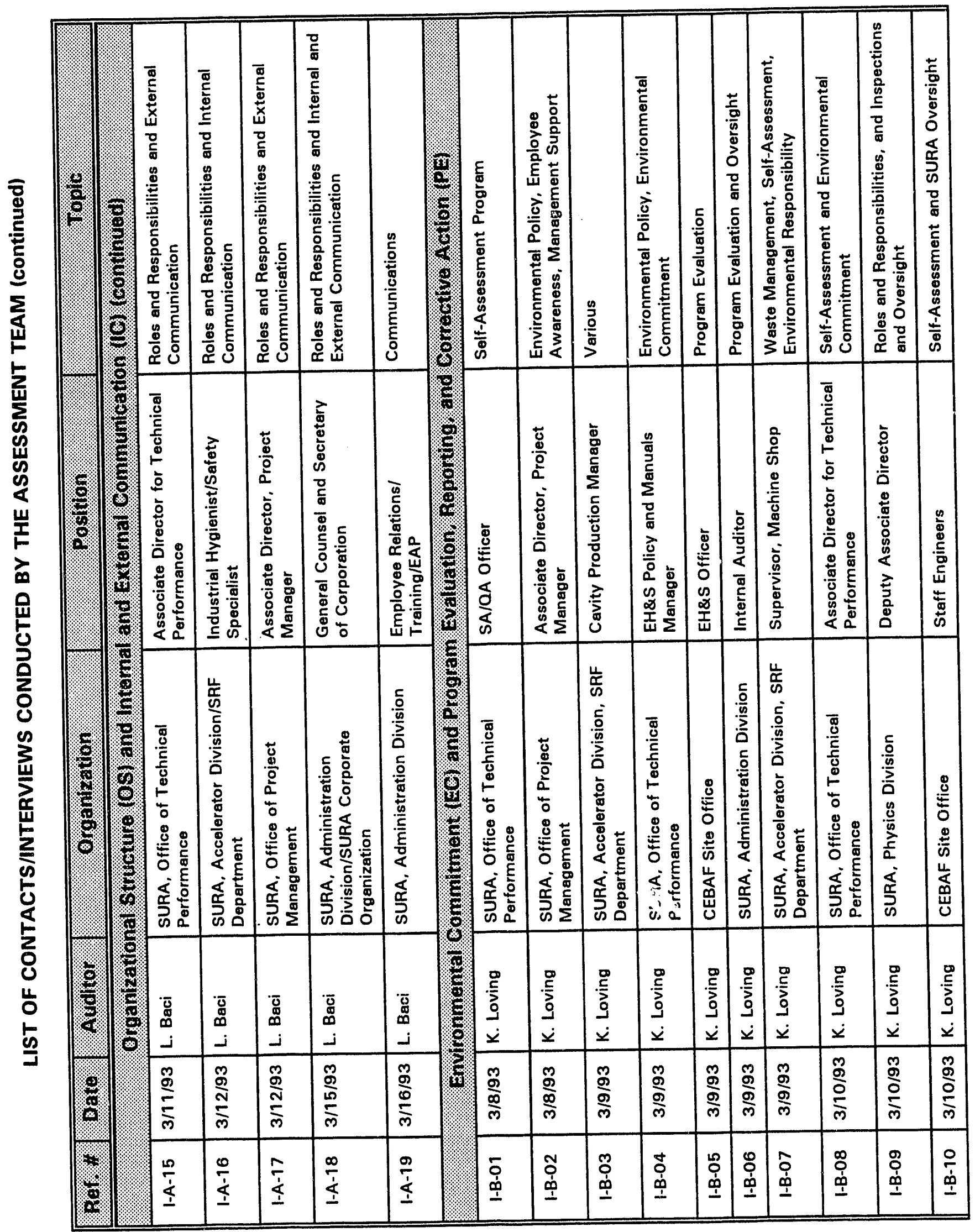




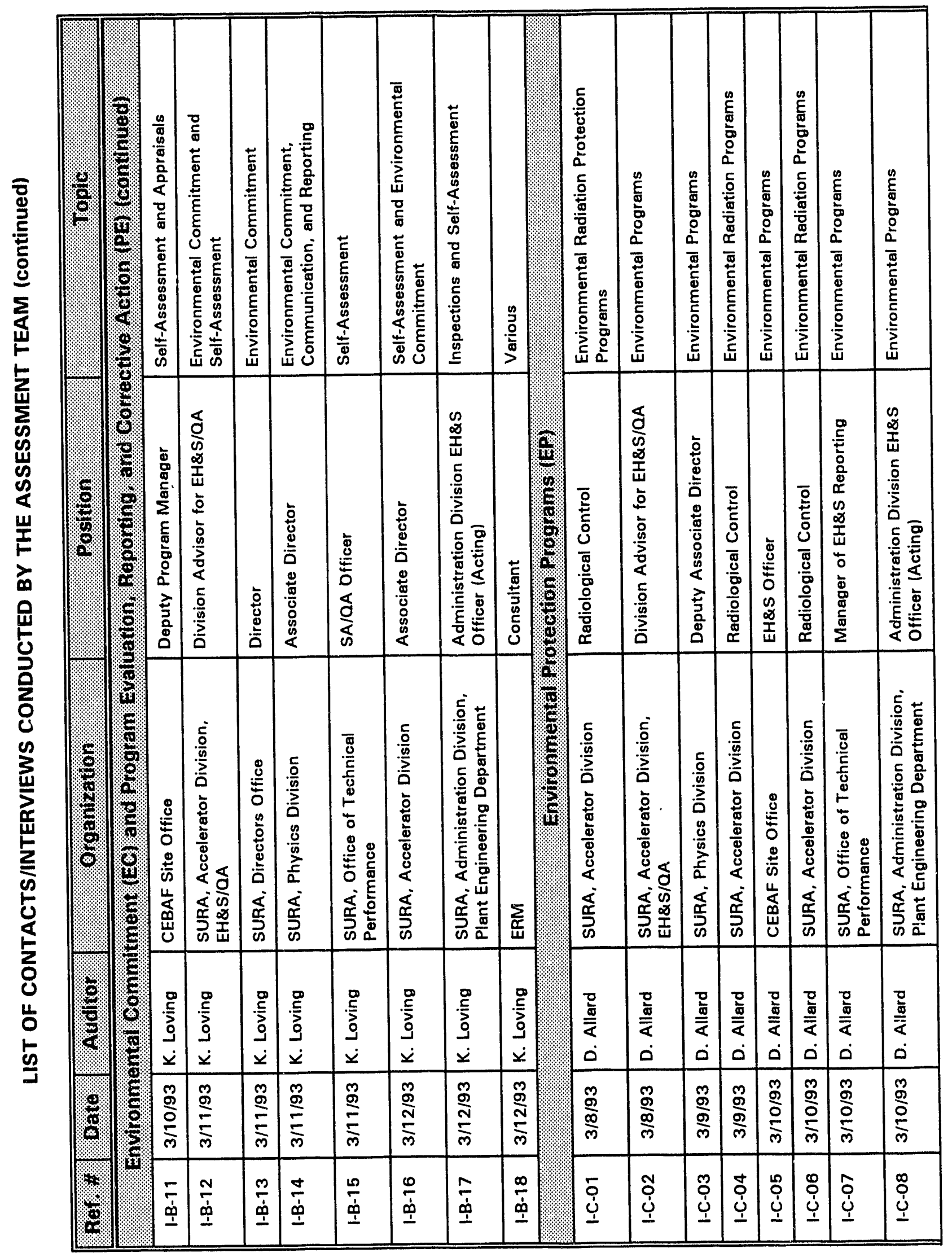




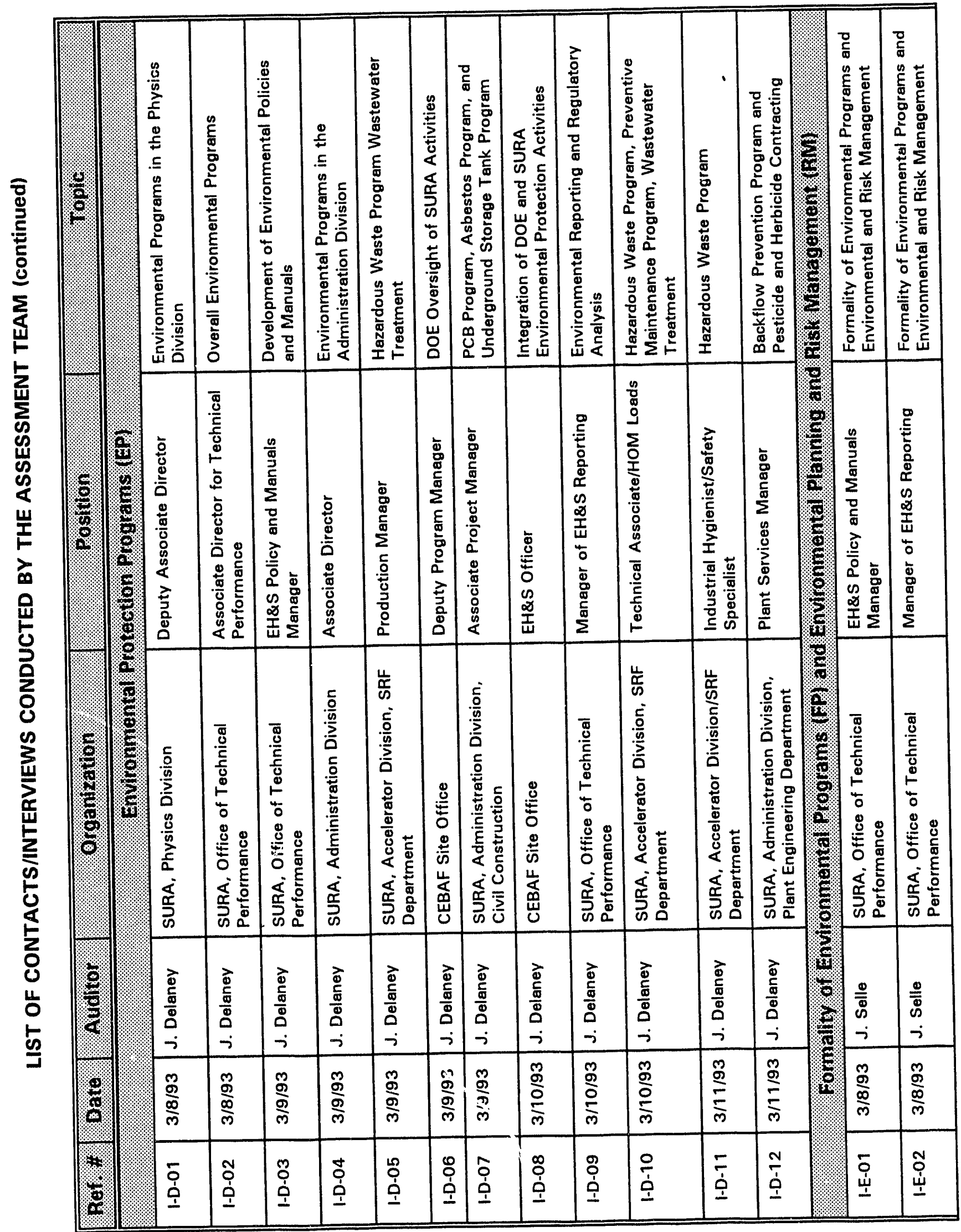




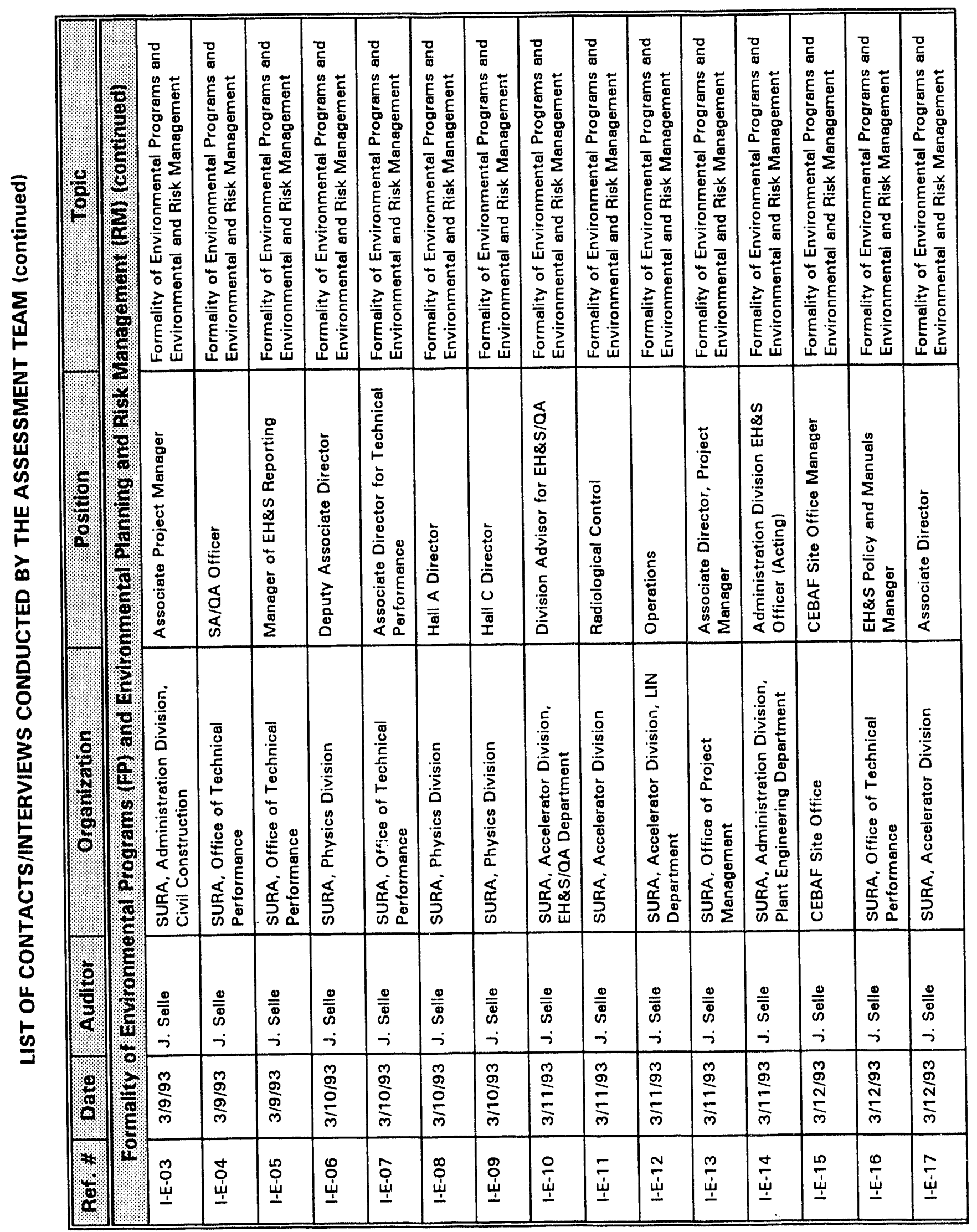




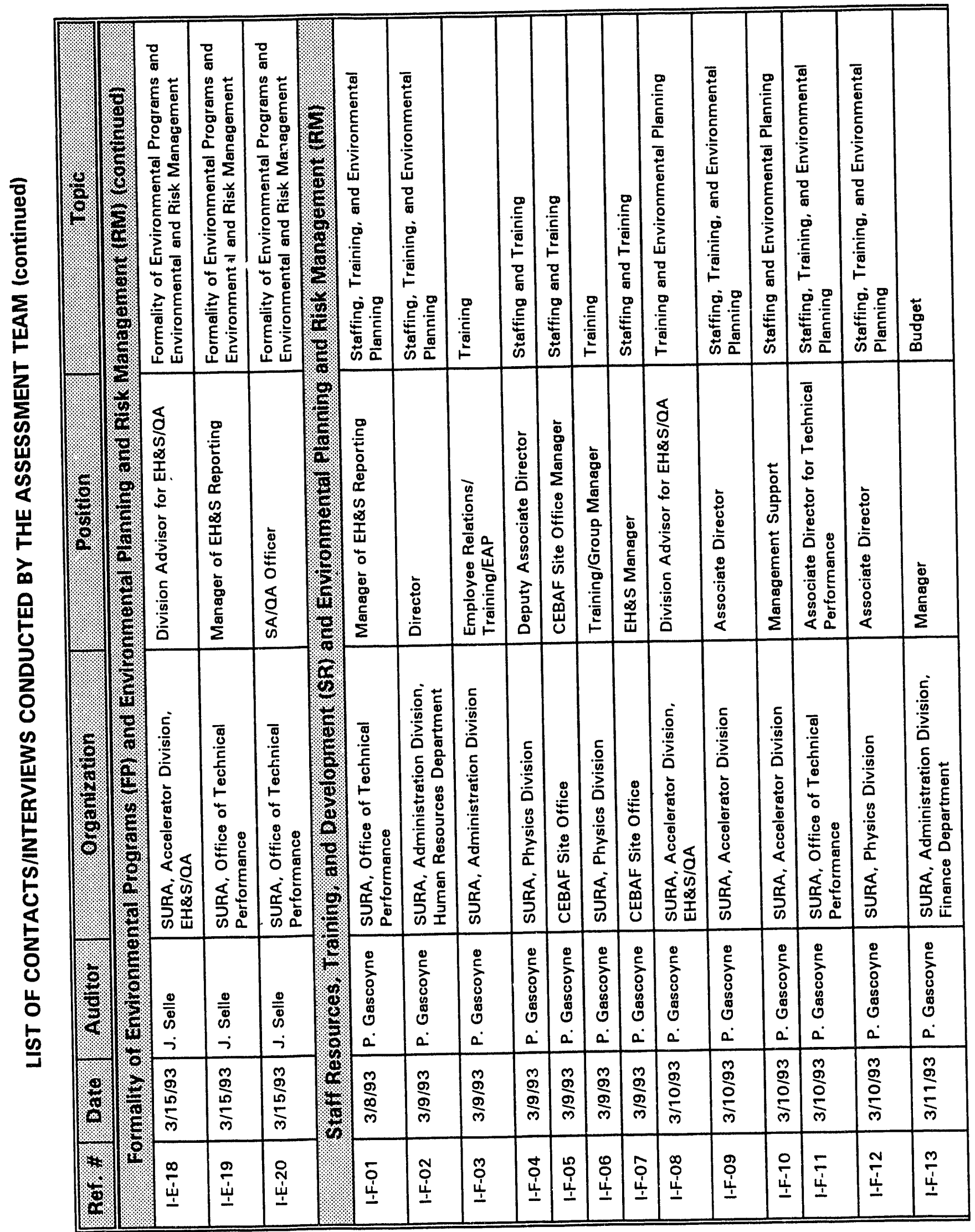




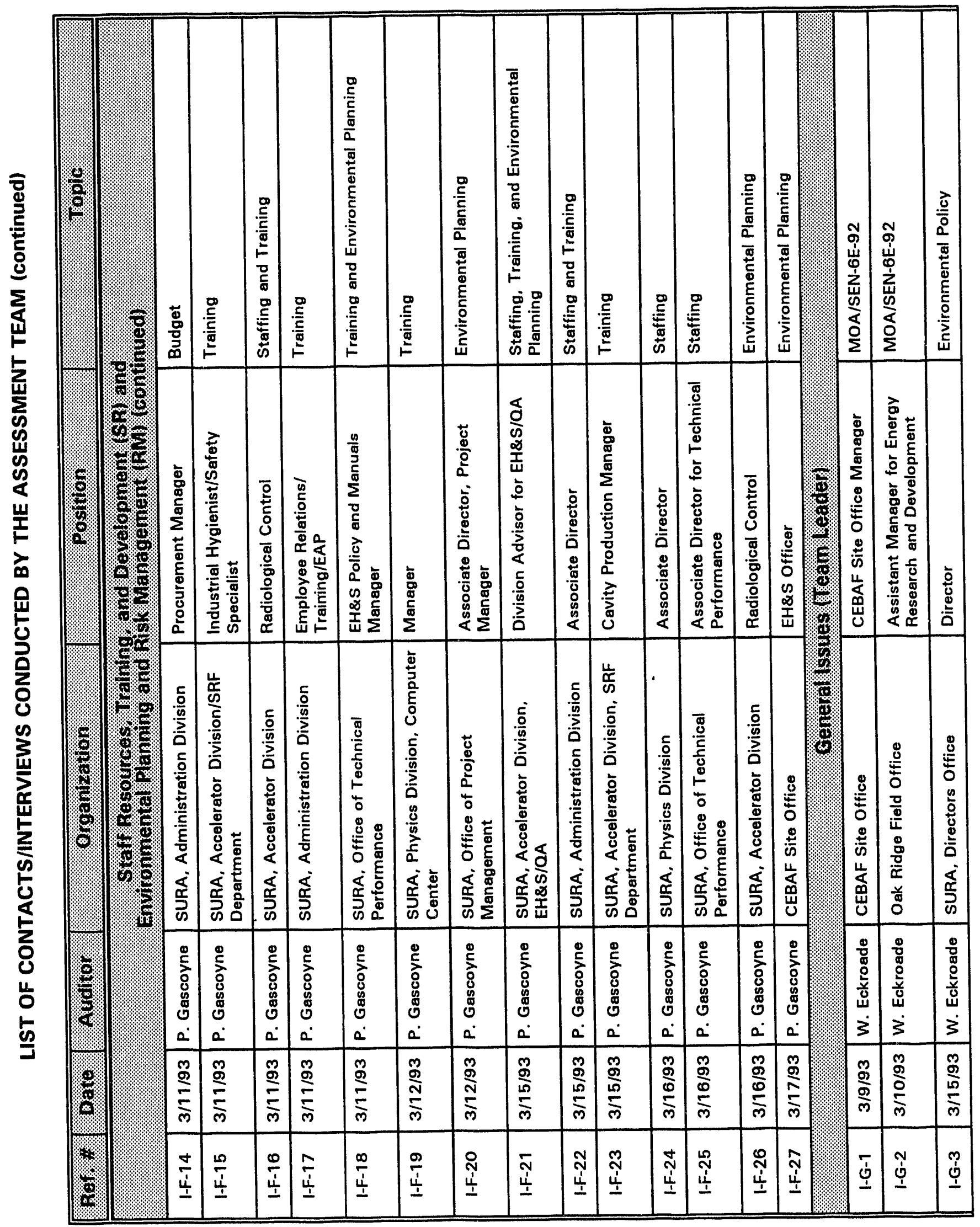




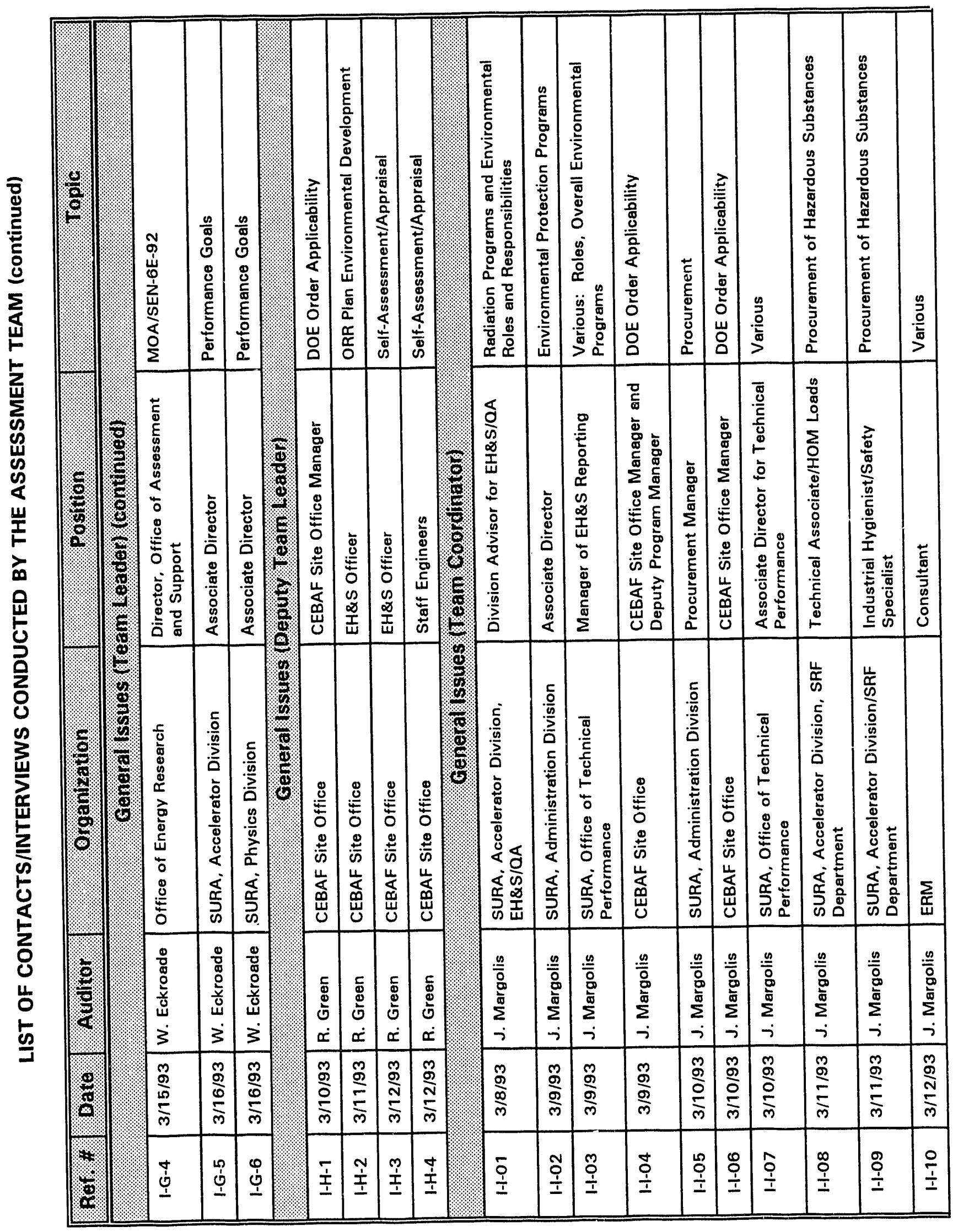




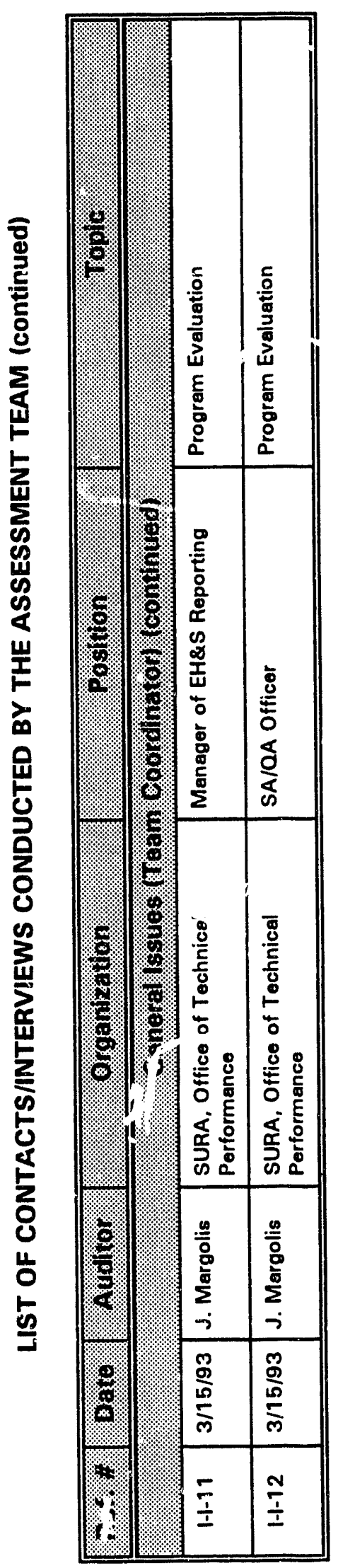


This page intentionally left blank.

E-10 


\section{APPENDIX F}

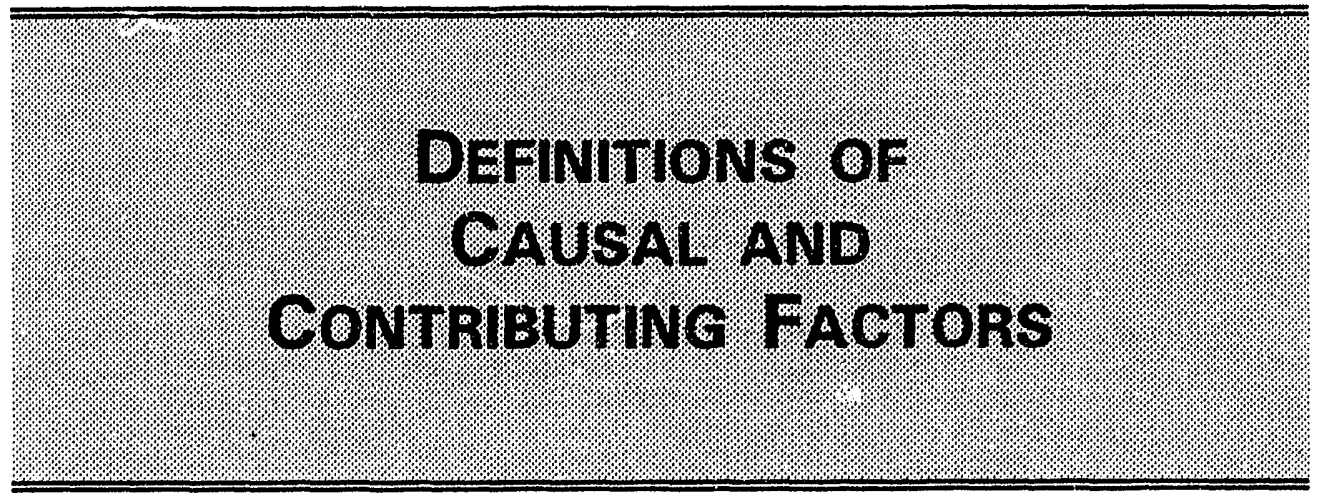


This page intentionally left blank. 
APPENDIX F:

DEFINITIONS OF CAUSAL AND CONTRIBUTING FAC̣TORS

\begin{tabular}{|c|c|}
\hline Causal factor: & Detinition. \\
\hline Policy & $\begin{array}{l}\text { Evaluate if ineffective, outdated, or nonexistent } \\
\text { policies contributed to the finding. }\end{array}$ \\
\hline Policy Implementation & $\begin{array}{l}\text { Ascertain if written policies reflecting Federal, state, } \\
\text { and local laws and regulations, codes, and standards } \\
\text { were appropriately disseminated, implemented, and } \\
\text { updated. }\end{array}$ \\
\hline Risk & $\begin{array}{l}\text { Evaluate if the site personnel responsible for a } \\
\text { situation contributing to a finding have assessed and } \\
\text { were aware of the relative degree of risk involved in } \\
\text { the action. }\end{array}$ \\
\hline Procedures & $\begin{array}{l}\text { Identify if written procedures that have been prepared } \\
\text { to effectively implement site policy, DOE Orders, and } \\
\text { Federal, state, and local laws and regulations were a } \\
\text { contributing factor to the finding. Determine if } \\
\text { unfamiliarity with, or unavailability of those } \\
\text { procedures contributed to the finding. }\end{array}$ \\
\hline Personnel & $\begin{array}{l}\text { Identify if the educational and work experience } \\
\text { backgrounds for personnel holding responsible } \\
\text { positions contributed to the finding. Determine if the } \\
\text { level of personnel knowledge about the technical and } \\
\text { environmental aspects of their jobs contributed to the } \\
\text { finding. }\end{array}$ \\
\hline Resources & $\begin{array}{l}\text { Ascertain if the number of personnel or extramural } \\
\text { resources available to a job were a contributing factor } \\
\text { to the finding. Evaluate if inadequacies in facilities } \\
\text { and equipment were a contributing factor to the } \\
\text { finding. }\end{array}$ \\
\hline Training & $\begin{array}{l}\text { Identify if adequate personnel training on } \\
\text { implementing site policy, DOE Orders, and Federal, } \\
\text { state, and local laws and regulations was a } \\
\text { contributing factor to the finding. }\end{array}$ \\
\hline
\end{tabular}




\section{DEFINITIONS OF CAUSAL AND CONTRIBUTING FACTORS (continued)}

\begin{tabular}{|c|c|}
\hline Carsal factor & Defrintion \\
\hline Change & $\begin{array}{l}\text { Evaluate if changes in site mission, function, } \\
\text { operation, and established requirements, which } \\
\text { rendered existing policies or procedures inadequate or } \\
\text { inappropriate, were contributing factors to the } \\
\text { finding. Evaluate if the timeliness and effectiveness } \\
\text { of changes to site and DOE policy, and the } \\
\text { implementing procedures, were a contributing factor } \\
\text { to the finding. }\end{array}$ \\
\hline Appraisals/Audits/Reviews & $\begin{array}{l}\text { Determine if ineffective or insufficient appraisals/ } \\
\text { audits/reviews or oversight were contributing factors } \\
\text { to the finding. These factors should only be used as } \\
\text { secondary contributing factors to the finding. }\end{array}$ \\
\hline Design & $\begin{array}{l}\text { Evaluate if inadequate design of a system was a } \\
\text { contributing factor to the finding. }\end{array}$ \\
\hline Human Factors & $\begin{array}{l}\text { Ascertain if human factors, such as fatigue or } \\
\text { deliberate circumvention of a safety system, were } \\
\text { contributing factors to the finding. }\end{array}$ \\
\hline Barriers and Controls & $\begin{array}{l}\text { Determine if inadequacies in established barriers and } \\
\text { controls, both administrative and physical, including } \\
\text { operational readiness, routine inspections, and } \\
\text { preventive maintenance, and/or a lack. of these } \\
\text { controls contributed to the finding. }\end{array}$ \\
\hline Supervision & $\begin{array}{l}\text { Identify if ineffective supervisory controls for } \\
\text { implementing policies, procedures, standards, laws, } \\
\text { etc., were a contributing factor to the finding. }\end{array}$ \\
\hline $\begin{array}{l}\text { Quality Assurance/ } \\
\text { Quality Control }\end{array}$ & $\begin{array}{l}\text { Identify if inadequacies in the quality } \\
\text { assurance/quality control program were causal } \\
\text { factors to the identified finding. This includes } \\
\text { inadequate followup to previously identified findings. }\end{array}$ \\
\hline
\end{tabular}




\section{APPENDIX G}

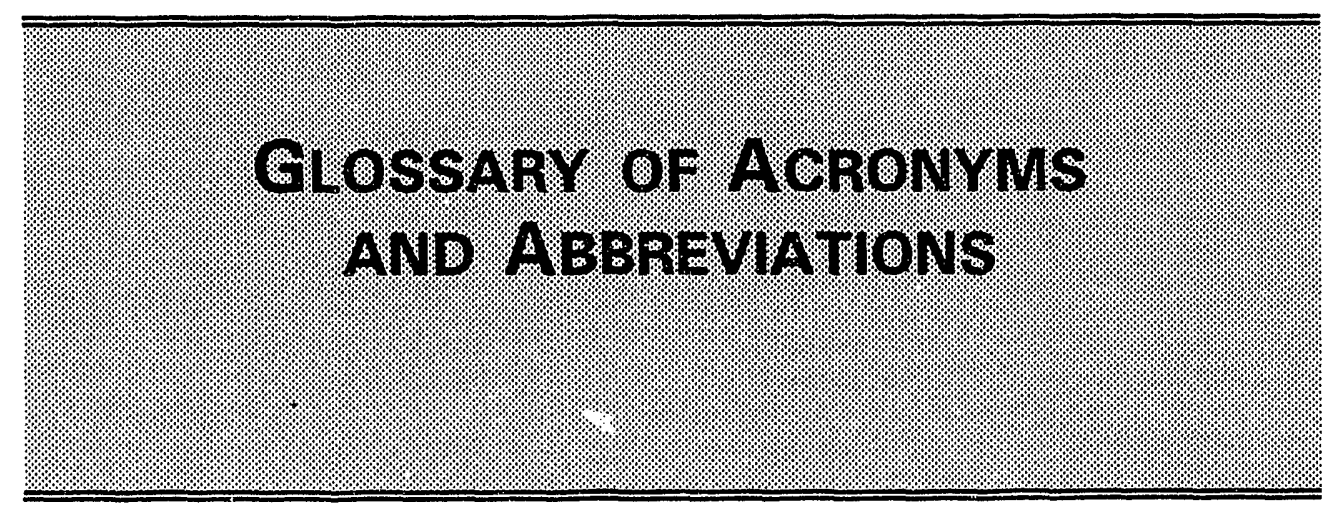


This page intentionally left blank. 
APPENDIX G:

\section{GLOSSARY OF ACRONYMS AND ABBREVIATIONS}

\begin{tabular}{|c|c|}
\hline agron.m. & Oefrintion. \\
\hline ADL & Arthur D. Little, Inc. \\
\hline AMERD & Assistant Manager for Energy Research and Development \\
\hline ARR & Accelerator Readiness Review \\
\hline BNA & Bureau of National Affairs \\
\hline CAA & Clean Air Act \\
\hline CEBAF* & Continuous Electron Beam Accelerator Facility \\
\hline CFR & Code of Federal Regulations \\
\hline CIS & CEBAF's Information Systems \\
\hline CLAS & CEBAF Large Acceptance Spectrometer \\
\hline CWA & Clean Water Act \\
\hline DOE* & U.S. Department of Energy \\
\hline EC & Environmental Commitment \\
\hline $\mathrm{EH}$ & Office of Environment, Safety and Health \\
\hline EH-1 & $\begin{array}{l}\text { Office of the Assistant Secretary for Environment, Safety and } \\
\text { Health }\end{array}$ \\
\hline $\mathrm{EH}-24$ & Office of Environmental Audit \\
\hline EH\&S* & $\begin{array}{l}\text { Environment, Health, and Safety (NOTE: site-specific organization } \\
\text { or documents with this specific designation) }\end{array}$ \\
\hline EM & Office of Environmental Restoration and Waste Management \\
\hline EP & Environriontal Protection Programs \\
\hline EPA* & U.S. Environmental Protection Agency \\
\hline EPCRA & Emergency Planning and Community Right-to-Know Act \\
\hline ER & Office of Energy Research \\
\hline ES\&H & Environment, Safety, and Health \\
\hline FP & Formality of Environmental Programs \\
\hline FTE & Full-Time Equivalent \\
\hline
\end{tabular}

* Indicates acronym is not defined or spelled out after the first usage in the body of the report. 
GLOSSARY OF ACRONYMS AND ABBREVIATIONS (continued)

\begin{tabular}{|c|c|}
\hline Acrony & ogfinition. \\
\hline $\mathrm{HO}$ & Headquarters \\
\hline IC & Internal and External Communication \\
\hline LINAC & Linear Accelerators \\
\hline M\&O & Management and Operating \\
\hline MOA & Memorandum of Agreement \\
\hline MSDS & Material Safety Data Sheet \\
\hline NE & Office of Nuclear Energy \\
\hline NEPA & National Environmental Policy Act \\
\hline NESHAP & National Emission Standards for Hazardous Air Pollutants \\
\hline NOV & Notice of Violations \\
\hline NSAC & Nuclear Science Advisory Council \\
\hline OR & Oak Ridge Field Office \\
\hline ORAU & Oak Ridge Associated Universities \\
\hline ORNL & Oak Ridge National Laboratory \\
\hline os & Organizational Structure \\
\hline OSHA & Occupational Safety and Health Administration \\
\hline OTP & Office of Technical Performance \\
\hline PCB & Polychlorinated Biphenyl \\
\hline PE & Program Evaluation, Reporting, and Corrective Action \\
\hline POC & Performance Objectives and Criteria \\
\hline PSAR & Preliminary Safety Assessment Document \\
\hline PSO & Program Senior Official \\
\hline QA & Quality Assurance \\
\hline RCRA & Resource Conservation and Recovery Act \\
\hline $\mathrm{RM}$ & Environmental Planning and Risk Management \\
\hline SA/QA & Self-Assessment/Quality Assurance \\
\hline
\end{tabular}

* Indicates acronym is not defined or spelled out after the first usage in the body of the report. 
GLOSSARY OF ACRONYMS AND ABBREVIATIONS (continued)

\begin{tabular}{|c|c|}
\hline acronym. & Defintition. \\
\hline SAD & Safety Assessment Document \\
\hline SARA & Superfund Amendments and Reauthorization Act \\
\hline SDWA & Safe Drinking Water Act \\
\hline SEN & Secretary of Energy Notice \\
\hline $\mathrm{SI}$ & Special Issue \\
\hline SPCC & Spill Prevention Control and Countermeasure \\
\hline SR & Staff Resources, Training, and Development \\
\hline SRF & Superconducting Radiofrequency \\
\hline SURA * & Southeastern Universities Research Association, Inc. \\
\hline TLD & Thermoluminescent Detectors \\
\hline TSCA & Toxic Substances Control Act \\
\hline
\end{tabular}

* Indicates acronym is not defined or spelled out after the first usage in the body of the report. 
This page intentionally left blank.

G-4 

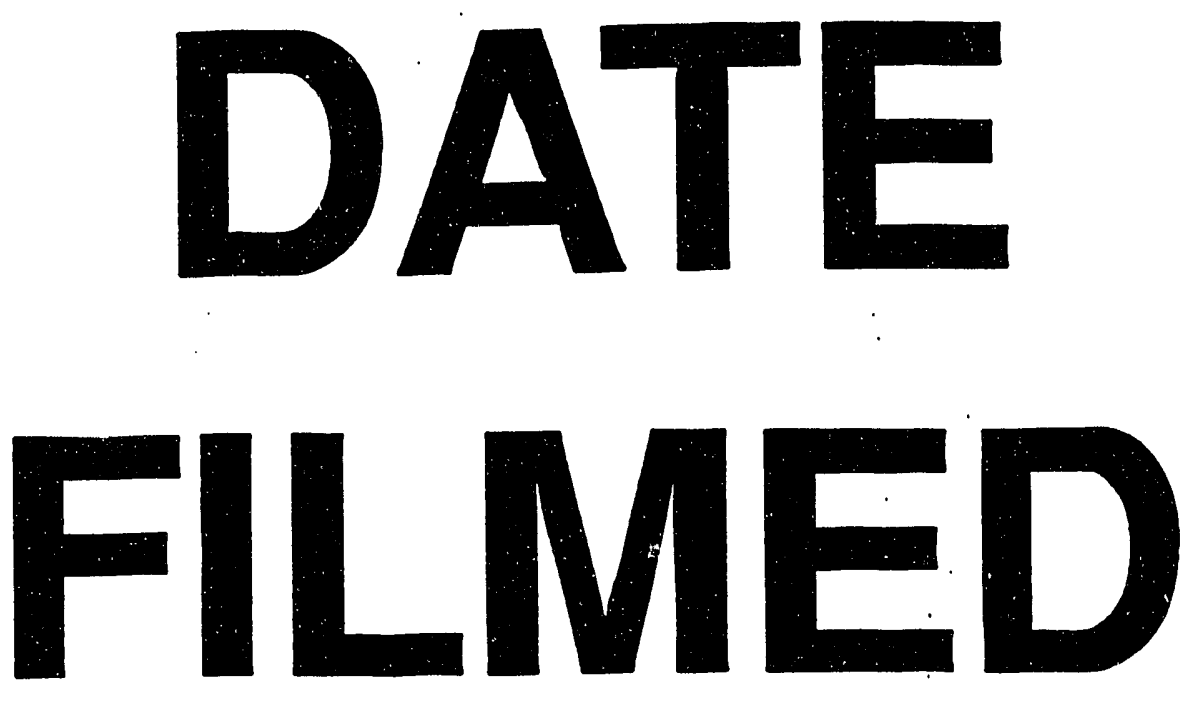

$10 / 7 / 93$
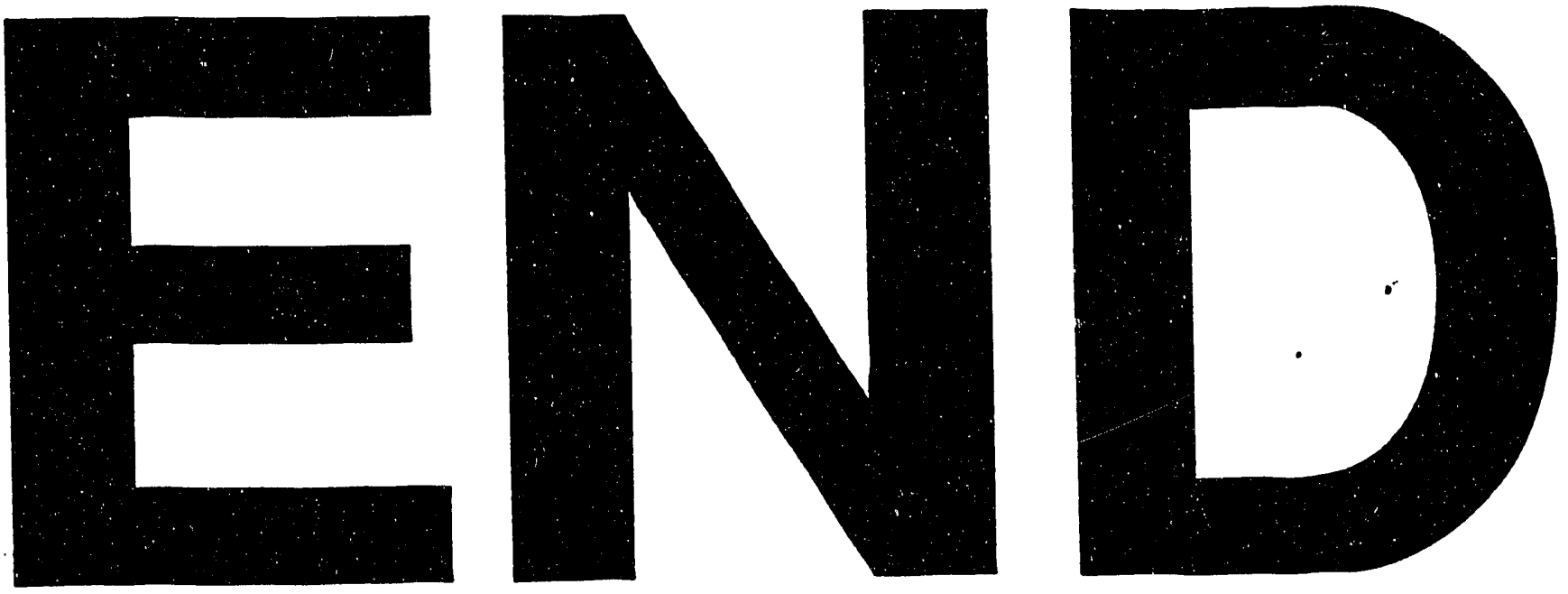
